\title{
DESENVOLVIMENTO DE CATALISADORES DE Pt-Co/C PARA A REAÇÃO DE REDUÇÃO DE OXIGÊNIO EM CÉLULAS A COMBUSTÍVEL DE MEMBRANA DE TROCA PROTÔNICA
}

José Ricardo Cezar Salgado

Tese apresentada ao Instituto de Química de São Carlos, da Universidade de São Paulo para a obtenção do título de Doutor em Ciências.

Orientador: Prof. Dr. Ernesto Rafael Gonzalez.

São Carlos.

2005. 
AGRADEÇO A Deus pela saúde, pela força DE VONTADE para prosseguir e acreditar na realização do trabalho.

Agradeço a meus pais José F. Salgado e Regina César e a todos meus familiares pela motivação, paciência e compreensão de minha ausência. 


\section{AGRADECIMENTOS}

Ao Prof. Dr. Ernesto Rafael Gonzalez pela sua orientação ao longo destes anos e por suas sugestões e conselhos sobre a vida profissional;

Ao Pesquisador Ermete Antolini pela valiosa discussão e colaboração no decorrer deste trabalho;

Aos Profs. Drs. Edson Antônio Ticianelli e Francisco Carlos Nart pelos comentários e pelas sugestões no exame de qualificação;

Aos Pesquisadores Dr. Valdecir A. Paganin e Dra. Janete Giz pelos comentários e pela colaboração no decorrer deste trabalho;

Á Profa. Dra. Yvonne P. Mascarenhas do IFSC/USP e ao Prof. Dr. Carlos de Oliveira de Paiva Santos UNESP/Araraquara pela contribuição nos estudos de difração de raios-X;

Ao Prof. Dr. Antônio Ricardo Zanatta pelas medidas de espectroscopia Raman;

Ao Laboratório Nacional de Luz Síncrotron, pelas facilidades das análises de espectroscopia de absorção de raios-X e microscopia eletrônica de transmissão;

Aos colegas do Grupo de Eletroquímica pela convivência diária, conversas e discussões em especial Maristela, Giuseppe, Raimundo, Flávio, Robson, Luís Gustavo, Elizabete e Adler;

Aos amigos e colegas da "UFU", Sérgio, Célia, Sandra, Daniel, Sara, Maria Tereza, Eliângela, Márlon, Carol, Augusto, Sô Cleber, Carolina, Marcelo que sempre estivemos juntos em São Carlos;

Ao Conselho Nacional de Desenvolvimento Científico e Tecnológico, pela bolsa concedida;

À Pro-Reitoria de Pós-Graduação da USP, pelo apoio financeiro para os trabalhos de campo e para as viagens aos eventos científicos;

A todos os funcionários do IQSC/USP que colaboraram direto ou indiretamente, em especial, Dr. Carlos Bento, Sílvia, Andréia, Vilneide, Lia, Eliana, Ângelo, Irineu, Oscar e Maria do Carmo. 


\section{SUMÁRIO}

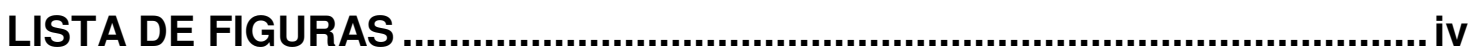

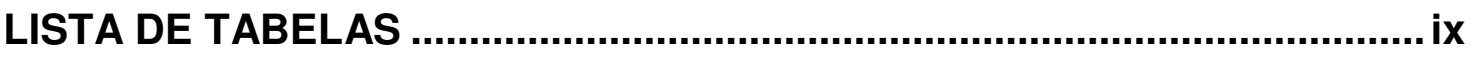

LISTA DE SÍMBOLOS E ABREVIATURAS …...........................................

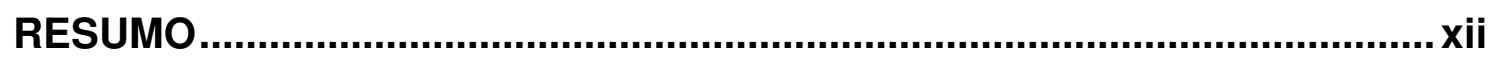

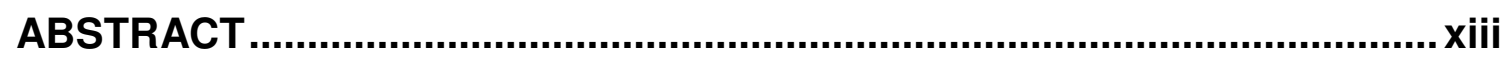

1. INTRODUÇÃO

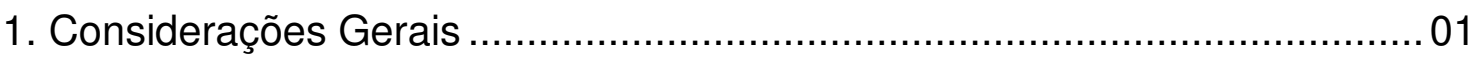

1.1. Tipos de Células a Combustível ........................................................... 02

1.1.1. Célula a Combustível de Eletrólito Alcalino.................................. 02

1.1.2. Célula a Combustível de Ácido Fosfórico ................................... 03

1.1.3. Células a Combustível de Carbonato Fundido e Óxido Sólido ....03

1.1.4. Célula a Combustível de Membrana de Troca Protônica.............. 04

1.2. Viabilidade das Células a Combustível PEM ............................................ 09

1.3. Catalisadores para Células a Combustível PEM ....................................11

1.4. Caracterização dos Catalisadores Suportados.......................................... 19

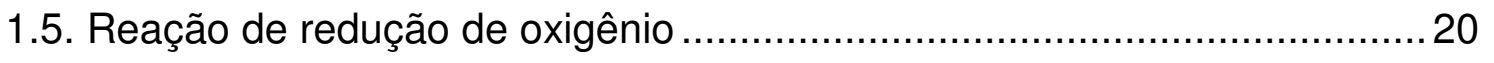

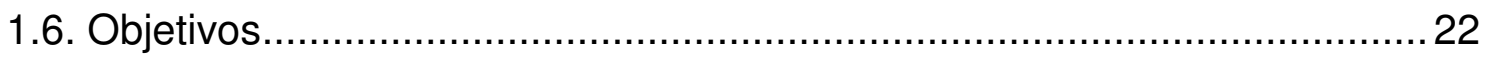




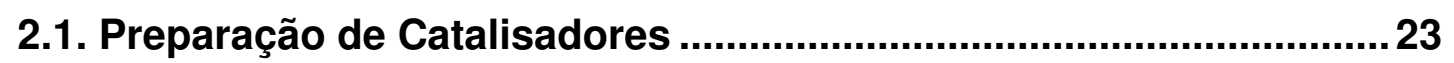

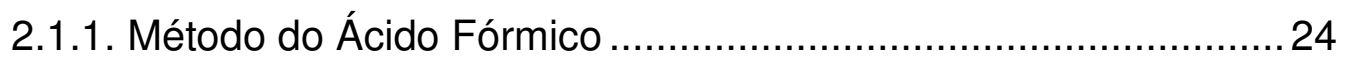

2.1.2. Método de Impregnação Convencional ....................................25

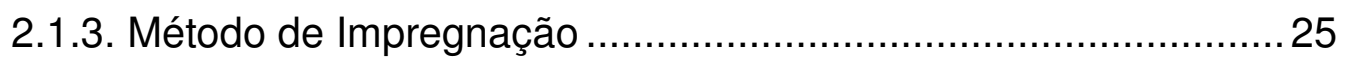

2.1.4. Método do Borohidreto de Sódio ............................................26

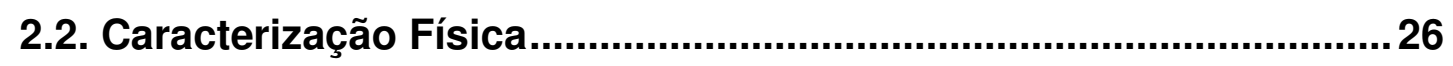

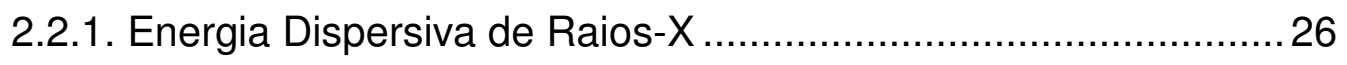

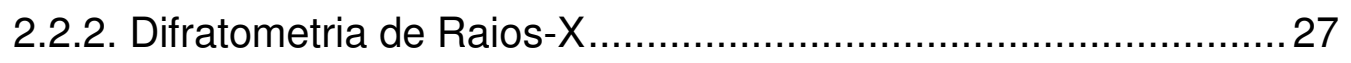

2.2.3. Microscopia Eletrônica de Transmissão ................................... 28

2.2.4. Espectroscopia de Absorção de Raios-X..................................29

2.2.5. Espectroscopia por Espalhamento Raman ................................ 33

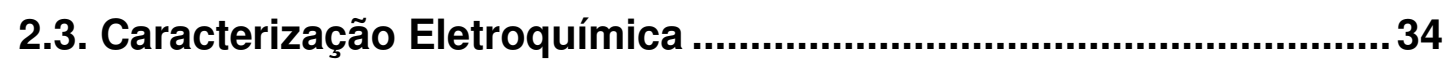

2.3.1. Eletrodos de Difusão de Gás ...................................................34

2.3.2. Preparação da Camada Difusora............................................. 35

2.3.3. Preparação da Camada Catalítica ............................................. 35

2.3.4. Membrana de Troca Protônica................................................... 36

2.3.5. Medidas Eletroquímicas em Meia Célula .................................... 36

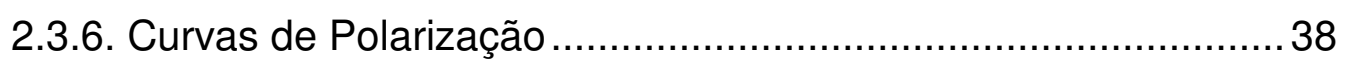

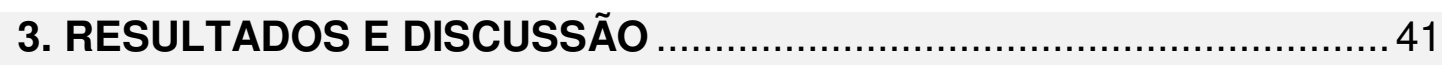

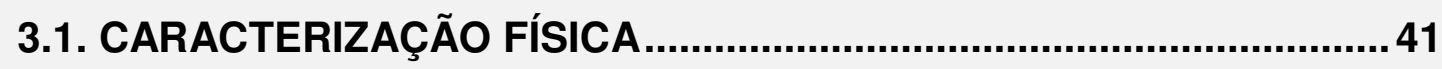

3.1.1. ENERGIA DISPERSIVA DE RAIOS-X.................................. 41

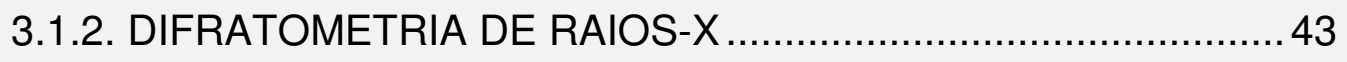

3.1.3. Microscopia Eletrônica de Transmissão ……………………........55

3.1.4. Espectroscopia de Absorção de Raios-X.................................. 61

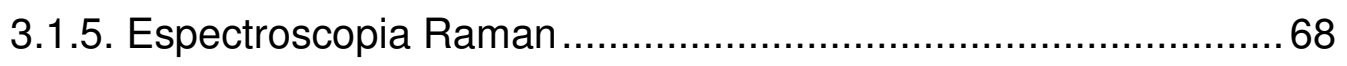




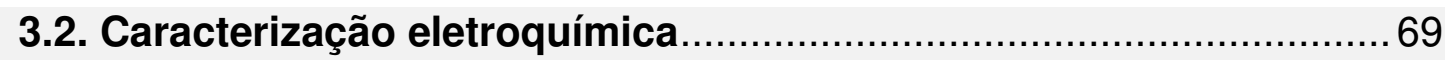

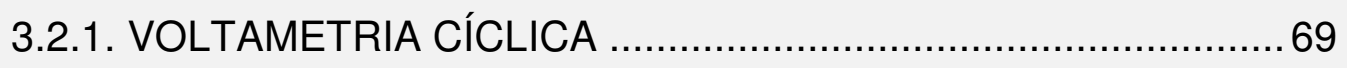

3.2.2. VOLTAMETRIA DE VARREDURA LINEAR PARA A RRO ........72

3.2.3. Desempenho dos Catalisadores na PEMFC ................................ 74

3.2.3.1. Preparados Pelo MAF........................................................ 77

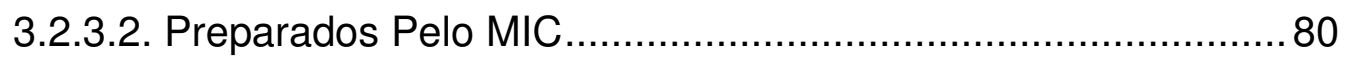

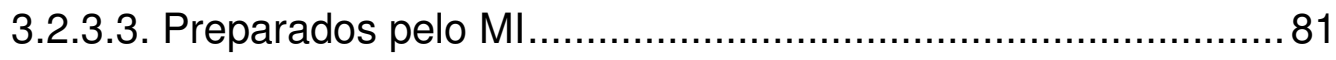

3.2.3.4. Preparados Pelo MB e Efeito do Tratamento Térmico............. 83

3.2.3.5. Estabilidade do Catalisador ................................................ 88

3.2.4. Desempenho dos Catalisadores em Célula de Metanol................92

3.2.4.1. VVL para a RRO em meio ácido e Metanol ........................... 92

3.2.4.2. VVL para a Oxidação de Metanol em Meia Célula .................. 94

3.2.4.3. Curvas de Polarização nas DMFC ......................................... 97

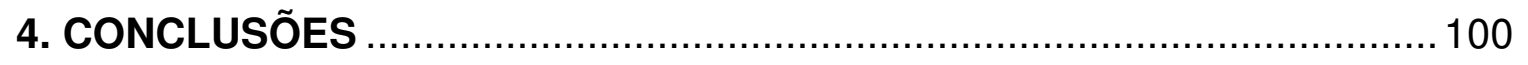

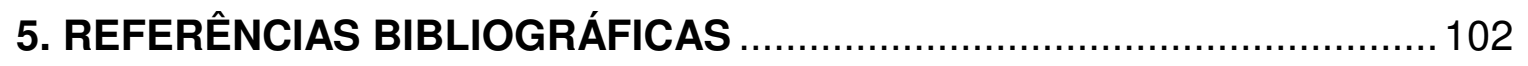




\section{LISTA DE FIGURAS}

Figura 1.1. llustração de uma célula a combustível PEM de $\mathrm{H}_{2} / \mathrm{O}_{2}$ 6

Figura 1.2. Quedas de desempenho de uma célula a combustível de PEMFC operando com $\mathrm{H}_{2} / \mathrm{O}_{2}$ comparadas com uma DMFC

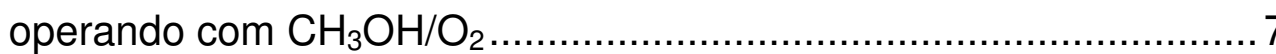

Figura 1.3. Formas de adsorção de moléculas de oxigênio sobre o material eletródico: (i) Modelo de Griffith; (ii) Modelo de Paulling e (iii) Modelo de ponte.

Figura 2.1. Esquema de uma célula eletroquímica usada para as medidas de XAS

Figura 2.2. Desenho esquemático de uma célula eletroquímica. (1) eletrodo de trabalho; (2) contra-eletrodo; (3) eletrodo de referência; (4) contato elétrico; (5) entrada e saída de gás e (6) volume de $70 \mathrm{~cm}^{3}$

Figura 2.3. Desenho esquemático que mostra os componentes de uma célula unitária de eletrólito polimérico sólido. (1) placa de alumínio; (2) entrada dos parafusos; (3) entrada para aquecedores; (4) aquecedores; (5) placa de grafite; (6) distribuidor do fluxo de gás; (7) guia de ajuste; (8) espaçadores; (9) membrana; (10) eletrodo difusão de gás; (11) termopar; (12) o'ring; (13) tubo de Teflon; (14) conectores.

Figura 3.1. Difratogramas de raios- $X$ para os catalisadores de $\mathrm{Pt}_{70} \mathrm{Co}_{30} / \mathrm{C}, \mathrm{MAF}\left(\mathrm{TT}=500\right.$ e $\left.900{ }^{\circ} \mathrm{C}\right), \mathrm{Pt}_{85} \mathrm{Co}_{15} / \mathrm{C}$, MIC (TT = 550 e $\left.900{ }^{\circ} \mathrm{C}\right)$ e $\mathrm{Pt} / \mathrm{C}$ E-TEK..

Figura 3.2. Difratogramas de raios- $X$ detalhados do pico (311) para o catalisador $\mathrm{Pt}_{70} \mathrm{Co}_{30} / \mathrm{C}$ MAF (como preparado e TT a $500 \mathrm{e}$ $\left.900{ }^{\circ} \mathrm{C}\right)$. 
Figura 3.3. Difratogramas de raios- $\mathrm{X}$ para os catalisadores de $\mathrm{Pt}-\mathrm{Co} / \mathrm{C}$ MI com diferentes composições atômicas. $\left(^{*}\right)$ picos de difração relacionados à estrutura ordenada, $\mathrm{Pt}_{3} \mathrm{Co}$.

Figura 3.4. Difratogramas de raios- $\mathrm{X}$ para os catalisadores $\mathrm{Pt}_{85} \mathrm{Co}_{15} / \mathrm{C}$ MB (sem e com TT a $500{ }^{\circ} \mathrm{C}$ ) e $\mathrm{Pt}_{50} \mathrm{Co}_{50} / \mathrm{C}$, E-TEK (sem e com TT a $\left.500{ }^{\circ} \mathrm{C}\right)$.. 46

Figura 3.5. Refinamento de Rietveld dos catalisadores. 52

Figura 3.6. Micrografias obtidas por MET para os catalisadores: (i) $\mathrm{Pt}_{75} \mathrm{Co}_{25} / \mathrm{C}, \mathrm{Ml}$; (ii) $\mathrm{Pt}_{85} \mathrm{Co}_{15} / \mathrm{C}, \mathrm{MB}$ e (iii) $\mathrm{Pt} / \mathrm{C}, \mathrm{E}-\mathrm{TEK}$. Magnificação 50 kx 55

Figura 3.7. Micrografias obtidas por MET para: (i) $\mathrm{Pt}_{75} \mathrm{Co}_{25} / \mathrm{C}$, MI; (ii) $\mathrm{Pt} / \mathrm{C}, \mathrm{E}-\mathrm{TEK}$; (iii) $\mathrm{Pt}_{85} \mathrm{Co}_{15} / \mathrm{C}, \mathrm{MB}$ e (iv) $\mathrm{Pt}_{85} \mathrm{Co}_{15} / \mathrm{C}, \mathrm{MB}, \mathrm{TT}$. Magnificação 150 kx. 56

Figura 3.8. Histogramas da distribuição do tamanho de partículas dos catalisadores

Figura 3.9. Histogramas da distribuição do tamanho de partículas dos catalisadores $\mathrm{Pt}_{85} \mathrm{Co}_{15} / \mathrm{C}$, sem e com tratamento térmico (TT)

Figura 3.10. Micrografia de alta resolução obtida por MET para o catalisador $\mathrm{Pt}_{75} \mathrm{Co}_{25} / \mathrm{C}$, (i) baixa e (ii) alta magnificação

Figura 3.11. Espectro de EDX para o catalisador $\mathrm{Pt}_{75} \mathrm{Co}_{25} / \mathrm{C}$. Campo 5 $\mathrm{nm}$ 
Figura 3.12. Micrografias de alta resolução obtidas por MET para o catalisador $\mathrm{Pt}_{85} \mathrm{Co}_{15} / \mathrm{C}$ : (a) região maior, (b) região média e (c) região pequena. Magnificação 800 kx.

Figura 3.13. Espectros de EDX para os catalisadores $\mathrm{Pt}_{85} \mathrm{Co}_{15} / \mathrm{C}, \mathrm{MB}$, STT: (a) região maior, (b) região média e (c) região pequena. Campo de $5 \mathrm{~nm}$ 61

Figura 3.14. Espectros XANES, na borda $L_{\| I}$ da Pt $(11564 \mathrm{eV})$, do catalisador $\mathrm{Pt}_{85} \mathrm{Co}_{15} / \mathrm{C}, \mathrm{MB}$ a diferentes potenciais. $\mathrm{T}=25^{\circ} \mathrm{C}$ 62

Figura 3.15. Espectros XANES na borda $L_{\text {III }}$ da $\mathrm{Pt}(11564 \mathrm{eV})$, dos catalisadores $\mathrm{Pt}_{75} \mathrm{Co}_{25} / \mathrm{C} \mathrm{Ml}$; $\mathrm{Pt}_{85} \mathrm{Co}_{15} / \mathrm{C} \mathrm{MB}$; $\mathrm{Pt} / \mathrm{C}$ E-TEK e para a folha de Pt. Potencial de polarização $300 \mathrm{mV}$. T = 25 ${ }^{\circ} \mathrm{C}$

Figura 3.16. Espectros XANES na borda $\mathrm{L}_{\text {III }}$ da Pt (11 $\left.564 \mathrm{eV}\right)$, dos catalisadores $\mathrm{Pt}_{75} \mathrm{Co}_{25} / \mathrm{C} \mathrm{Ml}$; $\mathrm{Pt}_{15} \mathrm{Co}_{15} / \mathrm{C} \mathrm{MB}$; $\mathrm{Pt} / \mathrm{C} \mathrm{E}$-TEK e folha de Pt. Potencial de polarização $1100 \mathrm{mV}$. T $=25^{\circ} \mathrm{C}$

Figura 3.17. Espectro EXAFS na borda $L_{\| I I}$ da Pt (11 $\left.564 \mathrm{eV}\right)$ para os catalisadores. $\mathrm{T}=25^{\circ} \mathrm{C}$ 65

Figura 3.18.Transformadas de Fourier $\left(k^{3}\right)$ das oscilações EXAFS para os catalisadores. Potencial de polarização $300 \mathrm{mV}$ $\left(\mathrm{Pt}_{75} \mathrm{Co}_{25} / \mathrm{C}\right)$ e $100 \mathrm{mV}\left(\mathrm{Pt}_{85} \mathrm{Co}_{15} / \mathrm{C} \mathrm{e} \mathrm{Pt} / \mathrm{C}\right) . \mathrm{T}=25^{\circ} \mathrm{C}$

Figura 3.19. Espectros Raman para os catalisadores: (a) $\mathrm{Pt}_{75} \mathrm{Co}_{25} / \mathrm{C}$, (b) $\mathrm{Pt}_{85} \mathrm{Co}_{85} / \mathrm{C}$ e (c) $\mathrm{Pt} / \mathrm{C}$ 69

Figura 3.20. Voltamogramas cíclicos para os catalisadores $\mathrm{Pt}-\mathrm{Co} / \mathrm{C}$ em meia célula. $v=50 \mathrm{mV} \mathrm{s}^{-1}, \mathrm{~T}=25^{\circ} \mathrm{C}$ 
Figura 3.21. Curvas de varredura linear dos catalisadores $\mathrm{Pt}-\mathrm{Co} / \mathrm{C} \mathrm{e}$ $\mathrm{Pt} / \mathrm{C}$ para a RRO em $\mathrm{H}_{2} \mathrm{SO}_{4} \quad 0,5 \mathrm{~mol} \mathrm{~L}^{-1}$. Densidade de corrente normalizada em relação à área superficial geométrica. $v=5 \mathrm{mV} \mathrm{s}^{-1} \mathrm{e} \mathrm{T}=25{ }^{\circ} \mathrm{C}$

Figura 3.22. Curvas de varredura linear dos catalisadores $\mathrm{Pt}-\mathrm{Co} / \mathrm{C} \mathrm{e}$ $\mathrm{Pt} / \mathrm{C}$ para a RRO em $\mathrm{H}_{2} \mathrm{SO}_{4} \quad 0,5 \mathrm{~mol} \mathrm{~L}^{-1}$. Densidade de corrente normalizada em relação à área superficial específica da Pt. $v=5 \mathrm{mV} \mathrm{s}^{-1}$ e $\mathrm{T}=25^{\circ} \mathrm{C}$

Figura 3.23. Curvas de polarização corrigidas de iR para os eletrodos contendo $\mathrm{Pt}_{70} \mathrm{Co}_{30} / \mathrm{C}$ MAF e Pt/C (E-TEK). 0,4 mg de Pt cm${ }^{-2}$; $15 \%$ de PTFE; Nafion ${ }^{\circledR} 115 . \mathrm{P}=1 \mathrm{~atm}$; $\mathrm{T}_{\text {Célula }}=80^{\circ} \mathrm{C}$. $\mathrm{T}_{\mathrm{H} 2 / \mathrm{O} 2}$ $=95 / 85^{\circ} \mathrm{C}$ 78

Figura 3.24. Curvas de polarização corrigidas de iR para os eletrodos contendo os catalisadores de Pt-Co/C MIC e Pt/C E-TEK. 0,4 $\mathrm{mg}$ de Pt cm${ }^{-2} ; 15 \%$ de PTFE; Nafion ${ }^{\circledR} 115 . \mathrm{P}=1 \mathrm{~atm} ; T_{\text {Célula }}$ $=80^{\circ} \mathrm{C} \cdot \mathrm{T}_{\mathrm{H} 2 / \mathrm{O} 2}=95 / 85^{\circ} \mathrm{C}$

Figura 3.25. Curvas de polarização corrigidas de iR para os eletrodos contendo $\mathrm{Pt}-\mathrm{Co} / \mathrm{C} \mathrm{Ml}$ com diferentes composições e para $\mathrm{Pt} / \mathrm{C}$ (E-TEK). 0,4 mg de Pt cm ${ }^{-2} ; 15 \%$ de PTFE; Nafion ${ }^{\circledR} 115$. P = $1 \mathrm{~atm} ; \mathrm{T}_{\text {Célula }}=80^{\circ} \mathrm{C} \cdot \mathrm{T}_{\mathrm{H} 2 / \mathrm{O} 2}=95 / 85^{\circ} \mathrm{C}$

Figura 3.26. Curvas de polarização corrigidas de iR para os eletrodos contendo $\mathrm{Pt}_{85} \mathrm{Co}_{15} / \mathrm{C}$ MB (sem e com TT) e $\mathrm{Pt}_{50} \mathrm{Co}_{50} / \mathrm{C}$ (ETEK, sem e com TT) e Pt/C. 0,4 mg de Pt cm $\mathrm{cm}^{-2} ; 15 \%$ de PTFE; Nafion ${ }^{\circledR} 115 . \mathrm{P}=1 \mathrm{~atm} ; \mathrm{T}_{\text {Célula }}=80^{\circ} \mathrm{C}$. $\mathrm{T}_{\mathrm{H} 2 / \mathrm{O} 2}=95 / 85$ ${ }^{\circ} \mathrm{C}$. 84

Figura 3.27. Atividade específica vs. tamanho de partículas de $\mathrm{Pt}$ obtidas por DRX e MET para $\mathrm{Pt}_{85} \mathrm{Co}_{15} / \mathrm{C} \mathrm{MB}$ (sem TT) e $\mathrm{Pt}_{50} \mathrm{Co}_{50} / \mathrm{C}(\mathrm{E}-\mathrm{TEK}$, sem TT) e Pt/C .86

Figura 3.28. Gráfico do potencial da célula vs. tempo de operação. Corrente aplicada $500 \mathrm{~mA} \mathrm{~cm}{ }^{-2} . \mathrm{P}=1 \mathrm{~atm} ; \mathrm{T}_{\text {Célula }}=80{ }^{\circ} \mathrm{C}$. $\mathrm{T}_{\mathrm{H} 2 / \mathrm{O} 2}=95 / 85{ }^{\circ} \mathrm{C}$ 89 
Figura 3.29. Difratogramas de raios- $X$ para os catalisadores $\mathrm{Pt}_{75} \mathrm{Co}_{25} / \mathrm{C}$ : (a) antes e (b) após a operação em célula

Figura 3.30. Mapeamento elementar do catalisador $\mathrm{Pt}_{75} \mathrm{Co}_{25} / \mathrm{C}$ antes da operação na célula unitária: (i) morfologia geral; (ii) carbono; (iii) Pt e (iv) Co. Magnificação 9 kx.

Figura 3.31. Mapeamento elementar do catalisador $\mathrm{Pt}_{75} \mathrm{Co}_{25} / \mathrm{C}$ após a operação na célula unitária: (i) morfologia geral; (ii) carbono; (iii) Pt e (iv) Co. Magnificação 9 kx

Figura 3.32. Redução de oxigênio em $\mathrm{H}_{2} \mathrm{SO}_{4} \quad 0,5 \mathrm{~mol} \mathrm{~L}^{-1}$ contendo diferentes quantidades de metanol. Catalisadores $\mathrm{Pt}_{75} \mathrm{Co}_{25} / \mathrm{C}$ (a), $\mathrm{Pt}_{85} \mathrm{Co}_{15} / \mathrm{C}$ (b) e Pt/C (c). $v=5 \mathrm{mV} \mathrm{s}^{-1}$ e T $=25^{\circ} \mathrm{C}$ 93

Figura 3.33. Dependência do potencial a $0 \mathrm{~A} \mathrm{~cm}^{-2}\left(E_{0 \mathrm{Acm}-2}\right)$ durante a redução de $\mathrm{O}_{2}$ em $\mathrm{H}_{2} \mathrm{SO}_{4} \quad 0,5 \mathrm{~mol} \mathrm{~L}^{-1}$ com diferentes concentrações de metanol

Figura 3.34. Curvas de varredura linear para a oxidação de metanol sobre catalisadores em $\mathrm{H}_{2} \mathrm{SO}_{4} 0,5 \mathrm{~mol} \mathrm{~L}^{-1}+$ metanol $3,0 \mathrm{~mol}$ $\mathrm{L}^{-1} \cdot v=5 \mathrm{mV} \mathrm{s}^{-1}$ e $\mathrm{T}=25^{\circ} \mathrm{C}$ 95

Figura 3.35. Curvas de polarização para os catalisadores para a RRO em DMFC. Densidades de corrente normalizada com relação à área geométrica. Ânodo $\mathrm{Pt}_{80} \mathrm{Ru}_{20} / \mathrm{C}$. Solução de metanol 2 mol L ${ }^{-1}, T_{\text {célula }}=\mathrm{T}_{\mathrm{O} 2}=90^{\circ} \mathrm{C}, \mathrm{P}_{\mathrm{O} 2}=3 \mathrm{~atm}$

Figura 3.36. Curvas de polarização para os catalisadores para a RRO em DMFC. Densidades de corrente normalizada com relação à área superficial específica da $\mathrm{Pt}$ 


\section{LISTA DE TABELAS}

Tabela 3.1. Características estruturais obtidas por EDX e DRX dos catalisadores. Composição atômica (EDX); temperatura de tratamento térmico (TT); parâmetro de rede (a); distância interatômica $\left(\mathrm{D}_{\mathrm{Pt}-\mathrm{M}}\right)$ e diâmetro médio das partículas $(\mathrm{d})$. 42

Tabela 3.2. Indicadores dos refinamentos dos DRX dos catalisadores. .54

Tabela 3.3. Características físicas dos catalisadores obtidas por MET. .56

Tabela 3.4. Faixa de valores de $\Delta \mathrm{k}$ e $\Delta \mathrm{r}$ usados para as transformadas diretas e inversa de Fourier $\left(\mathrm{k}^{3}\right)$ na análise dos dados. 66

Tabela 3.5. Características físicas das análises TF para os catalisadores: $\mathrm{N}, \mathrm{R}, \sigma^{2}$ e $\Delta \mathrm{E}^{\circ}$ 68

Tabela 3.6. Parâmetros cinéticos obtidos pelas curvas de polarização dos catalisadores em célula a combustível unitária. 76 


\section{LISTA DE ABREVIATURAS E SÍMBOLOS}

PEMFC: Polymer exchange membrane fuel cell e/ou Célula a combustível de membrana trocadora de prótons;

DMFC: Direct methanol fuel cell e/ou célula a combustível de metanol direto;

MEA: Membrane Electrode Assembly e/ou conjunto membrana/eletrodo;

RRO: Reação de redução de oxigênio;

MAF: $\quad$ Método do ácido fórmico;

MB: $\quad$ Método do borohidreto de sódio;

MI: $\quad$ Método de impregnação;

MIC: $\quad$ Método de impregnação convencional;

EDG: Eletrodo de difusão de gás;

PTFE: Politetrafluoretileno;

DRX: $\quad$ Difratometria de raios- $X$;

XANES: $\quad$ X-ray absorption near edge structure;

EXAFS: Extended X-ray absorption fine structure;

LNLS: Laboratório Nacional de Luz Síncrotron;

LME: $\quad$ Laboratório de Microscopia Eletrônica;

MET: $\quad$ Microscopia eletrônica de transmissão;

EDX: $\quad$ Energia dispersiva de raios- $X$;

MEV: $\quad$ Microscopia eletrônica de varredura;

ERH: Eletrodo reversível de hidrogênio;

g: Grama;

$\lambda$ : $\quad$ Comprimento de onda da radiação;

$\beta$ : $\quad$ Largura a meia altura;

k: $\quad$ Constante de proporcionalidade;

dec: Década;

b: $\quad$ Coeficiente angular de Tafel; 

A: Ampere;
i: $\quad$ Densidade de corrente;
d: Diâmetro médio das partículas;
eV: $\quad$ Elétron-volt;
u.a.: Unidade arbitrária;
${ }^{\circ} \mathrm{C}$ : $\quad$ Graus Celsius; 


\section{RESUMO}

A pesquisa e desenvolvimento de novos materiais catalisadores para as reações eletródicas em células a combustível de membrana trocadora de prótons são de grande importância para a viabilização destes sistemas como geradores de energia. Neste trabalho foram preparados catalisadores de Pt-Co suportados em carbono (Pt$\mathrm{Co} / \mathrm{C}$ ) por diferentes métodos e são apresentados os resultados da caracterização física por diferentes técnicas. Os resultados da avaliação da atividade eletrocatalítica para a reação de redução de oxigênio (RRO) em ácido sulfúrico, na ausência e presença de metanol e a avaliação do desempenho destes materiais em células a combustível unitárias alimentadas com $\mathrm{H}_{2}$ e/ou metanol (no ânodo) e $\mathrm{O}_{2}$ (no cátodo) são também apresentados. Em linhas gerais, observou-se que os catalisadores de $\mathrm{Pt}-\mathrm{Co} / \mathrm{C}$ apresentaram maior atividade catalítica para a RRO quando comparados ao catalisador $\mathrm{Pt} / \mathrm{C}$ sendo o método de impregnação o melhor método de preparação dentre os investigados. $\mathrm{O}$ catalisador $\mathrm{Pt}_{75} \mathrm{Co}_{25} / \mathrm{C}$, preparado pela deposição do $\mathrm{Co}$ sobre $\mathrm{Pt} / \mathrm{C}$ seguido pelo tratamento à alta temperatura, apresentou o melhor desempenho para a RRO devido à provável formação de uma liga que apresenta menor tamanho de partícula e menor distância interatômica Pt-Pt que o Pt/C. Adicionalmente, este material apresentou boa estabilidade nos testes em célula a combustível alimentada com $\mathrm{H}_{2} / \mathrm{O}_{2}$. Catalisadores $\mathrm{Pt}-\mathrm{Co} / \mathrm{C}$ mostraram boa tolerância ao metanol quando usados como cátodos com maior atividade para a RRO que o $\mathrm{Pt} / \mathrm{C}$, tanto em ácido sulfúrico na ausência e presença de metanol como na célula a combustível de metanol direto. 


\begin{abstract}
Research and development of new catalyst materials for the electrodic reactions in polymer electrolyte fuel cells are of great importance for the development of these systems as sources of energy. In this work electrocatalyts Pt-Co supported on carbon (Pt-Co/C) were prepared by different methods. Additionally to conventional electrochemical characterization, the materials were physically characterized by means of several different techniques. The evaluation of the electrocatalytic activity for the oxygen reduction reaction (ORR) in acid media, in the absence and presence of methanol, as well as the evaluation of the performance in fuel cells fed with $\mathrm{H}_{2}$ or methanol (in the anode) and $\mathrm{O}_{2}$ (in the cathode) are investigated. Pt-Co/C electrocatalyts presented better catalytic activity for the ORR when compared to $\mathrm{Pt} / \mathrm{C}$. Additionally, the impregnation method was found as being the best preparation method investigated. $\mathrm{Pt}_{75} \mathrm{Co}_{25} / \mathrm{C}$ electrocatalyts prepared by deposition of $\mathrm{Co}$ on $\mathrm{Pt} / \mathrm{C}$ followed by thermal treatment at high temperatures presented the best performance for the ORR due the probable formation of an alloy with small particle size and shorter Pt-Pt bond distance compared to $\mathrm{Pt} / \mathrm{C}$. This material presented good stability in fuel cells. Pt-Co/C electrocatalyts showed good tolerance to methanol when used as cathode materials, showing better activity for the ORR compared to $\mathrm{Pt} / \mathrm{C}$, in acid medium in the absence and presence of methanol and in direct methanol fuel cells.
\end{abstract}




\section{CAPÍTULO I \\ INTRODUÇÃO}

\section{Considerações Gerais}

No presente, uma das grandes preocupações da humanidade é com a disponibilidade energética, com os problemas ambientais causados pela queima dos combustíveis fósseis e o alto comprometimento de suas reservas. O estudo de alternativas energéticas é premente. Neste contexto, destacam-se os estudos em células a combustível como sistemas de geração de energia com elevada eficiência e baixos índices de poluição.

As células a combustível são dispositivos que convertem energia química em energia elétrica. O interesse prático destes sistemas em aplicações estacionárias e em veículos automotores é devido à sua elevada eficiência na conversão de energia $[1-4]$.

\subsection{Tipos de Células a Combustível}

A classificação das células a combustível normalmente se dá pelo tipo de eletrólito que utilizam, que por sua vez, define a temperatura de operação, como também a flexibilidade com relação ao combustível utilizado [1-3]. Estes fatores decidem a aplicação adequada para os diferentes tipos de células a combustível. Com relação à temperatura de operação: as células a combustível de baixa temperatura operam abaixo de $200{ }^{\circ} \mathrm{C}$, as de temperaturas intermediárias operam em aproximadamente $600{ }^{\circ} \mathrm{C}$ e as células a combustível de alta temperatura podem requerer temperaturas de até $1000{ }^{\circ} \mathrm{C}$ para o funcionamento. 


\subsubsection{Célula a Combustível de Eletrólito Alcalino}

A célula a combustível de eletrólito alcalino, que geralmente opera em temperatura abaixo de $125{ }^{\circ} \mathrm{C}$, é a de melhor rendimento em geração de energia. $\mathrm{O}$ bom desempenho foi demonstrado em 1950 e depois pelo programa espacial da NASA em 1960, que requeria sistemas para geração de energia com alta densidade de potência e com alto grau de confiabilidade. A célula a combustível alcalina usa hidróxido de potássio concentrado (85 \%) como eletrólito para operação em altas temperaturas $\left(250{ }^{\circ} \mathrm{C}\right)$ e menos concentrado $(35-50 \%)$ para operação em temperaturas menores $\left(<125^{\circ} \mathrm{C}\right)$. O eletrólito é mantido em uma matriz (usualmente amianto), e uma ampla classe de catalisadores foram usados (tais como $\mathrm{Ni}, \mathrm{Ag}$, óxidos metálicos e metais nobres como platina). A desvantagem deste tipo de célula é a sensibilidade ao dióxido de carbono que pode estar presente em ambos os combustíveis ou oxidantes [1-3].

\subsubsection{Célula a Combustível de Ácido Fosfórico}

As células a combustível de ácido fosfórico operam tipicamente entre 150 e $220{ }^{\circ} \mathrm{C}$ e são mais adequadas para aplicações estacionárias de pequeno porte. $\mathrm{O}$ seu principal uso é em aplicações estácionárias por causa da baixa densidade de energia e do eletrólito líquido corrosivo utilizado. Este tipo de célula usa ácido fosfórico concentrado ( 100\%) como eletrólito. A matriz usada para conter o ácido é usualmente carbeto de silício e os catalisadores nos ânodos e cátodos é o pó de platina. 


\subsubsection{Células a Combustível de Carbonato Fundido e Óxido Sólido}

As células a combustível de carbonato fundido e óxido sólido requerem altas temperaturas $\left(600-1000{ }^{\circ} \mathrm{C}\right)$ para o funcionamento do eletrólito e são as mais adequadas para aplicações estacionárias de grande escala devido ao tempo considerável requerido para atingir a temperatura de operação.

A célula a combustível de óxido sólido usa um eletrólito sólido de óxido nanoporoso, usualmente óxido de itrio $\left(\mathrm{Y}_{2} \mathrm{O}_{3}\right)$ estabilizado com zircônia $\left(\mathrm{ZrO}_{2}\right)$. A célula opera a 900-1000 ${ }^{\circ} \mathrm{C}$ onde ocorre a condução de íons de oxigênio.

A célula a combustível de carbonato fundido usa um eletrólito composto de uma combinação de carbonatos de metais alcalinos ( $\mathrm{Li}, \mathrm{Na}, \mathrm{K})$, os quais são retidos em uma matriz cerâmica de $\mathrm{LiAlO}_{2}$. A temperatura de operação situa-se entre 600 e $1000{ }^{\circ} \mathrm{C}$ com íons carbonato promovendo a condução iônica.

Nestas células devido a altas temperaturas não são requeridos catalisadores de metais nobres.

\subsubsection{Célula a Combustível de Membrana de Troca Protônica}

Dentre as células a combustível, a célula a combustível de membrana de troca protônica ou membrana polimérica (Polymer Exchange Membrane Fuel Cell, PEMFC) é a mais indicada para pequenas plantas estacionárias e veículos automotores, devido à elevada densidade de potência quando o combustível é o hidrogênio $(\sim 1 \mathrm{~kW} / \mathrm{kg})$ e por operar a baixas temperaturas (desde 25 até $\left.80{ }^{\circ} \mathrm{C}\right)$ [1-3]. A PEMFC utiliza como eletrólito uma membrana trocadora de prótons (geralmente um polímero perfluorsulfonado, Nafion ${ }^{\circledR}$, Du Pont), e eletrodos de difusão de gás, 
constituídos por camadas eletrocatalíticas depositadas sobre meios difusores de reagentes [3]. O ânodo da PEMFC pode ser alimentado com hidrogênio gasoso ou soluções de álcoois e o cátodo com oxigênio.

Uma questão importante no momento, com a relação às células a combustível, é a opção pelo combustível utilizado: hidrogênio, álcoois ou gasolina [5]. O hidrogênio seria usado diretamente; para os álcoois as opções são a reforma ou o uso direto, enquanto que para a gasolina a única opção é a reforma. A princípio, destaca-se a utilização do hidrogênio, considerado combustível do futuro, em substituição aos combustíveis fósseis [6]. Entretanto, deve ser considerado que o hidrogênio em quantidades apreciáveis deve ser gerado através de métodos adequados. O hidrogênio precisa ser produzido, por exemplo, pela eletrólise da água ou pela reforma de outros combustíveis fósseis como gás natural, gasolina ou renováveis como os álcoois. Entretanto, outros problemas da utilização do hidrogênio são o armazenamento, estocagem e distribuição, que requerem tecnologias relativamente sofisticadas e de custo elevado. Neste sentido, devido a questões logísticas, as pesquisas estão voltadas para a utilização de combustíveis líquidos em células a combutível, dentre eles, os álcoois [7-11], como metanol [7-9] e o etanol [10-11].

A utilização de metanol em células a combustível, célula a combustível de metanol direto (Direct Methanol Fuel Cell, DMFC), está sendo ativamente pesquisada, particularmente visando às aplicações automotivas e portáteis [7], mas as densidades de potência obtidas ainda são baixas. Os grandes inconvenientes do metanol são: a lenta reação de oxidação, envenenamento do cátodo, sua volatilidade e o alto grau de toxicidade. As DMFC usam o mesmo tipo de eletrólito polimérico, mas a vantagem básica é a oxidação direta de metanol no ânodo, 
eliminando a necessidade de combustível reformado e tornando o sistema como um todo muito mais compacto.

Na configuração básica, a PEMFC consiste de dois eletrodos de difusão de gás, um ânodo e o cátodo, unidos a uma membrana polimérica, como mostra a Figura 1.1. Cada um dos eletrodos é constituído por catalisadores de platina ou ligas de platina. O conjunto de eletrodos, catalisadores e membrana forma o MEA (membrane and electrodes assembly). Os gases reagentes são introduzidos nos eletrodos (ânodo e cátodo) por canais de fluxo. Na oxidação o combustível $\mathrm{H}_{2}$ dissocia-se no compartimento anódico em elétrons e prótons. Os elétrons são conduzidos por um circuito externo enquanto os prótons migram através do eletrólito até o compartimento catódico. Oxigênio, do ar atmosférico, elétrons e prótons combinam-se para formar água e calor [1]. A Figura 1.1 apresenta uma PEMFC alimentada com $\mathrm{H}_{2} / \mathrm{O}_{2}$.

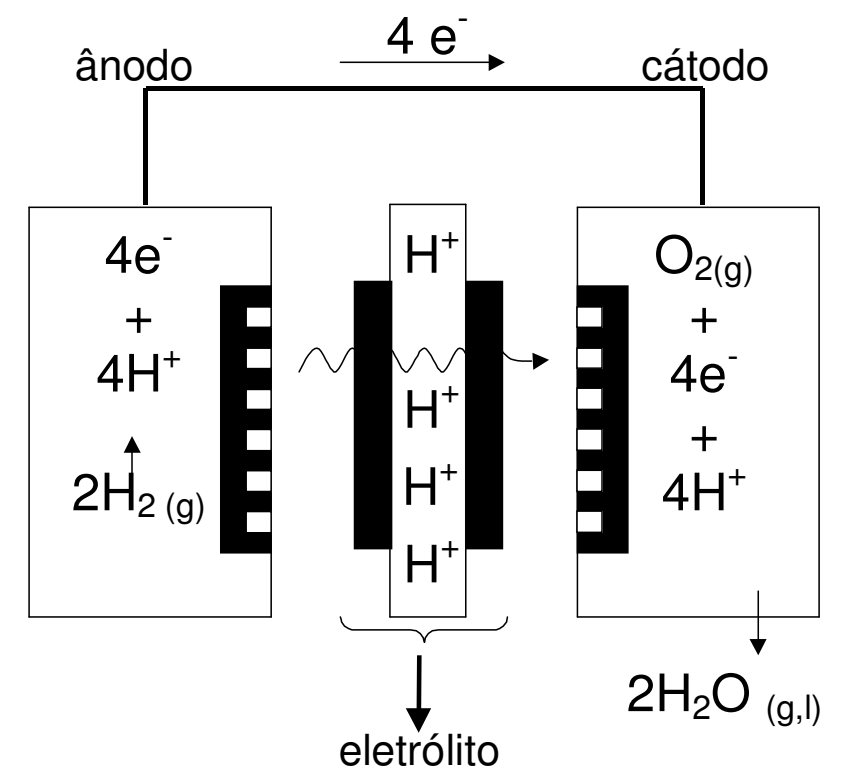

FIGURA 1.1. Ilustração da PEMFC de $\mathrm{H}_{2} / \mathrm{O}_{2}$. 
As reações eletroquímicas que se processam em uma célula a combustível PEMFC alimentadas com $\mathrm{H}_{2} / \mathrm{O}_{2}$ ou metanol/ $\mathrm{O}_{2}$ são a oxidação do combustível (hidrogênio ou metanol) e a redução de oxigênio, levando a formação dos produtos [12].

No ânodo:

$$
\begin{gathered}
3 \mathrm{H}_{2} \rightarrow 6 \mathrm{H}^{+}+6 e^{-} \\
\mathrm{CH}_{3} \mathrm{OH}+\mathrm{H}_{2} \mathrm{O} \rightarrow \mathrm{CO}_{2}+6 \mathrm{H}^{+}+6 e^{-}
\end{gathered}
$$

No cátodo:

$$
3 / 2 \mathrm{O}_{2}+6 \mathrm{H}^{+}+6 e^{-} \rightarrow 3 \mathrm{H}_{2} \mathrm{O}
$$

A Figura 1.2 representa uma curva de polarização (potencial vs. densidade de corrente) para uma célula a combustível unitária. Observa-se que o potencial da célula sofre uma diminuição com o aumento da densidade de corrente. Esta diminuição está relacionada às perdas, chamadas de polarização e são originadas de três fatores [13]: (1) polarização por ativação; (2) polarização por queda ôhmica e (3) polarização por concentração. Estas perdas resultam em um potencial da célula menor do que o valor teórico termodinâmico $\left(1,23 \vee\right.$ a $\left.25^{\circ} \mathrm{C}\right)$. 


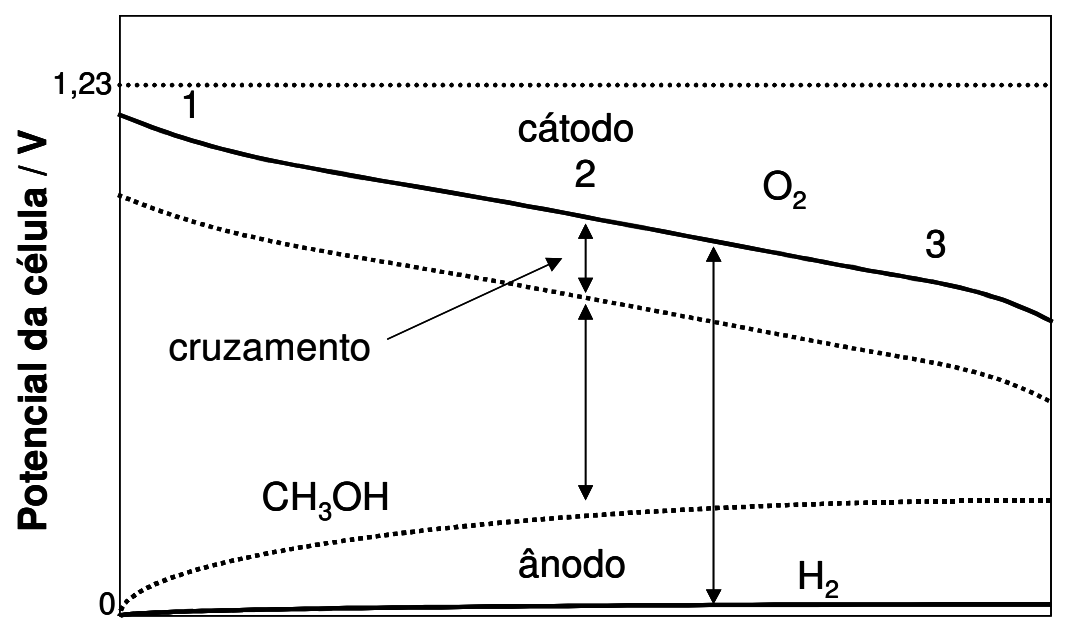

Densidade de corrente / $\mathrm{A} \mathrm{cm}^{-2}$

FIGURA 1.2. Quedas de desempenho da PEMFC de $\mathrm{H}_{2} / \mathrm{O}_{2}$ comparadas com uma DMFC de $\mathrm{CH}_{3} \mathrm{OH} / \mathrm{O}_{2}$.

A polarização por ativação é dominante em baixa densidade de corrente. Ela está presente quando a velocidade de uma reação eletroquímica na superfície de um eletrodo é controlada por uma cinética mais lenta. Um catalisador incorporado à estrutura do eletrodo desempenha um papel fundamental no aumento das velocidades das reações e, conseqüentemente, na minimização dos sobrepotenciais de ativação. Se em uma célula a combustível constituída de dois eletrodos operando com H2/O2 (ânodo/cátodo) é considerada que toda a contribuição de perda de potencial refere-se ao cátodo (reação de redução de oxigênio) [14]. Neste caso, a cinética da oxidação de hidrogênio é rápida e tem valor nulo. No entanto, para uma célula alimentada com outro combustível como, por exemplo, metanol, o sobrepotencial do ânodo não pode ser desprezado.

As perdas de polarização por queda ôhmica ocorrem por causa da resistência ao fluxo de íons no eletrólito e da resistência do fluxo de elétrons através do eletrodo. As perdas dominantes através do eletrólito podem ser reduzidas por meio de uma melhora na interface do eletrodo e aumentando-se a condutividade iônica do 
próprio eletrodo. A polarização por queda ôhmica varia diretamente com a corrente, abrangendo uma grande faixa da curva de polarização porque a resistência da célula permanece praticamente constante.

Enquanto os gases reagentes são consumidos no eletrodo durante a reação eletroquímica, há uma perda de potencial devido à formação de um gradiente de concentração na interface eletrodo/eletrólito. As perdas por transporte de massa ocorrem sobre toda a faixa de densidade de corrente, mas são mais visíveis em valores mais altos, onde é difícil abastecer todos os sítios ativos com os reagentes.

A curva de polarização que reflete 0 desempenho de uma célula a combustível é afetada ainda por vários parâmetros operacionais, como temperatura, pressão, composição dos gases reagentes.

Já em células a combustível de metanol direto, além de estas apresentarem as perdas de polarização acima citadas, há o problema da lenta cinética da eletrooxidação do metanol no ânodo e o cruzamento (crossover) do metanol através da membrana polimérica, como será discutido adiante [15-17].

\subsection{Viabilidade das Células a Combustível PEM}

Como vimos anteriormente, cada tipo de célula tem sua particularidade. Neste sentido, este trabalho enfoca os estudos nas células a combustível PEM. A viabilidade comercial da célula a combustível PEM é confrontada com vários fatores, dentre eles, a cinética lenta nas reações catódica e anódica [15,16], o alto custo das membranas poliméricas e dos catalisadores à base de Pt (platina) e o cruzamento do metanol que atravessa a membrana do ânodo para o cátodo (DMFC) [17-21]. 
Quanto ao uso de catalisadores, eles são dispersos em partículas de carbono de alta área superficial. Platina e ligas de platina são usados como catalisadores em ambos os eletrodos nas células PEM. Entretanto, devido à limitação cinética imposta pela reação de redução de oxigênio, perdas de potencial catódico de 0,3-0,4 V sob condições típicas de operação mostram à importância do desenvolvimento de catalisadores mais ativos do que os atualmentes empregados [14].

Por outro lado, na DMFC, os maiores problemas (que acarretam o decréscimo da eficiência da conversão de energia química do metanol em energia elétrica) são a lenta cinética de eletrooxidação do metanol no ânodo e o cruzamento do metanol. A lenta cinética da oxidação se deve às reações intermediárias que ocorrem, como por exemplo, a formação de monóxido de carbono que é formado durante a desidrogenação do metanol [22].

O transporte do metanol através da membrana, que tipicamente acontece em DMFC e é usualmente conhecido como cruzamento de metanol, ocorre pela difusão como resultado do gradiente de concentração e também devido ao arraste eletroosmótico da água pelos prótons e consequentemente do metanol dissolvido nesta água.

O problema do cruzamento de metanol em DMFC tem sido amplamente estudado [16-21]: metanol adsorve sobre sítios da Pt no cátodo (reduzindo a área efetiva do cátodo para a reação de redução de oxigênio, RRO). Ademais a reação direta entre o metanol e oxigênio gera um potencial misto, reduzindo o potencial da célula e gerando água adicional. Este problema seria resolvido através do uso de eletrólito com menor permeabilidade de metanol ou desenvolvendo novos eletrocatalisadores com maior tolerância ao metanol e maior atividade catalítica para a RRO do que Pt. 
São poucos os materiais eletrocatalíticos que oxidam metanol em baixas temperaturas [7-10,23,24]. A platina apresenta alta atividade e estabilidade, principalmente em meio ácido $[7,25]$, mas a Pt pura não é o catalisador ideal para a oxidação de metanol, pois sua superfície é facilmente envenenada por monóxido de carbono (CO), e este $\mathrm{CO}$ requer altos sobrepotenciais para oxidar se a dióxido de carbono (CO2). Dentre os materiais binários, Pt-Ru é o catalisador que fornece resultados mais promissores para a reação de oxidação de metanol $[26,27]$. Neste caso, a função do Ru é formar óxidos que facilitam a oxidação do intermediário CO a CO2. Porém, o alto custo e pouca disponibilidade do Ru são desvantagens deste material para uso prático. Contudo, elementos alternativos ao $\mathrm{Ru}$, tais como o segundo metal, $M(M=S n$, Co e $\mathrm{Ni})$, mostraram tolerantes ao CO. Neste sentido, dois modelos têm sido propostos para explicar o efeito do M: (i) o mecanismo bifuncional $[28,29]$ onde nos sítios ativos de Pt as espécies CO são adsorvidas e desidrogenadas enquanto sobre os sítios $\mathrm{M}$ as espécies $\mathrm{OH}$ são adsorvidas a potenciais menos positivos do que em Pt pura e (ii) o modelo ligante $[28,30]$ que propõe uma modificação da estrutura eletrônica da Pt pela presença de M fazendo os átomos de Pt mais susceptíveis para a adsorção de espécies $\mathrm{OH}$ e para adsorção dissociativa do metanol.

\subsection{Catalisadores para Células a Combustível PEM}

Em células a combustível de baixas temperaturas, catalisadores de $\mathrm{Pt}$ dispersos em partículas de carbono de alta área superficial e Pt black apresentam melhores atividades catalíticas tanto para a reação de oxidação de hidrogênio como para a reação de redução de oxigênio [31]. 
Algumas alternativas aos catalisadores de platina como cátodos para a RRO em células a combsutível PEM são os catalisadores de metais não nobres baseados em calcogênios [32-34] e os macrociclos de metais de transição dispersos em carbono ativo $[35,36]$. Estes catalisadores apresentaram atividade catalítica próxima à da platina na ausência e presença de metanol. Entretanto, em meio ácido livre de metanol, estes materiais não foram ativos como a platina dispersa.

Outros catalisadores à base de Pt e ligas bimetálicas de metais de transição Pt-M, com $\mathrm{M}=\mathrm{Co}, \mathrm{V}, \mathrm{Cr}$, Ti e Ni, podem apresentar melhor atividade catalítica para a RRO comparados à platina pura [37-55].

A preferência pelos materiais bimetálicos para a $R R O$ em relação à $P t / C$ é atribuída a diversos fatores, dentre eles, a rugosidade da superfície devido à remoção de alguns metais base, o qual aumenta a área superficial da Pt [39]; a distância mais favorável da interação Pt-Pt [37]; vacância dos orbitais d da Pt $[34,37,55]$ e distribuição de átomos sobre a superfície [51].

Jalan e Taylor [37] acreditam que o aumento da atividade catalítica observada para as ligas de Pt deve-se à diminuição da distância interatômica Pt-Pt. Outros trabalhos, como o de Paffett e col. [39] interpretaram a melhora da atividade catalítica para a RRO sobre as ligas de Pt como sendo devido ao fator de rugosidade da superfície, causado pela dissolução do metal mais oxidado da liga. Resultados divergentes sobre a atividade catalítica $[37,56]$ e dissolução dos componentes menos nobres em PAFC [39,57] sugeriram a possibilidade de diferentes propriedades eletroquímicas interferirem no desempenho do catalisador em materiais bimetálicos suportados [45]. Assim, o aumento da atividade catalítica da RRO observado em eletodos de difusão de gás para diferentes catalisadores 
baseados em ligas de Pt seria atribuído a fatores específicos, como tamanho de partícula do catalisador ou a fatores estruturais do eletrodo.

Mukerjee e col. [44] e Min e col. [42] atribuíram o aumento da atividade catalítica da Pt à combinação de efeitos eletrônicos (vacância da banda d da Pt) e geométricos (distância da ligação interatômica Pt-Pt). Min e col. [42] investigaram o efeito do tamanho de partícula e da distância Pt-Pt na atividade catalítica. Os autores observaram uma menor atividade catalítica com o aumento do tamanho das partículas. Foi observada também uma maior atividade catalítica com uma menor distância interatômica Pt-Pt.

Diversos métodos foram descritos para a preparação de $\mathrm{Pt}$ [58] e ligas de $\mathrm{Pt}$ [59] suportados em carbono, muitos dos quais envolvem redução química ou eletroquímica dos metais a partir de soluções que contêm os íons precursores. Os resultados obtidos com os diferentes métodos mostram grandes discrepâncias porque as propriedades físicas dos materiais, tais como a dispersão, a homogeneidade, o grau de liga e o tamanho de partícula do metal, dependem da rota de preparação.

Um método comum na preparação de catalisadores Pt-M suportados em carbono consiste na impregnação de um segundo metal sobre a Pt previamente suportada em carbono, seguida da formação de uma liga a altas temperaturas em atmosfera de hidrogênio $[37,42,51]$. No tratamento térmico, a altas temperaturas $\left(900{ }^{\circ} \mathrm{C}\right.$ ), ocorre o indesejável crescimento das partículas da liga, através da sinterização e coalescência das partículas de Pt [60], o qual resulta num decréscimo da atividade catalítica. 
Usando este método, Beard e Ross [51] prepararam catalisadores de Pt-Co/C de composição atômica 3:1 a partir do material comercial Pt/C de duas formas, um método de preparação em meio ácido e outro em meio alcalino. O tratamento térmico (TT) foi feito para cada catalisador a temperatura de $700-1200{ }^{\circ} \mathrm{C}$ em atmosfera inerte. Os autores não observaram a redução dos materiais sem o tratamento térmico. Após o TT observou-se um decréscimo do parâmetro de rede com o aumento da temperatura. Nos dois casos o valor do parâmetro de rede foi maior do que o valor obtido para Pt3Co suportado em carbono $(0,3854 \mathrm{~nm})[38,45]$. O tamanho de partícula para o material preparado em meio ácido foi maior do que o dos catalisadores preparados em meio alcalino. $\mathrm{O}$ tamanho de partícula quando o material foi tratado a $1200{ }^{\circ} \mathrm{C}(12 \mathrm{~nm})$ foi aproximadamente 4 vezes maior do que 0 observado para o catalisador sem TT.

Catalisadores de Pt-Co, Pt-Cr e Pt-Ni suportados em carbono de alta área superficial foram preparados por Shukla e col. [61] e Min e col. [42]. Shukla e col. [61] prepararam Pt-Co/C com composição nominal 1:1 a partir de Pt/Vulcan XC-72 com $16 \%$ de metal disperso em água destilada. Os autores observaram que os catalisadores constituídos por Pt-Co/C exibiram uma maior atividade catalítica para a RRO em comparação às demais ligas $(\mathrm{Cr}$ e $\mathrm{Ni})$ e à $\mathrm{Pt} / \mathrm{C}$. Estes autores também notaram uma mudança na estrutura cristalográfica para as ligas de Pt em relação à Pt pura através de estudos difração de raios-X (DRX). Uma estrutura com fase tetragonal de face-centrada foi formada para os catalisadores Pt-Co/C e Pt-Co-Cr/C. Nestes estudos, os autores não discutiram o efeito do parâmetro de rede e nem da formação de liga. 
Min e col. [42] prepararam catalisadores de $\mathrm{Pt}-\mathrm{Co} / \mathrm{C}$ a partir do material comercial com $10 \%$ de metal. Quantidade apropriada de solução de $\mathrm{CoCl} 2$ foi adicionada lentamente à solução contedo Pt/C. A composição atômica conseguida foi Pt:Co 3:1. Os catalisadores foram tratados termicamente entre 700 e $1100{ }^{\circ} \mathrm{C}$ por $2,5 \mathrm{~h}$ em atmosfera redutora ( $10 \%$ de $\mathrm{H} 2+90 \%$ de N2). Estes catalisadores exibiram uma estrutura fcc. Os autores observaram que com o aumento da temperatura do tratamento térmico aumenta o tamanho de partículas de 3,0 para 8,6 nm e o parâmetro de rede dos clusters de Pt decresce de 0,3923 para 0,3855 nm.

Recentemente, outros grupos publicaram trabalhos que tratam de catalisadores bimetálicos de Pt preparados pela co-redução dos precursores dos sais metálicos em baixa temperatura. Estes autores obtiveram tamanho de partículas da liga relativamente menores que Pt/C [62]. Xiong e col. [63] prepararam catalisadores de ligas bimetálicas Pt-Co na composição atômica de Pt:Co 27:73 (20 \%) sobre carbono Vulcan $\mathrm{XC}-72 \mathrm{R}$ seguido pela redução da mistura dos sais precursores com formiato de sódio. A redução dos sais também foi feita pela adição de algumas gotas de borohidreto de sódio seguido pela redução em formiato de sódio. O tamanho de partícula encontrado foi de $3,6 \mathrm{~nm}$ e $4,5 \mathrm{~nm}$, sem e com borohidreto de sódio, respectivamente. Neste trabalho os autores não discutiram a quantidade de cobalto que formou liga com Pt.

Geralmente, o principal problema em se tratando da preparação de ligas de Pt-M suportadas em carbono é a pequena quantidade do segundo metal no catalisador, isto é, a composição verdadeira do catalisador tem menos deste metal do que a composição nominal [60]. 
Além disso, muitos estudos vêm destacando o efeito do tamanho de partículas na atividade catalítica para a RRO. Os resultados são contraditórios, alguns trabalhos [64-66] mostram que a atividade diminui quando o tamanho de partículas aumenta enquanto que Kinoshita [67] argumenta que a atividade aumenta, passa por um máximo e então decresce com a diminuição do tamanho de partículas. Isto foi atribuído a uma mudança na distribuição dos átomos superficiais das faces (100) e (111) do material [67] ou à ocupação da banda d da Pt [68,69]. A aglomeração de Pt causa um decréscimo no desempenho do catalisador devido ao decréscimo da área superficial da Pt por unidade de massa deste metal. Uma vez que se sabe da dificuldade de preparar catalisadores de ligas bimetálicas Pt-M com diferente composição atômica e com o mesmo tamanho de partículas, também este efeito tem que ser levado em conta para a atividade da RRO. Estudos prévios [6870] indicaram que a formação de óxido e a vacância da banda d dependem do tamanho de partículas de Pt. A hibridização do estado $5 \mathrm{~d}$ com o estado desocupado sobre o nível de Fermi reduz o número verdadeiro de elétrons na banda d, e esta hibridização torna-se menos favorável com o aumento no tamanho de partículas. Quando o tamanho de partícula aumenta, a vacância da banda d decresce e a força de adsorção de espécies oxigenadas decresce. Assim, a redução de intermediários que contêm oxigênio sobre a superfície da Pt é favorecida.

No atual estágio de desenvolvimento de catalisadores bimetálicos, a direção dos trabalhos é de avaliar a atividade catalítica para a RRO na presença de metanol e de avaliar o desempenho na DMFC. No entanto, os poucos resultados encontrados da atividade catalítica das ligas bimetálicas comparadas à Pt/C são satisfatórios. 
Um aumento na atividade catalítica para a RRO na presença de metanol sobre catalisadores de Pt-Ni [71] e Pt-Cr [72] foi observado em resultados obtidos em eletrodo de disco-anel e resultados de curvas de polarização em DMFC com PtFe [73]. Neergat e col. [74] descreveram que uma melhor atividade catalítica para os catalisadores Pt-Co suportados em carbono com composição atômica 1:1 para a RRO em DMFC, comparado à Pt/C e outras ligas bimetálicas, deve-se a um aumento na cinética da redução de oxigênio [74].

A maioria dos catalisadores bimetálicos à base de Pt investigada para as reações em células a combustível é estudada em nível fundamental, e os vários mecanismos propostos têm como base experimentos em meia célula $[46,75]$. Contudo, as conclusões a respeito da atividade catalítica frente à RRO são contraditórias e na maioria dos casos as conclusões obtidas dos trabalhos fundamentais são difíceis de transportar para os sistemas tecnológicos. Por isso, é relevante avaliar os catalisadores nas condições operacionais de células a combustível unitárias alimentadas com hidrogênio e/ou metanol direto no ânodo e oxigênio no cátodo, a fim de poder avaliar o desempenho dos catalisadores sob condições operacionais.

Para este fim, os eletrodos de difusão de gás têm-se mostrado satisfatórios e são amplamente utilizados para as reações eletródicas em células a combustível [76-77]. Os eletrodos de difusão são eletrodos de alta área específica, desenhados para promover correntes elevadas em situações onde ocorrem reações eletroquímicas cineticamente lentas, como a reação de redução de oxigênio, permitindo a obtenção de altas densidades de corrente [77]. 
Os valores da atividade catalítica para a RRO são geralmente expressos em atividade de massa (a densidade de corrente dividida pela quantidade de $\mathrm{Pt}$ ) ou atividade específica (que é a densidade de corrente dividida pela área eletroativa do eletrodo ou o tamanho de partícula). A atividade de massa tem implicações práticas devido ao custo do eletrodo, que depende da quantidade de platina usada. Para conseguir uma dispersão econômica do metal (<1 mg Pt cm-2) os eletrodos da célula a combustível são preparados por nanopartículas de $\mathrm{Pt}(\mathrm{d}<5 \mathrm{~nm})$ suportadas em carbono de alta área superficial. De fato, para a RRO a atividade específica decresce com o tamanho de partículas, enquanto que a atividade específica para partículas maiores $(\mathrm{d}>5 \mathrm{~nm})$ é aproximadamente a mesma que para um eletrodo liso de Pt. Como resultado da atividade de massa vs. o tamanho de partículas para a RRO em eletrólito contendo ácido sulfúrico o máximo situa-se em 3,5 nm [67].

\subsection{Caracterização dos Catalisadores Suportados}

A caracterização física e eletroquímica dos catalisadores é fundamental para conhecer as características físicas, tais como: o tamanho de partículas, homogeneidade, distribuição de partículas sobre o suporte de carbono, composição da liga e estado de oxidação, e correlacionar estes fatores às atividades eletrocatalíticas para a reação de redução de oxigênio. Dentre as inúmeras técnicas usadas para caracterizar os materiais suportados estão [38,42,61]. A técnica de energia dispersiva de raios-X (EDX) analisa de forma semiquantitativa a composição nominal dos materiais. Esta técnica está acoplada ao microscópio eletrônico de varredura. A técnica de difração de raios-X (DRX) [44], que foi empregada com o objetivo de determinar os parâmetros estruturais, tais como, estrutura cristalina dos 
materiais, parâmetro de rede, grau de ligação e estimativa do tamanho médio de partícula dos catalisadores.

A caracterização física dos materiais por microscopia eletrônica de transmissão (MET) permite avaliar a morfologia da superfície, determinar o diâmetro médio e obter uma distribuição do tamanho de partículas suportadas sobre o carbono. Pôde-se ainda, com o uso de MET determinar a composição nominal com o emprego de EDX acoplada ao microscópio eletrônico de transmissão.

A espectroscopia de absorção de raios-x (sigla em inglês, XAS - X-ray absorption spectroscopy) foi utilizada no trabalho para avaliar a influência do segundo metal sobre a platina. Essa técnica permite determinar propriedades eletrônicas (XANES - X-ray absorption near-edge structure), geométricas e estruturais (EXAFS - Extended X-ray absorption fine structure), como a presença de partículas superficiais na forma oxidada e o grau de interação entre átomos de uma liga Pt-Co $[38,42]$.

Quanto à avaliação eletroquímica dos catalisadores, uma das técnicas de caracterização mais adequadas é a voltametria cíclica [55]. De forma particular foi utilizada a voltametria cíclica com o intuito de determinar a área eletroquimicamente ativa através da adsorção de $\mathrm{H}_{2}$ [75] e monóxido de carbono [26].

\subsection{Reação de Redução de Oxigênio}

Diferentes mecanismos têm sido propostos para a RRO em soluções ácidas para uma série de materiais eletródicos metálicos [78]. Como, por exemplo, para a platina em meio ácido, o oxigênio é reduzido diretamente a água, através da reação global (1.4):

$$
\mathrm{O}_{2}+4 \mathrm{H}^{+}+4 e^{-} \Leftrightarrow 2 \mathrm{H}_{2} \mathrm{O}
$$


Porém em alguns outros materiais, a reação leva à formação de peróxido de hidrogênio através de uma reação (1.2) que envolve dois elétrons:

$$
\mathrm{O}_{2}+2 \mathrm{H}^{+}+2 e^{-} \Leftrightarrow \mathrm{H}_{2} \mathrm{O}_{2}
$$

E este peróxido é novamente reduzido a água com adição de $2 \mathrm{e}^{-}$(1.2):

$$
\mathrm{H}_{2} \mathrm{O}_{2}+2 \mathrm{H}^{+}+2 e^{-} \Leftrightarrow 2 \mathrm{H}_{2} \mathrm{O}
$$

De acordo com o mecanismo de reação, há três formas pelas quais as moléculas de oxigênio podem se adsorver na superfície do eletrodo, sendo elas ilustradas pelos modelos de Griffith, Paulling e de ponte, confome Figura 1.3 [79]. Se a adsorção seguir os modelos de Griffith e de ponte, o mecanismo de redução envolverá 4 elétrons. Por outro lado, se a adsorção seguir o modelo de Pauling, eventualmente a redução dar-se-á segundo um mecanismo envolvendo dois elétrons, resultando como produto $\mathrm{H}_{2} \mathrm{O}_{2}$. Adicionalmente, estas formas de adsorção poderão estar ocorrrendo simultaneamente e a prepoderância de um ou outro mecanismo dependerá dos impedimentos estéricos e do espaçamento entre os sítios ativos, ou em outras palavras, do material eletródico e/ou das condições experimentais empregadas.

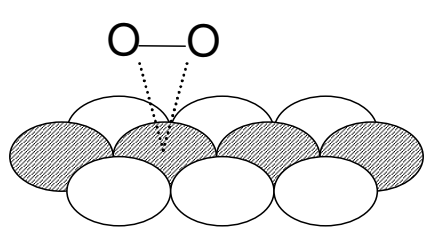

(i)

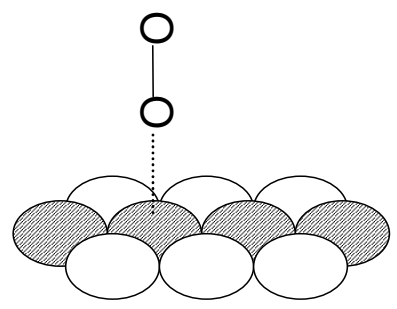

(ii)

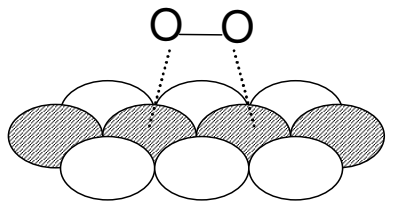

(iii)

FIGURA 1.3. Formas de adsorção de moléculas de oxigênio sobre o material eletródico: (i) Modelo de Griffith; (ii) Modelo de Paulling e (iii) Modelo de ponte. Faces (111). 


\subsection{Objetivos}

Em linhas gerais, o objetivo do presente trabalho é o desenvolvimento de catalisadores bimetálicos de Pt-Co suportados em carbono $(\mathrm{Pt}-\mathrm{Co} / \mathrm{C})$ para a reação de redução de oxigênio (RRO) em células a combustível de membrana trocadora de prótons de baixa temperatura. Especificamente, o trabalho envolveu a preparação de catalisadores de Pt-Co/C por diferentes métodos e a caracterização física através de técnicas de difração de raios- $X$, energia dispersiva de raios- $X$, espectroscopia de absorção de raios-X, espectroscopia Raman e microscopia eletrônica de transmissão. A avaliação eletroquímica da atividade eletrocatalítica dos catalisadores de Pt-Co/C para a RRO foi realizada em ácido sulfúrico (meia célula), na ausência e presença de metanol, como também o desempenho do catalisador PtCo/C para a RRO em células a combustível unitárias alimentadas com hidrogênio ou metanol (no ânodo) e oxigênio (no cátodo).

\section{CAPÍTULO II}

\section{EXPERIMENTAL}

\subsection{Preparação de Catalisadores}

Catalisadores bimetálicos de Pt-Co suportados em carbono (Pt-Co/C) foram preparados pela técnica de impregnação em carbono de alta área superficial (Vulcan XC-72, Cabot, 240 $\mathrm{m}^{2} \mathrm{~g}^{-1}$ ). A metodologia consiste na adição de soluções de ácido hexacloroplatínico $\left(\mathrm{H}_{2} \mathrm{PtCl}_{6} \cdot 6 \mathrm{H}_{2} \mathrm{O}\right.$, Johnson Matthey) e hidróxido de cobalto $\left(\mathrm{Co}(\mathrm{OH})_{2} \cdot 6 \mathrm{H}_{2} \mathrm{O}\right.$, Aldrich) sobre o substrato de carbono, seguida da redução direta dos metais com diferentes agentes redutores. Os catalisadores foram feitos com 20 
$\%$ em massa de metal sobre carbono. Assim, foram utilizados os métodos de redução por ácido fórmico (MAF) [80], de impregnação convencional (MIC) [81], de impregnação do metal de transição (Co) (MI) [61] e o de redução por borohidreto de sódio (MB) [82].

Para efeito de comparação foram utilizados os catalisadores comerciais (ETEK, Inc.) Pt/C e Pt-Co/C, este último com 50:50 em átomos, dos metais. A seguir, serão descritos sucintamente os métodos acima citados.

\subsubsection{Método do Ácido Fórmico (MAF)}

O MAF é o método mais utilizado pelo Grupo de Eletroquímica do IQSC/USP na preparação de catalisadores à base de platina suportados em carbono (Pt/C e Pt$M / C, M=R u, M o, W$, etc.) $[26,80,83-86]$ para estudos em células a combustível. Em estudos recentes sobre diferentes métodos de preparação de catalisadores de Pt/C, o catalisador preparado pelo MAF apresentou o melhor desempenho para a reação de redução de oxigênio na célula a combustível alimentada com $\mathrm{H}_{2} / \mathrm{O}_{2}$ [83].

O MAF consiste da impregnação do pó de carbono em solução de ácido fórmico (agente redutor) com posterior adição de sais de platina e cobalto a $80{ }^{\circ} \mathrm{C}$ sob agitação. Com a finalidade de verificar a presença ou ausência dos sais de $\mathrm{Pt}^{4+}$ e $\mathrm{Co}^{2+}$ utilizou-se iodeto de potássio e o tiocianato de amônio, respectivamente. A ausência dos íons é indicada pela mudança da coloração amarela-avermelhada (Pt) e rosa-azul (Co) ao colocar uma gota em papel de filtro. O material foi filtrado, lavado com água e seco a $80{ }^{\circ} \mathrm{C}$ por $2 \mathrm{~h}$. 
Os materiais $\mathrm{Pt}-\mathrm{Co} / \mathrm{C}$ preparados por este método foram submetidos a um tratamento térmico num tubo de quartzo em atmosfera de $\mathrm{H}_{2}$ /argônio (1:9) a 500 e $900{ }^{\circ} \mathrm{C}$ por $1 \mathrm{~h}$.

\subsubsection{Método de Impregnação Convencional (MIC)}

O método de impregnação convencional (MIC) consiste na redução dos sais de Pt $\left(\mathrm{H}_{2} \mathrm{PtCl}_{6} \cdot 6 \mathrm{H}_{2} \mathrm{O}\right)$ e $\mathrm{Co}\left(\mathrm{Co}(\mathrm{OH})_{2} \cdot 6 \mathrm{H}_{2} \mathrm{O}\right)$ impregnados sobre carbono em banho ultra-sônico por 3 h [81]. O material foi seco, sendo em seguida a redução feita em atmosfera de $\mathrm{H}_{2}$ /argônio (1:9) a 550 ou $900{ }^{\circ} \mathrm{C}$ por $3 \mathrm{~h}$. Os materiais submetidos ao tratamento térmico são identificados como TT.

\subsubsection{Método de Impregnação (MI)}

Este método consiste na incorporação dos sais contendo cobalto à $\mathrm{Pt} / \mathrm{C}$ com $20 \%$ de metal (E-TEK) [61]. O catalisador Pt/C foi disperso em água destilada em banho ultra-sônico por $30 \mathrm{~min}$. $\mathrm{O}$ pH da dispersão foi mantido no valor de $8 \mathrm{com}$ solução de hidróxido de amônio. Uma solução de cloreto de cobalto $\left(\mathrm{CoCl}_{2} \cdot 6 \mathrm{H}_{2} \mathrm{O}\right.$, Aldrich), calculada de acordo com a composição nominal, foi adicionada a esta dispersão. Assim, a dispersão foi mantida no ultra-som e foi adicionado $\mathrm{HCl}$ diluído para levar o pH até 5. Continuou-se em ultra-som por mais $1 \mathrm{~h}$ e então a massa resultante foi filtrada e seca a $85^{\circ} \mathrm{C}$. Para a redução de íons Co foi realizado um tratamento térmico num tubo de quartzo em atmosfera de $\mathrm{H}_{2} / \operatorname{Ar}(1: 9)$ a $900{ }^{\circ} \mathrm{C}$ por 1 h. Os catalisadores foram preparados com $20 \%$ de Pt e 1 a $3 \%$ de Co ambos com relação ao suporte de carbono. 


\subsubsection{Método do Borohidreto de Sódio (MB)}

O MB baseia-se na impregnação do carbono com solução de sais de platina e cobalto e, posteriormente, redução destes metais em solução de borohidreto de sódio $\left(0,04 \mathrm{~mol} \mathrm{~L}^{-1}\right)$ [82]. O sal de cobalto foi dissolvido em uma mistura $50 \% \mathrm{v} / \mathrm{v}$ de água e metanol e foram adicionadas algumas gotas de ácido clorídrico. Posteriormente, adicionou-se uma solução de hidróxido de amônio até a formação de um complexo de cobalto ( $\mathrm{pH}$ entre 8-9). O agente redutor é adicionado lentamente em pequenas porções em banho ultra-som a temperatura ambiente $(\sim 25$ $\left.{ }^{\circ} \mathrm{C}\right) . \mathrm{O}$ catalisador obtido é filtrado, lavado com água e seco a $80^{\circ} \mathrm{C}$ por $2 \mathrm{~h}$.

Depois de obtido, o material $\mathrm{Pt}-\mathrm{Co} / \mathrm{C} \mathrm{MB}$ foi submetido a um tratamento térmico em tubo de quartzo em atmosfera de $\mathrm{H}_{2}$ /argônio (1:9) a $500{ }^{\circ} \mathrm{C}$ por $1 \mathrm{~h}$.

\subsection{Caracterização Física}

\subsubsection{Energia Dispersiva de Raios-X}

As relações atômicas dos catalisadores $\mathrm{Pt}-\mathrm{Co} / \mathrm{C}$ foram determinadas pela técnica de energia dispersiva de raios-X (EDX). Fez-se também o mapeamento elementar para alguns materiais suportados. O equipamento usado para a técnica de EDX é acoplado a um microscópio eletrônico de varredura (EDX/MEV), LEO, modelo 440, Leica-Zeiss, com um detector de Si (Li) com janela de berílio, na região de 0-25 keV. 


\subsubsection{Difratometria de Raios-X}

A técnica de difração de raios-X (DRX) foi empregada com o objetivo de determinar os parâmetros estruturais dos catalisadores utilizados, tais como, estrutura cristalina, parâmetro de rede, grau de ligação e diâmetro médio das partículas dos catalisadores investigados. Para a análise dos difratogramas foi empregado o método de Rietveld, o qual analisa quantitativamente os resultados de DRX através do refinamento do espectro de difração [87].

A partir dos difratogramas de raios- $X$ foi possível determinar o tamanho médio das partículas calculado a partir da largura da metade da altura máxima do pico referente ao plano (220) da estrutura cúbica de face centrada (grupo espacial: F m 3 $\mathrm{m}, 225)$ da platina, com ângulo em torno de $2 \theta=70^{\circ}$. Este pico foi escolhido porque não sofre interferência da banda larga do suporte de carbono. Desta forma, podemse subtrair as contribuições do background. Para a estimativa do diâmetro das partículas fez-se um ajuste gaussiano do pico e empregou-se a equação de Scherrer [88]:

$$
d=\frac{k \lambda}{\beta \cos \theta}
$$

Sendo d é o diâmetro médio das partículas de Pt. k é uma constante de proporcionalidade que depende da forma da partícula e da maneira de se medir a largura do pico. No caso da medida da largura à meia altura do pico ( $\beta$, rad), o valor de $\mathrm{k}$ pode se situar entre 0,84 e 0,89, dependendo da geometria das partículas. $\lambda$ é o comprimento de onda da radiação $\left(\mathrm{Cu} \mathrm{k}_{\alpha}, \lambda=1,5406 \AA\right.$ ) gerada à corrente de 100 $\mathrm{mA}$ e voltagem de $50 \mathrm{kV}$. 
A velocidade de varredura foi de $3^{\circ}$ e $0,02^{\circ}\left(2 \theta \mathrm{min}^{-1}\right)$ nos intervalos de 20 $100^{\circ}$ e $60-80^{\circ}$, respectivamente. O equipamento utilizado foi um Difratômetro Universal de Raios-X (URD-6, Carl Zeiss-Jena). A varredura para as análises de DRX utilizando-se o método de Rietveld foi feita no modo step scan com passos de $0,02^{\circ} \mathrm{e}$ intervalos de $5 \mathrm{~s}$ entre $3^{\circ} \mathrm{e} 100^{\circ}$.

O valor do parâmetro de rede foi obtido por refinamento pelo método dos mínimos quadrados [89], sendo o programa GSAS4 [90] utilizado para o refinamento dos dados pelo método de Rietveld.

\subsubsection{Microscopia Eletrônica de Transmissão}

A caracterização física dos catalisadores $\mathrm{Pt}-\mathrm{Co} / \mathrm{C}$ e $\mathrm{Pt} / \mathrm{C}$ por microscopia eletrônica de transmissão de alta resolução (MET) tem como objetivo avaliar a morfologia da superfície dos materiais, determinar o diâmetro médio e obter a composição e distribuição do tamanho das partículas suportadas sobre o carbono.

A preparação das amostras é feita pela dispersão de uma pequena porção do material em água através de banho ultra-sônico por 10 min. Para a deposição do catalisador utilizou-se uma grade de $\mathrm{Cu}$, com 3 mm de diâmetro e 300 mesh, recém coberta de um filme fino de carbono.

Para avaliar a morfologia superficial dos materiais, as imagens foram obtidas em diferentes regiões da grade numa magnificação de $50 \mathrm{kx}$. Para determinar o tamanho médio e estimar a distribuição das partículas, as imagens foram obtidas com um aumento de $150 \mathrm{kx}$. Para a construção dos histogramas foi determinado o diâmetro de cada partícula, para aproximadamente 500 partículas. Para a determinação dos parâmetros estruturais, as imagens foram obtidas com um 
aumento de 800 kx. Determinou-se ainda a composição atômica dos materiais com o emprego da técnica de EDX acoplada à MET.

As medidas de MET foram realizadas no Laboratório de Microscopia Eletrônica do Laboratório Nacional de Luz Síncrotron (LME/LNLS) empregando-se microscópio eletrônico de alta resolução (modelo JEOL, JEM-3010, URP) com operação a 300 kV e resolução pontual de 0,17 nm.

\subsubsection{Espectroscopia de Absorção de Raios-X}

A caracterização dos materiais com o emprego da técnica de espectroscopia de absorção de raios-X (X-ray absorption spectroscopy, XAS) possibilita a compreensão dos processos eletrocatalíticos das reações eletroquímicas pois, de maneira seletiva, permite estudar a organização estrutural e eletrônica local dos catalisadores suportados em carbono.

A espectroscopia de absorção próximo a borda, XANES (X-ray absorption near-edge structure), fornece informações sobre a densidade eletrônica nos orbitais 5d da Pt. A espectroscopia da estrutura fina de absorção, EXAFS (Extended X-ray absorption fine structure), fornece parâmetros geométricos e estruturais, dentre eles, a distância da ligação Pt-Pt e Pt-Co e o número de coordenação da Pt. Estes fatores podem ser correlacionados com a atividade catalítica dos materiais $[38,44,45]$.

As medidas de espectroscopia de absorção de raios- $X$ foram realizadas na estação XAFS do Laboratório Nacional de Luz Síncrotron (LNLS) com o anel operando à 1,37 GeV e corrente nominal de $100 \mathrm{~mA}$. O monocromador utilizado foi um duplo cristal de silício (111) que opera na região de 4-12 keV. Para a calibração utilizou-se uma folha metálica de platina. A aquisição dos dados foi feita com três 
câmaras de ionização (incidência $I_{0}$, transmissão $I_{t}$ e referência $I_{r}$ ). Um gás ionizado foi utilizado nas câmaras $I_{0}$, $I_{t}$ e $I_{r}$ para monitorar as intensidades de incidência e transmissão de raios- $\mathrm{X}$.

Para as medidas foram preparadas duas pastilhas contendo $6 \mathrm{mg} \mathrm{de} \mathrm{Pt} \mathrm{cm}{ }^{-2}$ para cada amostra. Esta quantidade de material permitiu obter valores razoáveis para o coeficiente de absorção. As medidas foram feitas in situ na célula espectroeletroquímica em solução de ácido sulfúrico $0,5 \mathrm{~mol} \mathrm{~L}^{-1}$ à temperatura de $25{ }^{\circ} \mathrm{C}$. Um eletrodo reversível de hidrogênio $(\mathrm{ERH})$ foi utilizado como eletrodo de referência. Durante as medidas a célula foi mantida isenta de oxigênio pelo borbulhamento contínuo de nitrogênio. As pastilhas foram colocadas em par (material em estudo/platina) e acopladas com espaçadores de Teflon junto a uma célula eletroquímica de acrílico. A Figura 2.1 mostra a célula eletroquímica utilizada para as medidas de absorção de raios- $X[38,44,45]$.

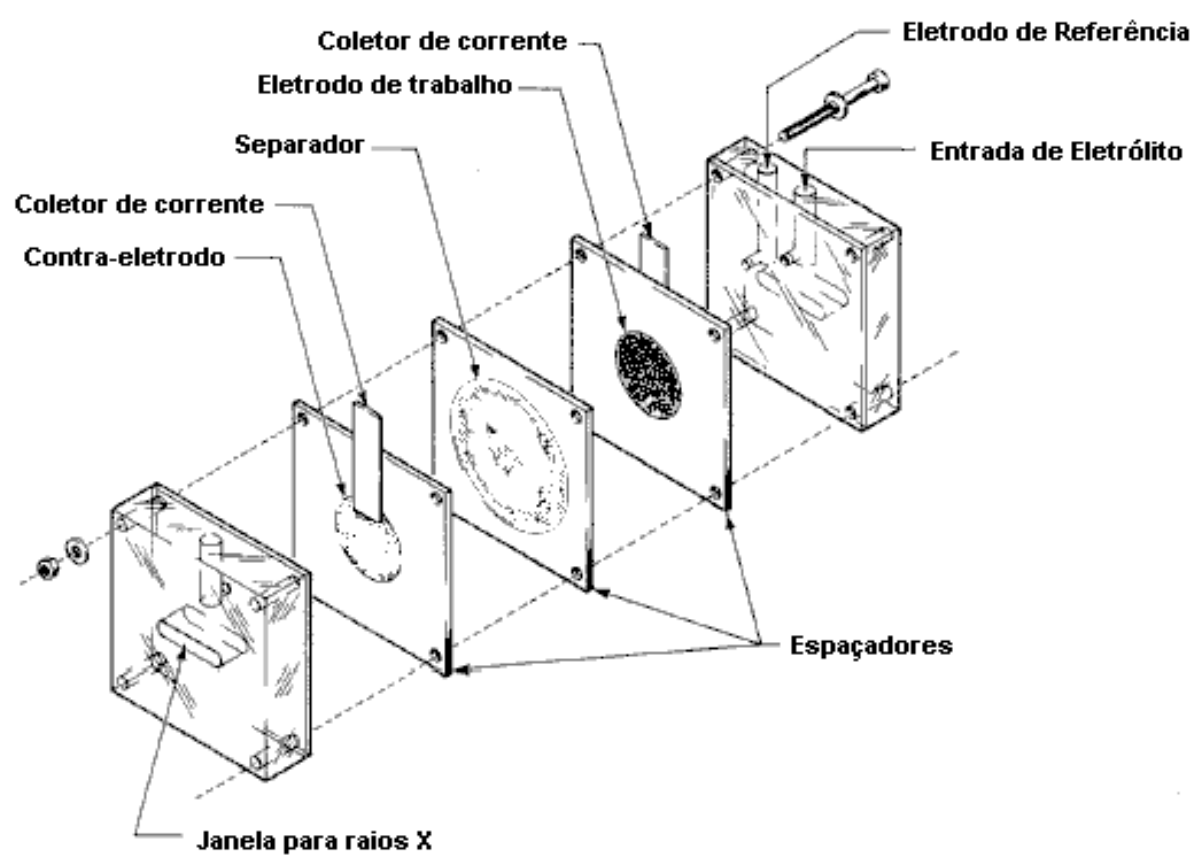

FIGURA 2.1. Esquema da célula eletroquímica usada para as medidas de XAS. 
Os espectros de absorção foram coletados na região compreendida entre 11450 e $12200 \mathrm{eV}$, sendo a escala de energia calibrada utilizando-se uma folha de platina como referência. Os espectros XANES e EXAFS das amostras foram registrados para a borda $\mathrm{L}_{\text {III }}$ da Pt $(11564 \mathrm{eV})$ e comparados com os espectros da folha de Pt. O programa utilizado para as análises dos dados de absorção de raios-X foi o WINXAS [91].

Para a análise das oscilações EXAFS, $\chi(K)$, os espectros foram obtidos a partir da normalização em relação ao coeficiente de absorção do átomo da amostra, $\mu(E)$, e a absorção para o átomo isolado, $\mu_{0}$ (E) (normalização da região do XANES) [92,93]. Os valores da análise EXAFS foram obtidos além de 50 eV acima da borda de absorção. A função EXAFS é obtida mediante a expressão:

$$
\chi(k)=\left\{\frac{\mu(E)-\mu_{0}(E)}{\mu_{0}(E)}\right\}
$$

O eixo da abscissa foi, então, transformado de energia $E$ para vetor de onda dos fotoelétrons, $k$, conforme a equação:

$$
k=\sqrt{\frac{2 m}{\hbar^{2}}\left(E-E_{0}\right)}
$$

Onde, $\mathrm{m}$ é a massa do elétron, $\hbar$ é a constante de Planck, $\mathrm{E}$ a energia do fotoelétron e $E_{0}$ a energia de ionização do átomo da amostra.

$\mathrm{Na}$ aproximação de espalhamento simples e ondas planas os resultados de EXAFS podem ser descritos pela expressão: 


$$
\chi(k)=\sum_{j} S_{0}^{2} \frac{N_{j}}{k R^{2}} F_{j}(k, \pi) \exp \left(-2 \sigma_{j}^{2} k\right) \exp \left(-\frac{2 R_{j}}{\lambda}\right) \operatorname{sen}\left[2 k R_{j}+\phi_{j}(k)\right]
$$

Onde $F_{j}(k, \pi)$ é a função da amplitude de espalhamento de cada um dos $N_{j}$ vizinhos equivalentes localizados a uma distância média $R_{j}$ do átomo que absorve, $\sigma_{i}$ é o fator de Debye-Waller, o qual leva em conta a desordem estática e térmica presente nos materiais, $\lambda(k)$ o caminho livre médio dos fotoelétrons e $\phi(k)$ a função de deslocamento de fase incluindo o átomo que absorve e os átomos vizinhos responsáveis pelo espalhamento dos fotoelétrons (neste caso, platina e cobalto, respectivamente).

\subsubsection{Espectroscopia por Espalhamento Raman}

A técnica de espectroscopia Raman fornece informações sobre os modos vibracionais e rotacionais de uma molécula, sendo utilizada na caracterização de materiais para a identificação de grupos químicos presentes na superfície dos catalisadores, através da detecção de seus modos vibracionais característicos. O estado de oxidação, natureza e/ou disposição espacial destes grupos são responsáveis pela eletroatividade e seletividade dos materiais. Os catalisadores suportados em carbono podem ser estudados por Raman porque o suporte apresenta um fraco espalhamento da radiação Raman, tornando fácil observar se os materiais ativos apresentam possíveis vibrações dos óxidos metálicos [94].

As medidas de espectroscopia Raman dos catalisadores Pt/C e Pt-Co/C foram realizadas em um espectrômetro Renishaw RM 2000, operando com potência de $70 \mu \mathrm{W}$. Os espectros foram coletados entre 150 e $800 \mathrm{~cm}^{-1}$ utilizando uma 
projeção contínua de um laser de $\mathrm{Ar}^{+}$(comprimento de onda de 632,8 nm e $1 \mu \mathrm{m}$ de diâmetro) sobre a amostras expostas ao ar, a temperatura ambiente.

\subsection{Caracterização Eletroquímica}

A caracterização eletroquímica dos materiais $\mathrm{Pt} / \mathrm{C}$ e $\mathrm{Pt}-\mathrm{Co} / \mathrm{C}$ foi realizada através de dois tipos de experimentos, um estudo em meia célula (célula eletroquímica constituída de três eletrodos imersos em solução aquosa) e outro estudo em célula a combustível unitária (célula com eletrodos para o combustível e para o oxidante separados por uma membrana polimérica como eletrólito). Para estes estudos foram confeccionados eletrodos de difusão de gás que foram usados em todos experimentos eletroquímicos.

\subsubsection{Eletrodos de Difusão de Gás}

Os eletrodos empregados nas células são eletrodos difusão de gás (EDG) e são constituídos por uma camada difusora e uma camada catalítica [95]. A camada difusora colocada em contato com o gás possui as funções básicas de distribuir o gás reagente, facilitar a remoção dos produtos e conectar eletricamente a camada catalisadora aos circuitos elétricos externos, enquanto que a camada catalisadora cumpre a função de promover eficientemente as reações eletroquímicas. A área geométrica dos eletrodos de trabalho foi de 1,23 e 4,62 $\mathrm{cm}^{2}$ para as medidas em célula eletroquímica e em célula unitária, respectivamente. A seguir será apresentada uma breve descrição do método de preparação dos EDG. 


\subsubsection{Preparação da Camada Difusora}

A camada difusora é constituída de pó de carbono (Vulcan XC-72, 85 \% em peso) e suspensão de politetrafluoretileno (PTFE, $15 \%$ em peso), sendo distribuída sobre um tecido de carbono (PWB-3, Stackpole). Primeiro, um pedaço de tecido de carbono de $10 \times 10 \mathrm{~cm}$ foi cortado, tratado a $450{ }^{\circ} \mathrm{C}$ por $1 \mathrm{~h}$ e imerso em solução de ácido nítrico a $85{ }^{\circ} \mathrm{C}$ por $1 \mathrm{~h}$. Depois, foi depositada a mistura de pó de carbono/PTFE. Finalmente, a camada difusora foi seca a $285{ }^{\circ} \mathrm{C}$ por 30 min para eliminar o dispersante (TRITON X100) existente na emulsão de PTFE e em seguida aquecido a $330{ }^{\circ} \mathrm{C}$ por mais 30 min, para que ocorra a sinterização do PTFE [95].

\subsubsection{Preparação da Camada Catalítica}

A camada catalítica contém uma mistura de catalisadores de $\mathrm{Pt} / \mathrm{C}$ ou liga bimetálica Pt-Co/C, solução de Nafion ${ }^{\circledR}$ como ligante e condutor iônico (Aldrich, solução a 5 \% em peso) e isopropanol (PA, Merck), como solvente. Esta suspensão foi homogeneizada em ultra-som por 12 min. Após secagem a temperatura ambiente, o material (catalisador e Nafion ${ }^{\circledR}$ ) foi novamente diluído em isopropanol para formar uma mistura que foi pintada sobre a camada difusora. Finalmente, os eletrodos foram secos a $80{ }^{\circ} \mathrm{C}$ por $1 \mathrm{~h}$ [95].

\subsubsection{Membrana de Troca Protônica}

Para o transporte de prótons entre o ânodo e o cátodo foram usadas as membranas de Nafion ${ }^{\circledR} 115$ e 117 (Du Pont) com espessuras de 125 e $175 \mu \mathrm{m}$, 
respectivamente. Estas membranas foram submetidas a tratamento de limpeza que consiste na imersão em solução de $3-5 \% \mathrm{H}_{2} \mathrm{O}_{2}$ a $80{ }^{\circ} \mathrm{C}$ por uma hora, seguida de lavagens com água quente (repetida por 3 vezes para retirar o excesso de $\mathrm{H}_{2} \mathrm{O}_{2}$ ). Em seguida, as membranas foram imersas em solução de $\mathrm{H}_{2} \mathrm{SO}_{4} \quad 0,5 \mathrm{~mol} \mathrm{~L}^{-1}$ a quente por $1 \mathrm{~h}$, e posteriormente, estas foram lavadas com água a $80{ }^{\circ} \mathrm{C}$ várias vezes para retirar o excesso de ácido sulfúrico. Este processo de limpeza proporciona a eliminação de impurezas orgânicas (com $\mathrm{H}_{2} \mathrm{O}_{2}$ ) e inorgânicas (com $\mathrm{H}_{2} \mathrm{SO}_{4}$ ) presentes nas membranas comerciais.

\subsubsection{Medidas Eletroquímicas em Meia Célula}

O estudo em meia célula foi feito com o emprego das técnicas de voltametria cíclica e voltametria de varredura linear em meio ácido, na ausência e na presença de concentrações variadas de metanol. De forma particular a voltametria cíclica foi utilizada com o intuito de determinar a área eletroquimicamente ativa através da adsorção de $\mathrm{H}_{2}[66,96]$ e caracterizar as propriedades superficiais dos eletrodos [97].

Para a realização dos experimentos eletroquímicos utilizou-se uma célula de Teflon de aproximadamente $70 \mathrm{~cm}^{3}$ de volume, como mostrada na Figura 2.2. Como eletrodo de trabalho foi utilizado o EDG contendo os catalisadores conforme mencionado no item 2.1. Um outro EDG contendo Pt/C E-TEK foi utilizado como contra-eletrodo e o eletrodo reversível de hidrogênio $(\mathrm{ERH})$ foi usado como eletrodo de referência. 


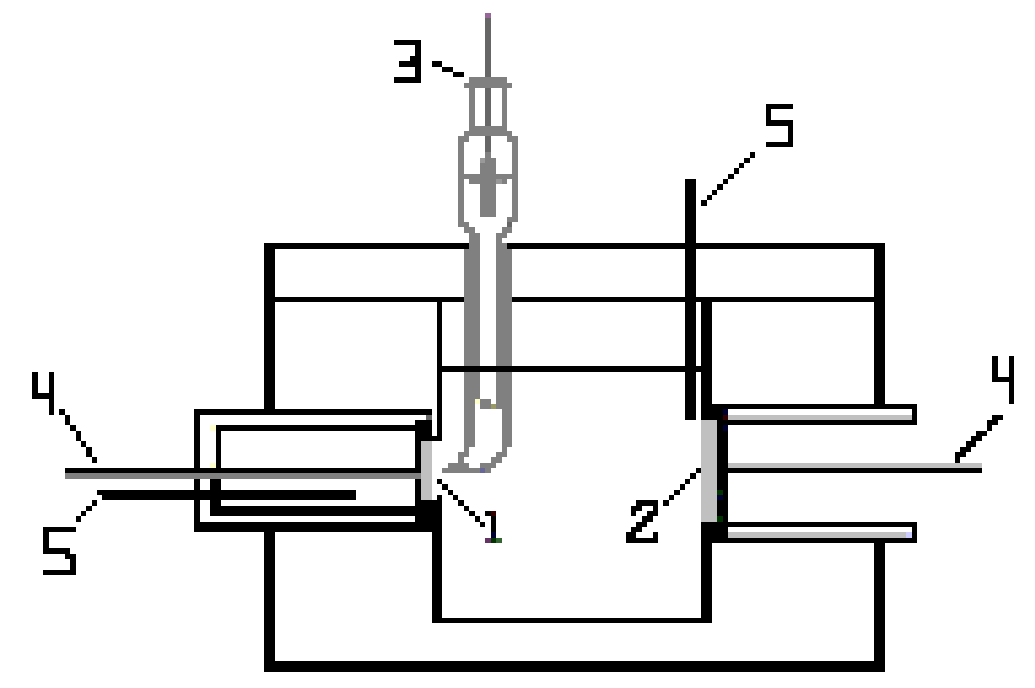

FIGURA 2.2. Desenho esquemático da célula eletroquímica. (1) eletrodo de trabalho; (2) contra-eletrodo; (3) eletrodo de referência; (4) contato elétrico e (5) entrada e saída de gás.

Os voltamogramas cíclicos (VC's) foram obtidos em solução aquosa de $\mathrm{H}_{2} \mathrm{SO}_{4}$ $0,5 \mathrm{~mol} \mathrm{~L}^{-1}$ (Merck) saturado com nitrogênio (super seco, White Martins) por aproximadamente $30 \mathrm{~min}$. A região de potencial de trabalho foi limitada pela redução de hidrogênio e pela oxidação da água no intervalo de 75 e $800 \mathrm{mV}$ vs eletrodo reversível de hidrogênio $(E R H)$. Os VC's foram coletados a uma velocidade de varredura de $20 \mathrm{mV} \mathrm{s}^{-1}$.

A área eletroquimicamente ativa foi determinada pela integração da carga associada à oxidação de hidrogênio, região compreendida entre 75 e $300 \mathrm{mV}$ vs. $\mathrm{ERH}$, corrigida pela carga da região da dupla camada. Foi assumido uma carga de $210 \mu \mathrm{C} \mathrm{cm}^{-2}$ para a formação de uma monocamada de hidrogênio adsorvido sobre a superfície da platina policristalina [96]. 
Posteriormente, voltametrias de varredura linear (VVL) foram obtidas em $\mathrm{H}_{2} \mathrm{SO}_{4}$ $0,5 \mathrm{~mol} \mathrm{~L}^{-1}$ (Merck) saturado com oxigênio (White Martins) por aproximadamente 30 min na ausência e presença de diferentes concentrações de metanol. A região de potencial investigada foi de 1100 até $100 \mathrm{mV}$ vs. ERH. Finalmente, uma VVL foi obtida com varredura de potencial no sentido positivo para avaliar os materiais frente à oxidação de metanol. As VVL's foram obtidas na velocidade à varredura de $5 \mathrm{mV}$ $\mathrm{s}^{-1}$ e temperatura ambiente.

O equipamento utilizado foi um Potenciostato $1285 \mathrm{~A}$, Solartron, conectado a um micro computador. Para a aquisição dos dados usou-se o Software Corrware for Windows.

\subsubsection{Curvas de Polarização}

Para avaliar o desempenho eletroquímico dos catalisadores Pt/C e Pt-Co/C em PEMFC alimentadas com $\mathrm{H}_{2} / \mathrm{O}_{2}$ e DMFC alimentadas com metanol/ $\mathrm{O}_{2}$ foram confeccionados eletrodos de difusão de gás (conforme descrito no item 2.3.1).

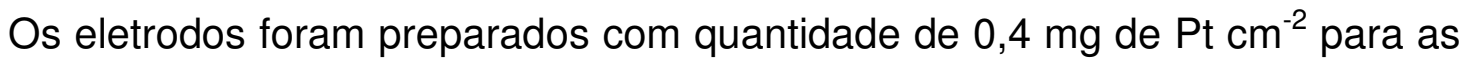
medidas em PEMFC e 1,0 mg de Pt $\mathrm{cm}^{-2}$ para as medidas em DMFC. Os eletrodos foram colocados um de cada lado da membrana e o conjunto (MEA) foi prensado a quente $\left(125^{\circ} \mathrm{C}\right.$ e $50 \mathrm{~kg} \mathrm{~cm}^{-2}$ ) durante 2 min [95]. O processo de prensagem torna-se necessário para minimizar os efeitos das resistências de contato entre a camada catalisadora e a membrana. Antes da montagem da célula, foram colocados os espaçadores para a prevenção contra vazamento dos gases e para evitar compressão excessiva dos eletrodos. 
Para as medidas em célula unitária foram utilizados o material com $20 \%$ Pt/C (E-TEK) no compartimento anódico para avaliar o desempenho dos catalisadores PtCo/C para a reação de redução de oxigênio (no cátodo). Nas DMFC, os ânodos foram constituídos por Pt-Ru/C (80:20) [98].

A célula foi acoplada a uma estação de teste munida de controladores de fluxo dos gases reagentes, da temperatura e da pressão.

As temperaturas usadas nas câmaras de umidificação dos gases reagentes para as PEMFC nos compartimentos catódicos e anódico foram de 85 e $95{ }^{\circ} \mathrm{C}$, respectivamente, com os gases reagentes à pressão atmosférica. A célula foi operada a $80{ }^{\circ} \mathrm{C}$. Termopares foram conectados à célula e aos umidificadores de gases para o controle da temperatura. As curvas de potencial da célula vs densidade de corrente foram obtidas após o condicionamento dos eletrodos por 120 min em $500 \mathrm{~mA} \mathrm{~cm}^{-2}$.

Nas DMFC, as curvas de polarização foram obtidas galvanostaticamente após o condicionamento dos eletrodos por 90 min em $250 \mathrm{~mA} \mathrm{~cm}^{-2}$ usando uma solução 2 mol L $\mathrm{L}^{-1}$ de metanol e a uma taxa de consumo de $2,5 \mathrm{~mL} \mathrm{~min}^{-1}$ no ânodo e no cátodo foi utilizado oxigênio umidificado a 70 e $90{ }^{\circ} \mathrm{C}$ e pressão de 1 e $3 \mathrm{~atm}$, respectivamente [95]. A Figura 2.3 mostra o desenho esquemático de uma célula unitária de membrana trocadora de prótons para as medidas eletroquímicas.

Os equipamentos utilizados foram uma fonte estabilizada, modelo TCA 20-50 BR1A da $\operatorname{TECTROL~}^{\circledR}$, com o ajuste da corrente e leitura do potencial através de multímetros ICE2-1K-2000 e ET-2001-MINIPA. 


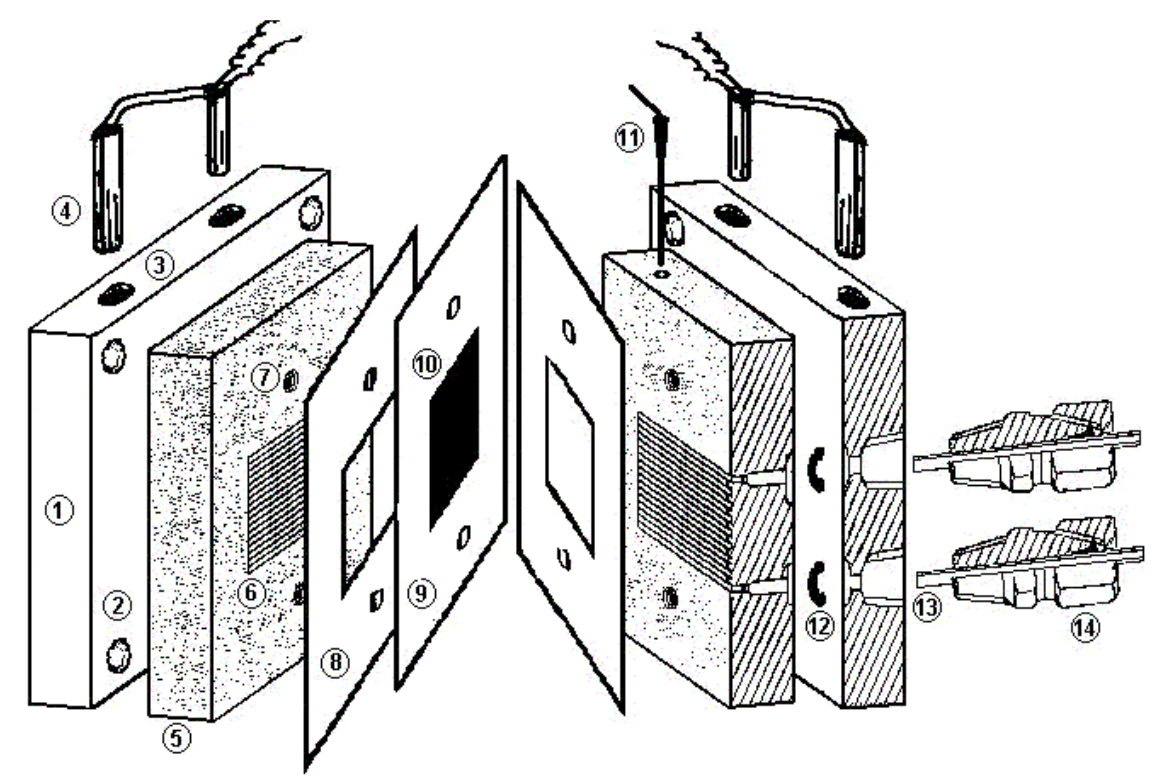

FIGURA 2.3. Desenho esquemático que mostra os componentes de uma célula unitária de eletrólito polimérico sólido. (1) placa de alumínio; (2) entrada dos parafusos; (3) entrada para aquecedores; (4) aquecedores; (5) placa de grafite; (6) distribuidor do fluxo de gás - serpentina; (7) guia de ajuste; (8) espaçadores; (9) membrana; (10) eletrodo difusão de gás; (11) termopar; (12) o'ring; (13) tubo de Teflon; (14) conectores. 


\section{CAPÍTULO III}

\section{RESULTADOS E DISCUSSÃO}

\subsection{Caracterização Física}

\subsubsection{Energia Dispersiva de Raios-X}

As composições atômicas para os catalisadores Pt-Co suportados em carbono preparados pelos diferentes métodos estão apresentadas na Tabela 3.1.

A composição atômica do catalisador $\mathrm{Pt}-\mathrm{Co} / \mathrm{C}$ preparado pelo MAF em diferentes regiões da mesma pastilha variou entre 60:40 e 80:20 (Pt:Co), indicando uma distribuição não homogênea de Co. Depois do tratamento térmico a $900{ }^{\circ} \mathrm{C}$ observou-se uma dispersão homogênea de átomos de Co em todos pontos da pastilha, sendo a composição próxima do valor nominal (70:30). 
TABELA 3.1. Características estruturais obtidas por EDX e DRX dos catalisadores. Composição atômica (EDX); temperatura do tratamento térmico (TT); parâmetro de rede (a); distância interatômica

\begin{tabular}{|c|c|c|c|c|c|c|}
\hline Método & $\begin{array}{l}\text { EDX } \\
\text { (Pt:M) }\end{array}$ & $\begin{array}{l}\text { EDX } \\
\text { (Pt:M) }\end{array}$ & $\begin{array}{l}\text { TT } \\
/{ }^{\circ} \mathrm{C}\end{array}$ & $\begin{array}{c}\text { a } \\
/ \mathrm{nm}\end{array}$ & $\begin{array}{l}\mathrm{D}_{\mathrm{Pt}-\mathrm{M}} \\
/ \mathrm{nm}\end{array}$ & $\begin{array}{c}\mathrm{d} \\
/ \mathrm{nm}\end{array}$ \\
\hline & & & prep. & 0,39159 & 0,2769 & 7,9 \\
\hline & $70: 30$ & 71:29 & 500 & 0,39143 & 0,2768 & 13,2 \\
\hline MAF & & & 900 & 0,39172 & 0,2770 & 21,3 \\
\hline $\mathrm{Pt} / \mathrm{C}$ & $(100)$ & $(100)$ & prep. & 0,39075 & 0,2763 & 4,5 \\
\hline MIC & $\begin{array}{l}85: 15 \\
84: 16\end{array}$ & $\begin{array}{l}85: 15 \\
85: 15\end{array}$ & $\begin{array}{l}500 \\
900\end{array}$ & $\begin{array}{l}0,39110 \\
0,38970\end{array}$ & $\begin{array}{l}0,2765 \\
0,2755\end{array}$ & $\begin{array}{l}3,9 \\
6,8\end{array}$ \\
\hline & $\begin{array}{l}75: 25 \\
80: 20\end{array}$ & $\begin{array}{l}75: 25 \\
82: 18\end{array}$ & & $\begin{array}{l}0,38410 \\
0,38680\end{array}$ & $\begin{array}{l}0,2716 \\
0,2735\end{array}$ & $\begin{array}{l}4,6 \\
6,7\end{array}$ \\
\hline MI & $\begin{array}{l}85: 15 \\
90: 10\end{array}$ & $\begin{array}{l}86: 14 \\
91: 09\end{array}$ & 900 & $\begin{array}{l}0,38800 \\
0,39230\end{array}$ & $\begin{array}{l}0,2743 \\
0,2774\end{array}$ & $\begin{array}{r}8,5 \\
17,4\end{array}$ \\
\hline MB & $85: 15$ & $85: 15$ & $\begin{array}{l}\text { prep. } \\
500\end{array}$ & $\begin{array}{l}0,38740 \\
0,38600\end{array}$ & $\begin{array}{l}0,2739 \\
0,2729\end{array}$ & $\begin{array}{l}3,8 \\
5,4\end{array}$ \\
\hline $\mathrm{Pt} / \mathrm{C}$ & $(100)$ & $(100)$ & prep. & 0,39010 & 0,2758 & 4,4 \\
\hline $\begin{array}{c}\text { E-TEK } \\
\text { Pt-Co/C }\end{array}$ & $50: 50$ & $50: 50$ & $\begin{array}{l}\text { com. } \\
500\end{array}$ & $\begin{array}{l}0,38740 \\
0,38540\end{array}$ & $\begin{array}{l}0,2739 \\
0,2726\end{array}$ & $\begin{array}{l}2,9 \\
3,3\end{array}$ \\
\hline $\mathrm{Pt} / \mathrm{C}$ & $(100)$ & $(100)$ & comercial & 0,39150 & 0,2768 & 2,8 \\
\hline
\end{tabular}




\subsubsection{Difratometria de Raios-X}

As Figuras de 3.1 a 3.4 mostram os difratogramas de raios-X obtidos para os catalisadores $\mathrm{Pt}-\mathrm{Co} / \mathrm{C}$ preparados por diferentes métodos e para $\mathrm{Pt} / \mathrm{C}$ E-TEK. Observa-se que os difratogramas apresentam picos correspondentes aos planos: (111), (200), (220), (311) e (222), característicos da estrutura cúbica de face centrada (fcc) da platina pura [99].

A Figura 3.1 apresenta os difratogramas para os catalisadores $\mathrm{Pt}-\mathrm{Co} / \mathrm{C}$ preparados pelo MAF, MIC e Pt/C (E-TEK). Observa-se que todos os materiais tratados termicamente apresentam reflexões intensas devido à coalescência e à sinterização das partículas menores. Por outro lado, os alargamentos apresentados pelas reflexões dos materiais $\mathrm{Pt}-\mathrm{Co} / \mathrm{C}$ como preparado e $\mathrm{Pt} / \mathrm{C}$ indicam um menor tamanho das partículas. Para o material preparado pelo MAF (como preparado) e TT a $500{ }^{\circ} \mathrm{C}$ não é observado o deslocamento dos picos de difração para maiores valores de $2 \theta$ com relação ao $\mathrm{Pt} / \mathrm{C}$, que são típicos de contração do parâmetro de rede e formação de liga. Indícios da formação de liga aparecem somente para o PtCo/C MAF quando este foi submetido ao TT a $900{ }^{\circ} \mathrm{C}$. Neste caso, pode-se observar um alargamento do pico (311), como mostra a Figura 3.2. A reflexão pode ser descrita como a formação de liga no centro e/ou na parte externa das partículas. $\mathrm{Na}$ Figura 3.1 verifica-se que o material $\mathrm{Pt}-\mathrm{Co} / \mathrm{C}$ preparado pelo MIC e tratado a $550{ }^{\circ} \mathrm{C}$ apresenta os picos mais alargados quando comparado com o material submetido ao TT a $900{ }^{\circ} \mathrm{C}$. Observou-se uma dependência do parâmetro de rede com a fração atômica de Co inserido na rede cristalina da Pt. De acordo com a Lei de Vegard [100], estima-se a formação de apenas $7 \%$ de liga $\mathrm{Pt}-\mathrm{Co} / \mathrm{C}$ para TT a $550{ }^{\circ} \mathrm{C}$ e aproximadamente $37 \%$ quando o material foi tratado a $900{ }^{\circ} \mathrm{C}$. 


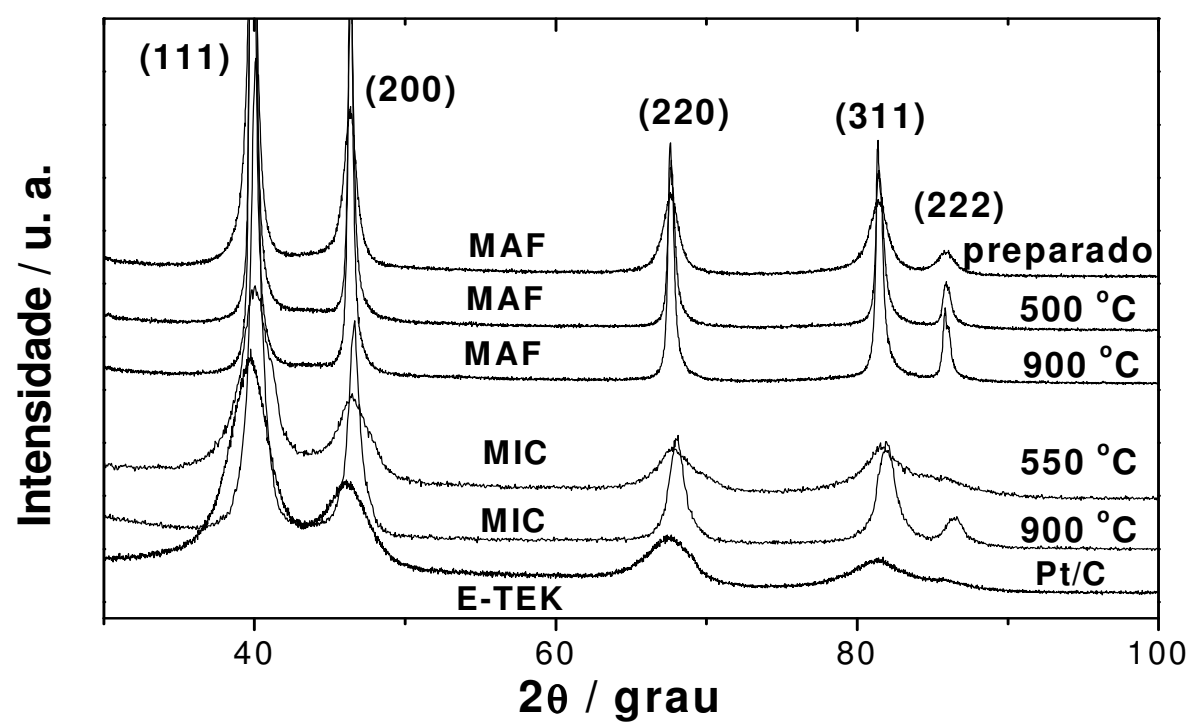

FIGURA 3.1. Difratogramas de raios- $X$ para os catalisadores $P t_{70} \mathrm{Co}_{30} / C$, MAF (TT a 500 e $900{ }^{\circ} \mathrm{C}$ ), $\mathrm{Pt}_{85} \mathrm{Co}_{15} / \mathrm{C}$, MIC (TT a 550 e $900{ }^{\circ} \mathrm{C}$ ) e Pt/C E-TEK.

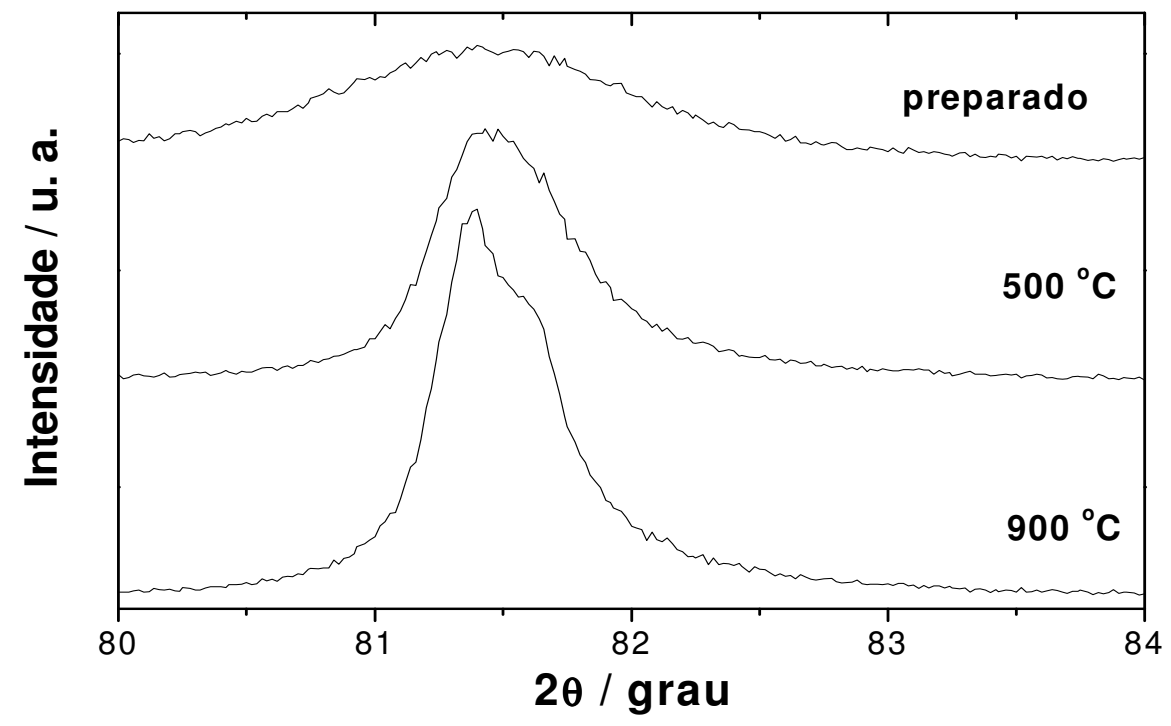

FIGURA 3.2. Difratogramas de raios- $X$ detalhados do pico (311) para o catalisador $\mathrm{Pt}_{70} \mathrm{Co}_{30} / \mathrm{C}$ preparado pelo MAF (como preparado e TT a 500 e $900{ }^{\circ} \mathrm{C}$ ).

A Figura 3.3 apresenta os difratogramas para os catalisadores $\mathrm{Pt}-\mathrm{Co} / \mathrm{C}$ preparados pelo Ml com diferentes composições de cobalto. Observa-se que com o aumento da concentração atômica de Co os picos de difração são deslocados para maiores valores de $2 \theta$ com relação à $P t / C$ pura, verificando-se uma diminuição nos valores do parâmetro de rede (Tabela 3.1) que indicam a formação de liga Pt-Co. 
Estes resultados sugerem mudanças na rede cristalina devido à incorporação de átomos de Co na estrutura da Pt, ou seja, uma substituição dos átomos de Pt por átomos de Co, visto que o raio atômico do Co é menor que o da Pt. O material Pt75Co25/C, além de apresentar estrutura fcc, apresenta picos de difração (*) que podem ser indicação de fases ordenadas, Pt3Co (Figura 3.3). Exceto o material com composição 90:10, os materiais apresentaram grau de liga nos valores de 63, 64 e $80 \%$ para as composições 85:15, 80:20 e 75:25, respectivamente.

A Figura 3.4 mostra os difratogramas do catalisador $\mathrm{Pt}-\mathrm{Co} / \mathrm{C}$ preparado pelo MB e para o material comercial Pt50Co50/C, antes e após tratamento térmico (TT a $500{ }^{\circ} \mathrm{C}$ ). Observa-se que para o material preparado pelo MB os picos de difração são intensos, indicando tamanhos de partícula maiores que os materiais comerciais, enquanto que estes apresentam picos mais largos. Observa-se também na Figura 3.4 que com o tratamento térmico os picos são deslocados para maiores valores de $2 \theta$ comparados aos materiais sem TT. 


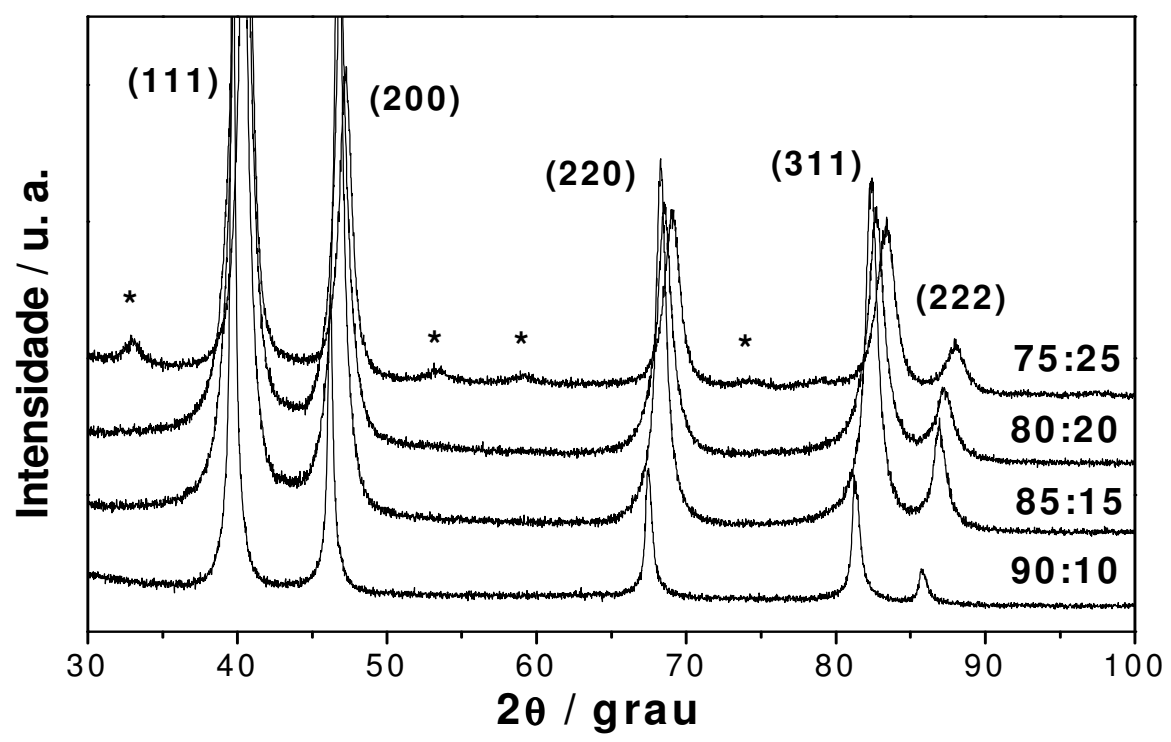

FIGURA 3.3. Difratogramas de raios- $X$ para os catalisadores $\mathrm{Pt}-\mathrm{Co} / \mathrm{C}$ preparados pelo MI com diferentes composições atômicas. (*) picos de difração relacionados à estrutura ordenada, $\mathrm{Pt}_{3} \mathrm{Co}$.

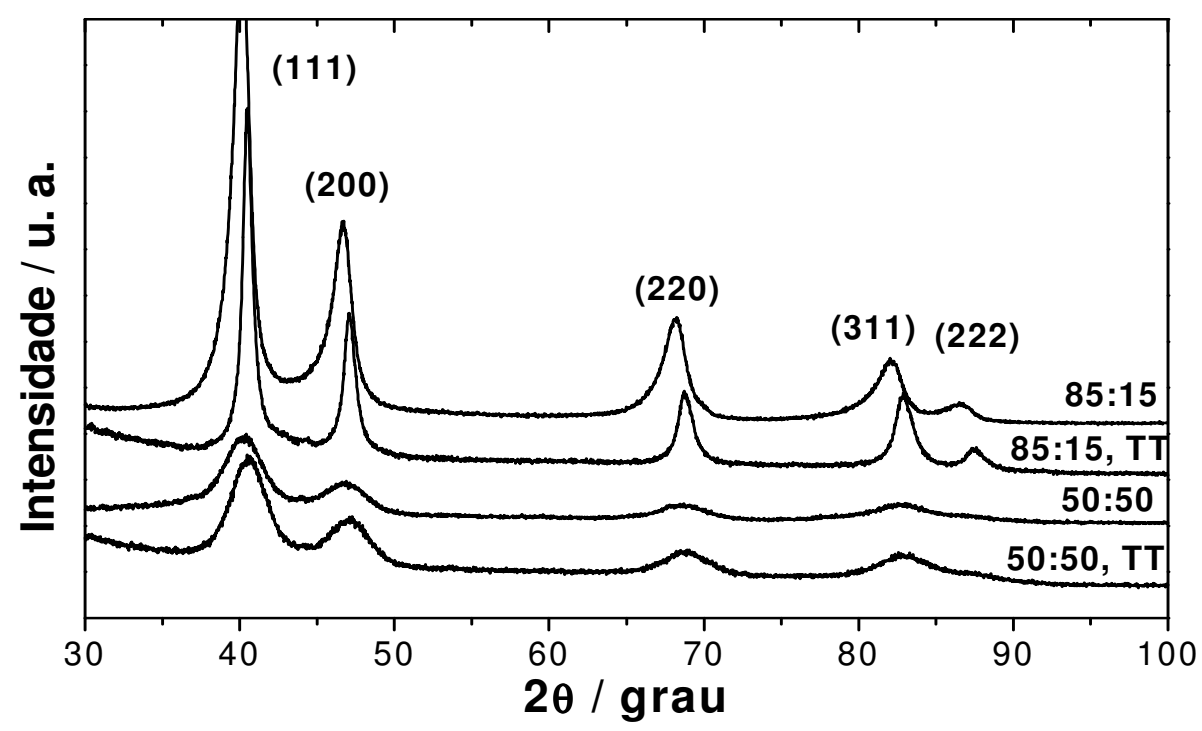

FIGURA 3.4. Difratogramas de raios- $X$ para os catalisadores $\mathrm{Pt}_{85} \mathrm{Co}_{15} / \mathrm{C}$ preparados pelo MB (sem e com TT a $500{ }^{\circ} \mathrm{C}$ ) e Pt $t_{50} \mathrm{Co}_{50}$ C, E-TEK (sem e com TT a $500{ }^{\circ} \mathrm{C}$ ). 
Nenhum pico de difração relacionado ao cobalto ou óxidos de cobalto ( $\mathrm{CoO}$ ou $\mathrm{Co}_{3} \mathrm{O}_{4}$ ) foi encontrado em quaisquer dos difratogramas, mostrados nas Figuras 3.1 a 3.4. A ausência deles pode ser explicada devido às partículas óxido de cobalto serem muito pequenas ou estarem presentes na forma amorfa.

A Tabela 3.1 apresenta os valores de composição atômica (EDX), parâmetro de rede (a), distância interatômica Pt-M ( $\left.\mathrm{D}_{\mathrm{Pt}-\mathrm{M}}\right)$ e diâmetro médio das partículas (d) dos catalisadores $\mathrm{Pt}$-Co/C e Pt/C preparados por diferentes métodos, além de $\mathrm{Pt}_{50} \mathrm{CO}_{50} / \mathrm{C}$ e $\mathrm{Pt} / \mathrm{C}$ (E-TEK). Os valores do parâmetro de rede (a) foram calculados pelo método dos mínimos quadrados [89]. A distância interatômica $\left(\mathrm{D}_{\mathrm{Pt}-\mathrm{M}}\right)$ foi obtida pela equação 3.1 relacionada à estrutura fcc da Pt [88].

$$
D_{P t-M}=\frac{\sqrt{2}}{2} a
$$

Observa-se na Tabela 3.1 que os valores do parâmetro de rede para os materiais $\mathrm{Pt}-\mathrm{Co} / \mathrm{C}$ preparados pelo MAF e MIC estão próximos do valor de $\mathrm{Pt} / \mathrm{C}$ $(0,39150 \mathrm{~nm})$. Isto pode ser devido a que nestes materiais não houve formação de liga $\mathrm{Pt}-\mathrm{Co} / \mathrm{C}$. A incorporação de Co no catalisador preparado pelo MAF forma partículas grandes de Pt-Co. O tamanho de partícula para os materiais $\mathrm{Pt-Co/C}$ (MAF) foi maior do que para Pt/C (MAF) e quando o material foi submetido ao TT a $900{ }^{\circ} \mathrm{C}$ o diâmetro foi ainda maior, $21,3 \mathrm{~nm}$, devido à aglomeração de partículas menores. 
Para os materiais Pt-Co/C (MI) com diferentes composições atômicas pode ser observado na Tabela 3.1 que, exceto para o $\mathrm{Pt}_{90} \mathrm{Co}_{10} / \mathrm{C}$, os valores do parâmetro de rede e o tamanho médio das partículas decrescem com o aumento da concentração de Co. Também para os catalisadores preparados pelo Ml o diâmetro das partículas foi maior nos catalisadores bimetálicos comparados à Pt/C (E-TEK), dados corroborados por outros autores [42,74].

Para os materiais Pt-Co/C MB ( $15 \%$ de Co) e E-TEK ( $50 \%$ de Co) os valores do parâmetro de rede são iguais $(0,38740 \mathrm{~nm}$, Tabela 3.1$)$, indicando que nestes catalisadores a composição atômica deve ser similar. Como será visto nos resultados das análises de MET (Figura 3.12), a composição das nanopartículas de Pt-Co/C MB é 91:9, estando próxima da composição nominal (85:15). Entretanto, para o material $\mathrm{Pt}_{50} \mathrm{C}_{50} / \mathrm{C}$ a maior parte do Co parece estar na forma não de liga. Os valores dos parâmetros de rede são ainda menores quando os materiais são submetidos a $500{ }^{\circ} \mathrm{C}$ sob atmosfera $\mathrm{H}_{2} / \mathrm{Ar}$ (MB, 0,38600 nm e E-TEK, 0,38540 nm). Neste caso, a diminuição do parâmetro de rede em ambos catalisadores pode se dever à presença de Co que não estava na forma de liga antes do tratamento térmico. Estes resultados parecem indicar que com o tratamento térmico ocorre uma conversão dos materiais da forma de óxido à forma reduzida na forma da liga homogênea Pt-Co [101]. O parâmetro de rede para o material comercial corresponde ao valor para $\mathrm{Pt}_{3} \mathrm{Co}$ suportado em carbono, como encontrado na literatura $[38,44,45]$. 
O tamanho médio das partículas para o material $\mathrm{Pt}-\mathrm{Co} / \mathrm{C}, \mathrm{MB}$ foi maior $(3,8$ nm) comparado ao material E-TEK (2,9 nm), do qual não se conhece o método de preparação. Observa-se na Tabela 3.1 que com o emprego do TT os materiais apresentaram diâmetros maiores que os materiais sem TT (5,4 nm para MB e 3,3 nm para o material comercial) devido à coalescência das partículas.

O tratamento térmico em atmosfera de hidrogênio durante a síntese dos catalisadores provavelmente causa a eliminação de quaisquer impurezas presentes na superfície do material, as quais bloqueiam os sítios ativos para a reação, combinado à redução da $\mathrm{Pt}$ do estado de maior oxidação (óxidos de $\mathrm{Pt}$ ) originalmente presentes. Por outro lado, a desvantagem, como foi visto nos resultados apresentados na Tabela 3.1, é o aumento do diâmetro médio das partículas.

Comparando os valores das distâncias interatômicas da Tabela 3.1, observase que as dos materiais bimetálicos Pt-Co TT são menores do que aquelas dos materiais sem TT e também, menores do que as do Pt/C. Alguns autores [42] relatam que uma maior atividade catalítica dos catalisadores se deve a uma menor distância Pt-Pt. A distância reduzida é favorável a uma forte adsorção de oxigênio com conseqüente enfraquecimento da ligação oxigênio-oxigênio para a etapa final de redução. 
O método de Rietveld (MR) foi empregado para os catalisadores Pt-Co e Pt suportados em carbono. Este método é baseado na construção de um padrão de difração calculado, de acordo com o modelo estrutural. O padrão calculado é obtido pela introdução direta dos dados cristalográficos, como:
a) simetria do grupo espacial;
b) posições atômicas;
c) posições de ocupação e parâmetros de rede.

Ao se ajustar o padrão calculado ao padrão observado obtém-se dados dos parâmetros estruturais do material e de parâmetros do perfil de difração.

O termo refinamento no MR refere-se ao processo de ajuste do modelo de parâmetros utilizados no cálculo de um padrão de difração, que seja o mais próximo do observado. O refinamento é feito pela minimização da soma das diferenças entre as intensidades calculadas e observadas, a cada passo angular do padrão de difração. O MR é aplicado ao intervalo angular total do padrão de difração, aumentando-se a precisão dos dados obtidos. Os requisitos básicos para o refinamento pelo MR são [102,103]:

a) medidas precisas de intensidades dadas em intervalos $2 \theta$;

b) um modelo inicial próximo à estrutura real do material e

c) um modelo que descreva a forma, a largura e erros sistemáticos nas posições dos picos de Bragg. 
A intensidade dos picos foi ajustada adequadamente, apresentando uma diferença maior na região de ângulos mais baixos onde se situam os picos mais intensos. O aumento das diferenças nesta região pode ser devido às características típicas da Pt que apresenta picos estreitos e de alta intensidade. $\mathrm{O}$ ajuste do perfil dos picos de difração é determinado pela escolha da função de perfil.

Teoricamente, a função que ajusta com mais precisão os picos de DRX é a função pseudo-Voigt. Esta função define a proporção entre as características lorentziana e gaussiana do perfil. A primeira etapa do refinamento foi feita com a aplicação desta função.

A teoria prevê a predominância do caráter lorentziano nos padrões de DRX. Por isso, o refinamento foi reiniciado com a aplicação da função de Lorentz modificada, que evita os problemas de correlação com as variáveis da largura à meia altura.

A Figura 3.5 mostra os resultados dos refinamentos para os catalisadores Pt$\mathrm{Co} / \mathrm{C}$ e $\mathrm{Pt} / \mathrm{C}$, com os difratogramas do material observado, calculado, background e a diferença entre o calculado e observado. Os materiais que possuem alta cristalinidade, como as ligas bimetálicas, apresentam perfis de difração com picos estreitos e intensidades altas. A linha próxima ao eixo das abscissas mostra a diferença entre o perfil calculado e o observado. Observa-se nas Figuras 3.5 (a) e (c) que estas linhas são aproximadamente retas, com pequenas distorções, demonstrando a boa qualidade do refinamento realizado, enquanto que a Figura 3.5 (b) apresenta distorções maiores. 


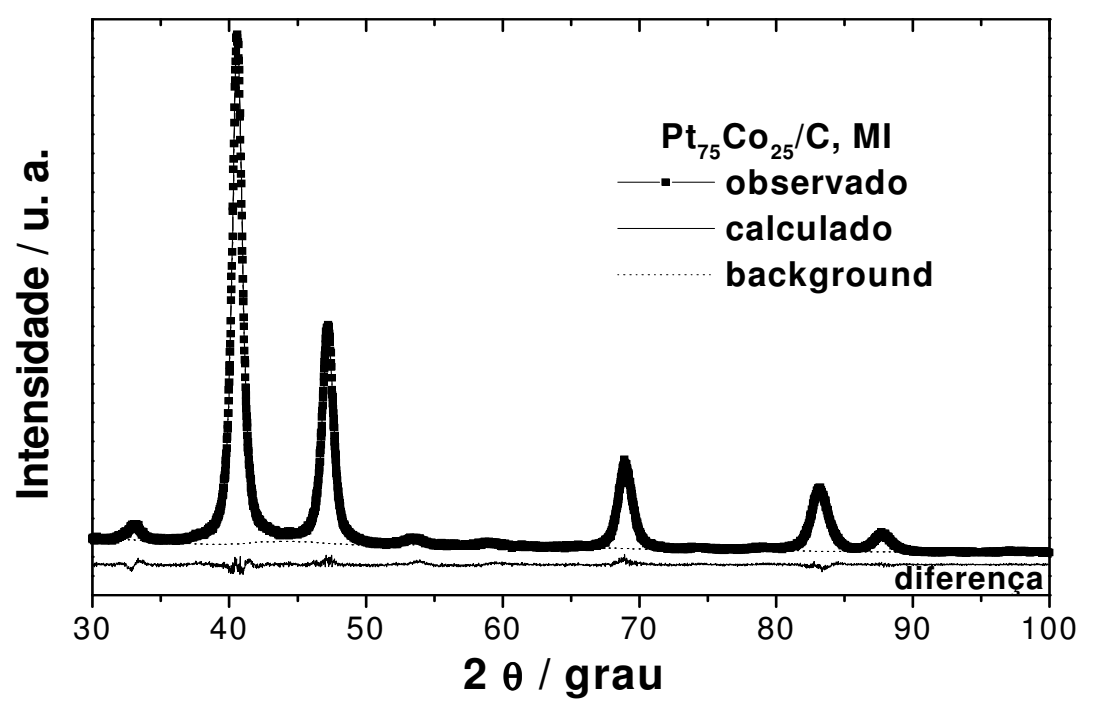

(a)

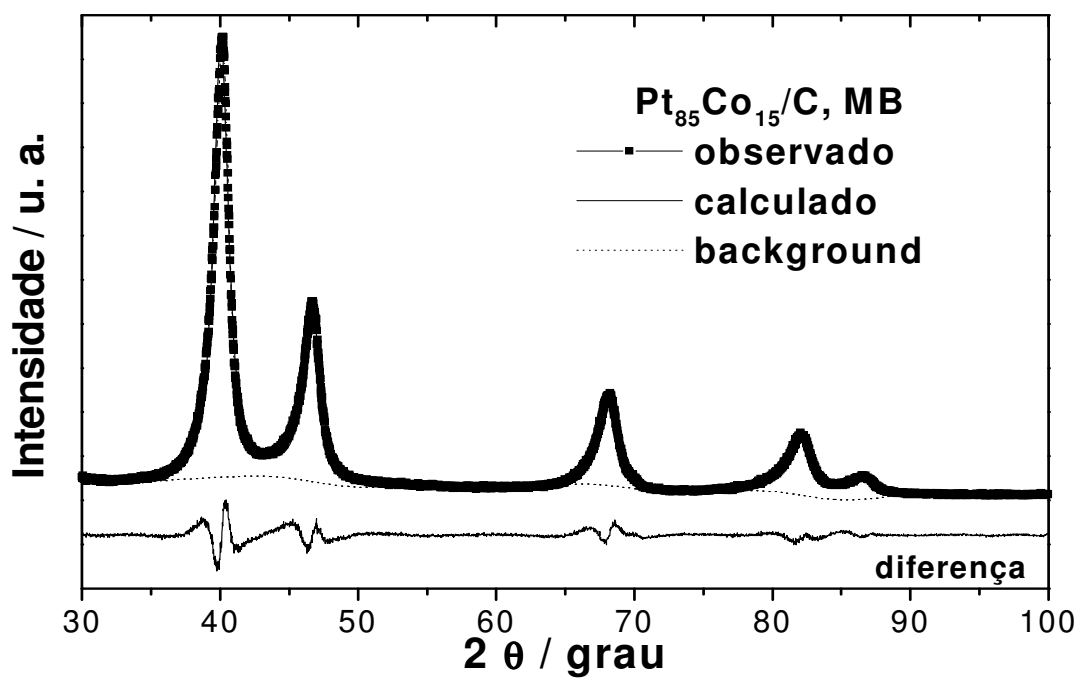

(b)

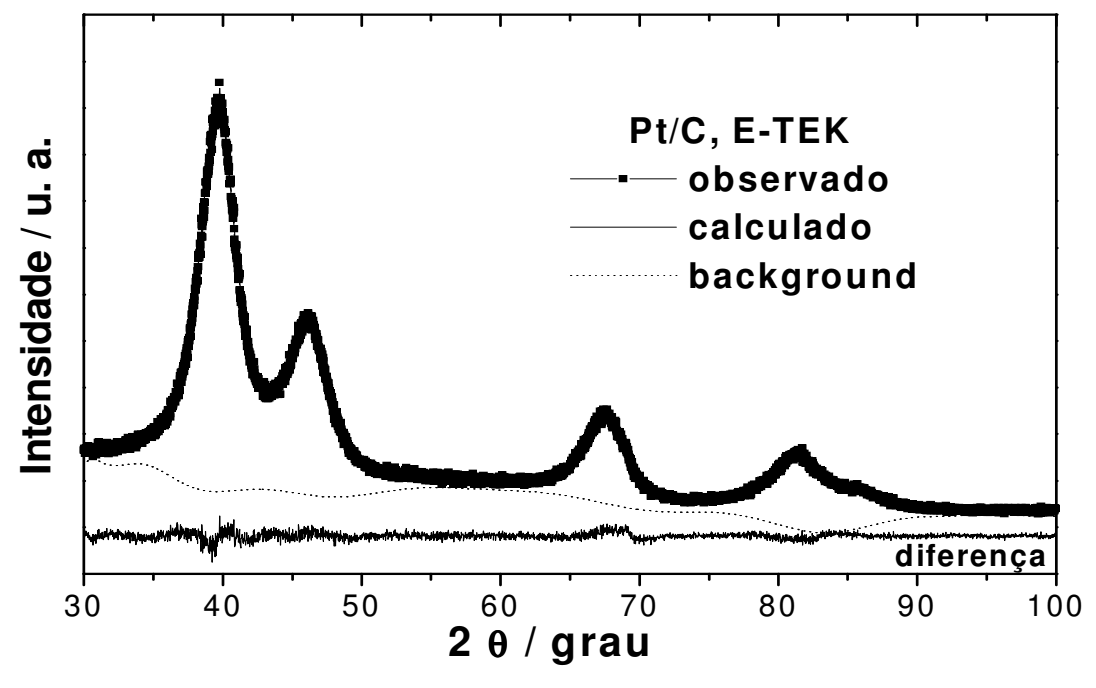

(c)

FIGURA 3.5. Refinamento de Rietveld dos difratogramas dos catalisadores. 
A qualidade do refinamento realizado pode ser observada através de alguns índices [90], tais como: fator de Bragg $\left(R_{B}\right)$, índice de perfil $\left(R_{p}\right)$, índice de perfil ponderado $\left(R_{w p}\right)$, valor esperado para $R_{\exp }$ e finalmente a qualidade do ajustado (goodness of fit, S).

O fator de Bragg $\left(R_{B}\right)$ indica a qualidade dos parâmetros estruturais refinados.

O numerador em Rwp é a própria função minimização, sendo, portanto o índice que nos dá a melhor indicação da qualidade do refinamento. Se durante o refinamento, Rwp convergir para valores pequenos, isto sugere um bom procedimento no refinamento; porém, se convergir para valores maiores que os do ciclo anterior, significa que algum(s) parâmetro(s) apresenta(m) problema(s). Nesse caso, deve-se parar o refinamento e analisar com cuidado os parâmetros para identificar aqueles com problemas e, então, tomar decisões que dependem do(s) parâmetro(s) envolvidos. Após as correções necessárias, prossegue-se com os refinamentos, sempre buscando diminuir o Rwp ao menor valor possível. É considerado o melhor resultado aquele que fornecer um difratograma de raios- $\mathrm{X}$ calculado mais próximo possível do observado. Ou seja, o que fornecer o mais baixo índice Rwp.

O valor de $S$ (qualidade do ajustado) compara o valor de $R_{w p}$ obtido no refinamento com o esperado $\left(R_{\text {exp }}\right)$ :

$$
S=\frac{R_{w p}}{R_{\text {exp }}}
$$

Quando $S$ encontra-se em torno de 1,0 o refinamento está completo, neste caso, o refinamento não pode melhorar, já que o perfil ponderado $\left(R_{w p}\right)$ já atingiu o valor esperado $\left(R_{\text {exp }}\right)$.

A Tabela 3.2 mostra os indicadores dos refinamentos dos difratogramas de raios-X dos catalisadores. Observa-se que os refinamentos apresentam bons 
valores para o índice $S$ de 1,974 para o catalisador $\mathrm{Pt}_{75} \mathrm{Co}_{25} / \mathrm{C}$ e 1,461 para 0 material $\mathrm{Pt} / \mathrm{C}$, sugerindo um bom procedimento de análise e também conforme visto nas Figuras 3.5 (a) e (c). Para o catalisador $\mathrm{Pt}_{85} \mathrm{Co}_{15} / \mathrm{C}$ o alto valor no índice $\mathrm{S}$ $(5,981)$ indica que o refinamento não foi satisfatório. Isto se deve ao fato deste material ser menos cristalino que os outros materiais investigados.

TABELA 3.2. Indicadores dos refinamentos dos DRX dos catalisadores.

\begin{tabular}{cccc}
\hline Parâmetros & $\mathbf{P t}_{75} \mathbf{C o}_{25} / \mathbf{C}, \mathbf{M I}$ & $\mathbf{P t}_{85} \mathbf{C o}_{15} / \mathbf{C}, \mathbf{M B}$ & $\mathbf{P t} / \mathbf{C}$, E-TEK \\
\hline Rwp / \% & 0,0533 & 0,0856 & 0,0419 \\
$\mathrm{~S} / \%$ & 1,974 & 5,981 & 1,461 \\
Parâmetro de rede / nm & 0,38514 & 0,38970 & 0,39164 \\
\hline
\end{tabular}

Observa-se na Tabela 3.2 que os valores do parâmetro de rede obtido pelo refinamento de Rietveld foram maiores do que os valores obtidos pelo método de mínimos quadrados. Os resultados obtidos com o tratamento de dados de DRX pelo MR foram bastante satisfatórios, tanto no que se refere aos parâmetros que definem a estrutura, como na definição da forma do perfil. Portanto, os valores obtidos pelo MR estão próximos dos valores esperados, sendo aceitáveis. 


\subsubsection{Microscopia Eletrônica de Transmissão (MET)}

A morfologia, o tamanho médio e a distribuição do tamanho de partículas foram determinados por MET. Foram obtidas micrografias para os catalisadores $\mathrm{Pt}_{75} \mathrm{Co}_{25} / \mathrm{C}(\mathrm{MI}), \mathrm{Pt}_{85} \mathrm{Co}_{15} / \mathrm{C}(\mathrm{MB})$ e Pt/C (E-TEK) numa magnificação de 50 e $150 \mathrm{kx}$, conforme apresentado nas Figuras 3.6 e 3.7, respectivamente. Observa-se na Figura 3.6 que os materiais apresentaram distribuição uniforme e homogênea das partículas sobre o carbono em quase todas as regiões analisadas. Por outro lado, os materiais $\mathrm{Pt}_{75} \mathrm{Co}_{25} / \mathrm{C} \mathrm{Ml}$ e $\mathrm{Pt}_{85} \mathrm{Co}_{15} / \mathrm{C} \quad \mathrm{MB}$ TT (Figura 3.7 (d)), apresentam aglomerados formados a partir das partículas menores em algumas regiões devido ao efeito já citado.

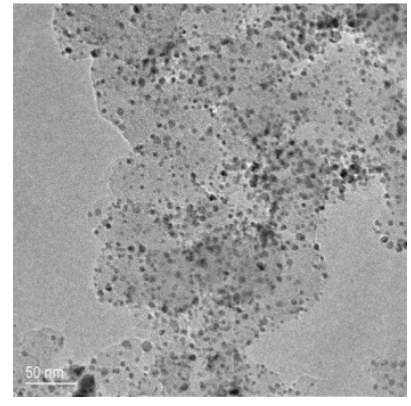

(a)

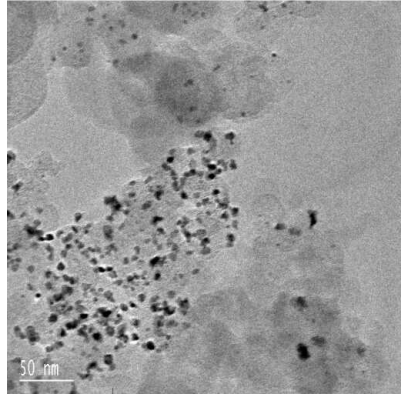

(b)

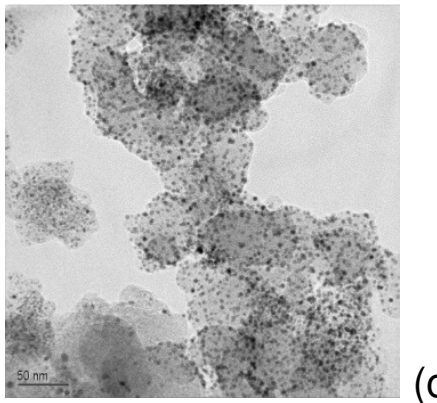

FIGURA 3.6. Micrografias obtidas por MET para os catalisadores: (a) $\mathrm{Pt}_{75} \mathrm{Co}_{25} / \mathrm{C}$, MI; (b) $P t_{85} \mathrm{Co}_{15} / C, M B$ e (c) Pt/C, E-TEK. Magnificação 50 kx. 

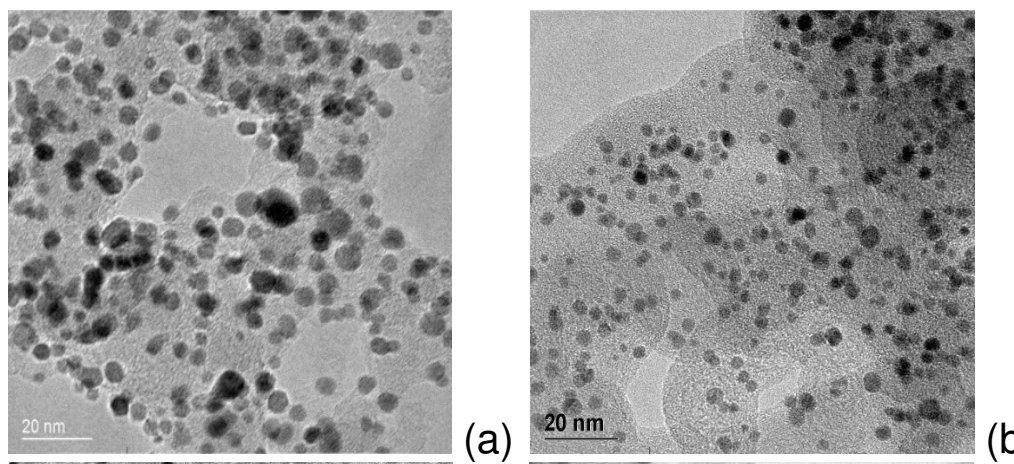

(b)
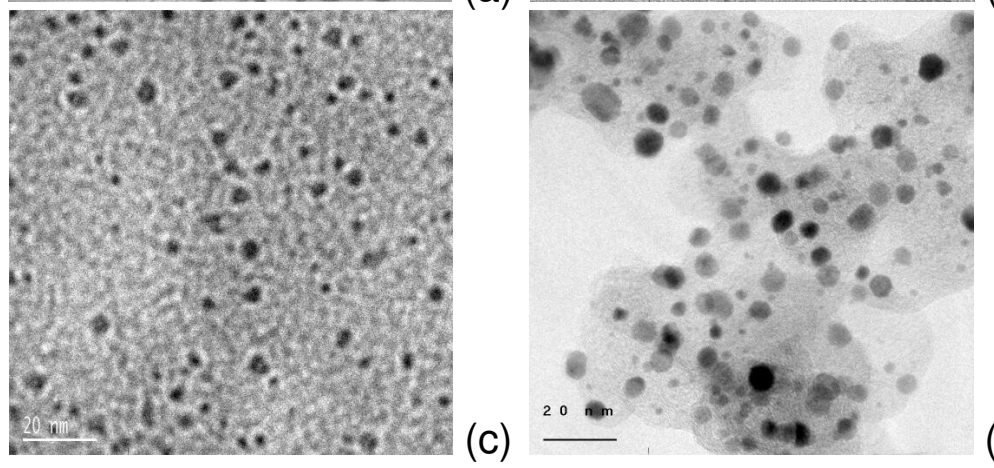

(d)

FIGURA 3.7. Micrografias obtidas por MET para: (a) $\mathrm{Pt}_{75} \mathrm{Co}_{25} / \mathrm{C}$, MI; (b) $\mathrm{Pt} / \mathrm{C}, \mathrm{E}-\mathrm{TEK}$; (c) $\mathrm{Pt}_{85} \mathrm{Co}_{15} / \mathrm{C}, \mathrm{MB}$ e (d) $\mathrm{Pt}_{85} \mathrm{Co}_{15} / \mathrm{C}, \mathrm{MB}$, TT. Magnificação $150 \mathrm{kx}$.

Nas Figuras 3.8 e 3.9 e na Tabela 3.3 são mostrados os histogramas da distribuição do tamanho de partículas para Pt-Co/C MI, MB (antes e após TT) e Pt/C (E-TEK).

TABELA 3.3. Características físicas dos catalisadores obtidas por MET.

\begin{tabular}{|c|cc|c|}
\hline Catalisador & $\begin{array}{c}\text { Porcentagem de } \\
\text { partículas / \% }\end{array}$ & $\begin{array}{c}\text { Intervalo do } \\
\text { tamanho / nm }\end{array}$ & $\begin{array}{c}\text { Diâmetro } \\
\text { médio / nm }\end{array}$ \\
\hline $\mathbf{P t}_{\mathbf{7 5}} \mathbf{C o}_{25}$ /C, MI & 72 & $3,0-4,5$ & $3,9 \pm 1,2$ \\
$\mathbf{P t}_{85} \mathbf{C o}_{15} / \mathbf{C}, \mathbf{M B}$ & 76 & $2,5-4,5$ & $3,7 \pm 1,3$ \\
$\mathbf{P t}_{85} \mathbf{C o}_{15} / \mathbf{C}$ (TT = 500 $\left.{ }^{\circ} \mathbf{C}\right)$ & 56 & $3,0-4,5$ & $4,0 \pm 1,6$ \\
$\mathbf{P t} / \mathbf{C}, \mathrm{E}-\mathrm{TEK}$ & 56 & $2,5-3,5$ & $3,0 \pm 0,9$ \\
\hline
\end{tabular}




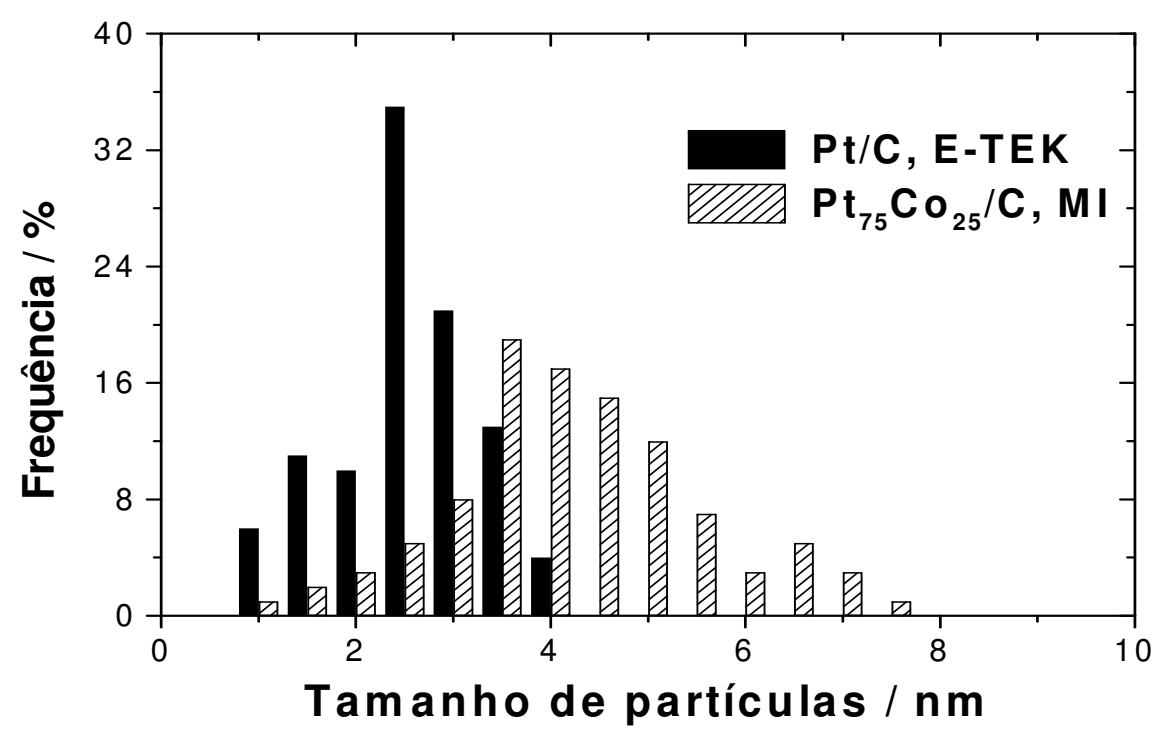

FIGURA 3.8. Histogramas da distribuição do tamanho de partículas dos catalisadores.

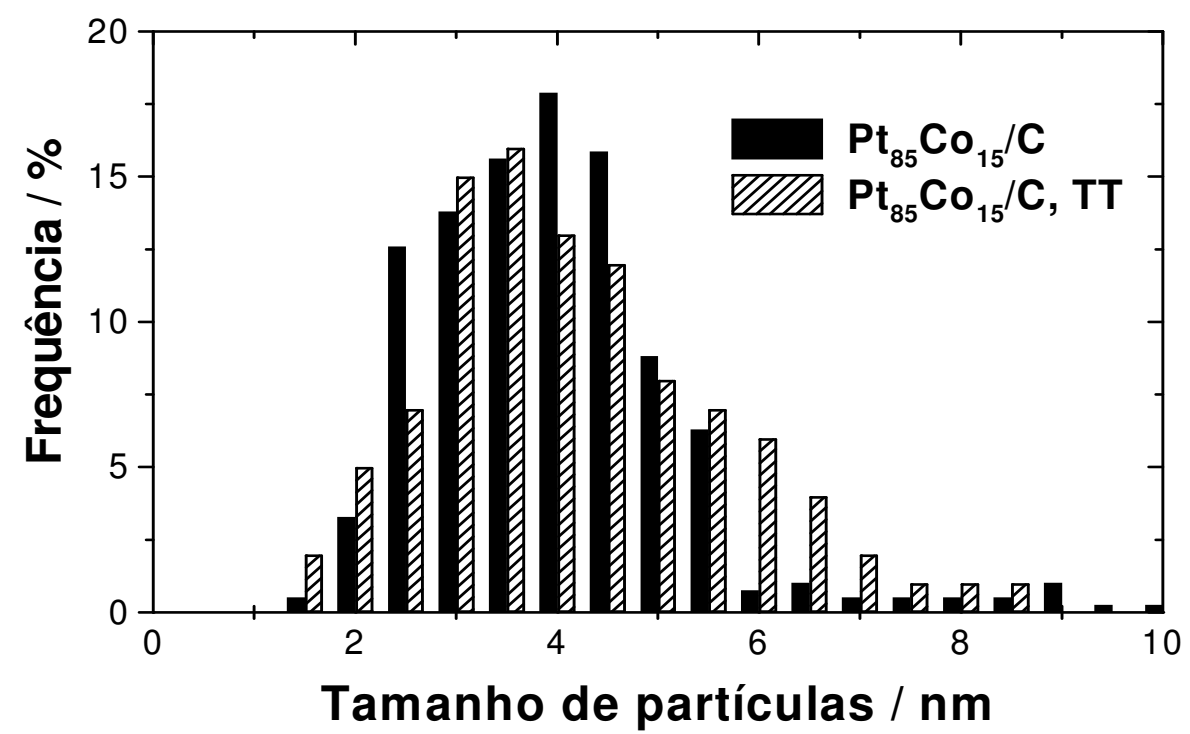

FIGURA 3.9. Histogramas da distribuição do tamanho de partículas dos catalisadores $\mathrm{Pt}_{85} \mathrm{Co}_{15} / \mathrm{C}$, sem e com tratamento térmico (TT). 
Comparando o tamanho de partículas apresentado pelos catalisadores observa-se claramente nos histogramas a presença de partículas maiores quando o material foi submetido ao tratamento térmico (Figura 3.9, Tabela 3.3). Estes resultados são consistentes com os dados obtidos por DRX (Tabela 3.1) e com os de resultados publicados por outros autores $[42,74]$.

A imagem de microscopia eletrônica de transmissão de alta resolução para o catalisador $\mathrm{Pt}_{75} \mathrm{C}_{25} / \mathrm{C}$ é apresentada na Figura 3.10. A imagem em baixa magnificação apresenta uma projeção bidimensional das partículas com impressão de formas esféricas e elípticas, ao contrário das facetas cubo-octaédricas esperadas. Entretanto, a aparência arredondada em volta das partículas pode ser causada por dois efeitos: (i) a inclinação das partículas das camadas inferiores faz as facetas parecerem levemente curvadas, e (ii) quando as partículas são alinhadas ao longo do eixo elas parecem ser esféricas por causa da interferência proveniente do substrato de carbono que oculta as bordas e os ângulos agudos [104]. Contudo, uma imagem mais detalhada das nanopartículas em alta magnificação (Figura 3.10 (b)), mostra os planos característicos de uma estrutura fcc com forma cubooctaédrica simétrica ou assimétrica, de acordo com as análises EDX/MET obtidas para amostras de Pt suportada em carbono.

A partir da técnica de energia dispersiva de raios- $X$ acoplada ao microscópio eletrônico de transmissão (EDX/MET) determinou-se a composição atômica das nanopartículas, cujos espetros são apresentados na Figura 3.11. De maneira geral, os resultados mostraram uma composição homogênea das nanopartículas de Pt-Co com preponderância para a composição atômica de 75:25, conforme resultados obtidos por EDX acoplado ao MEV (Tabela 3.1). Entretanto, em nanopartículas de 5 
nm observa-se uma composição 81:19, em acordo com as medidas calculadas por DRX (composição do bulk = 80:20).
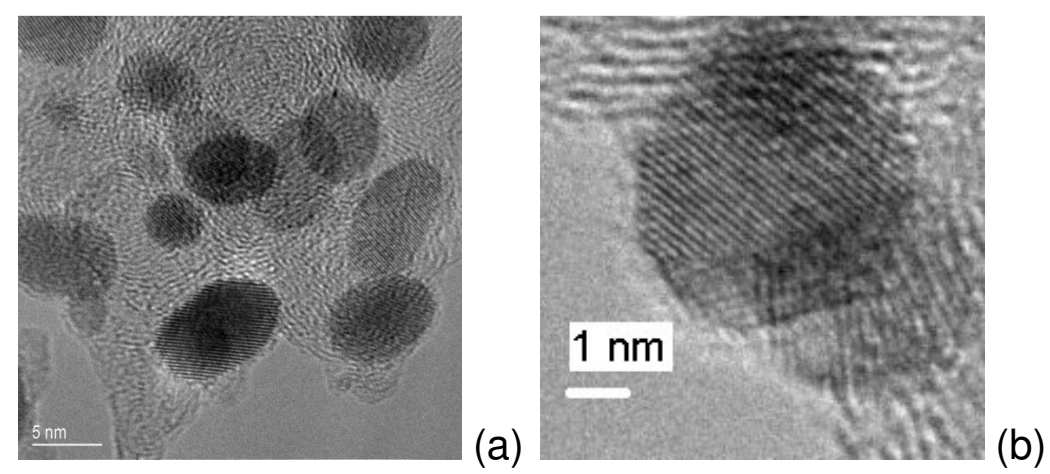

FIGURA 3.10. Micrografia de alta resolução obtida por MET para o catalisador $\mathrm{Pt}_{75} \mathrm{Co}_{25} / \mathrm{C}$, (a) baixa e (b) alta magnificação.

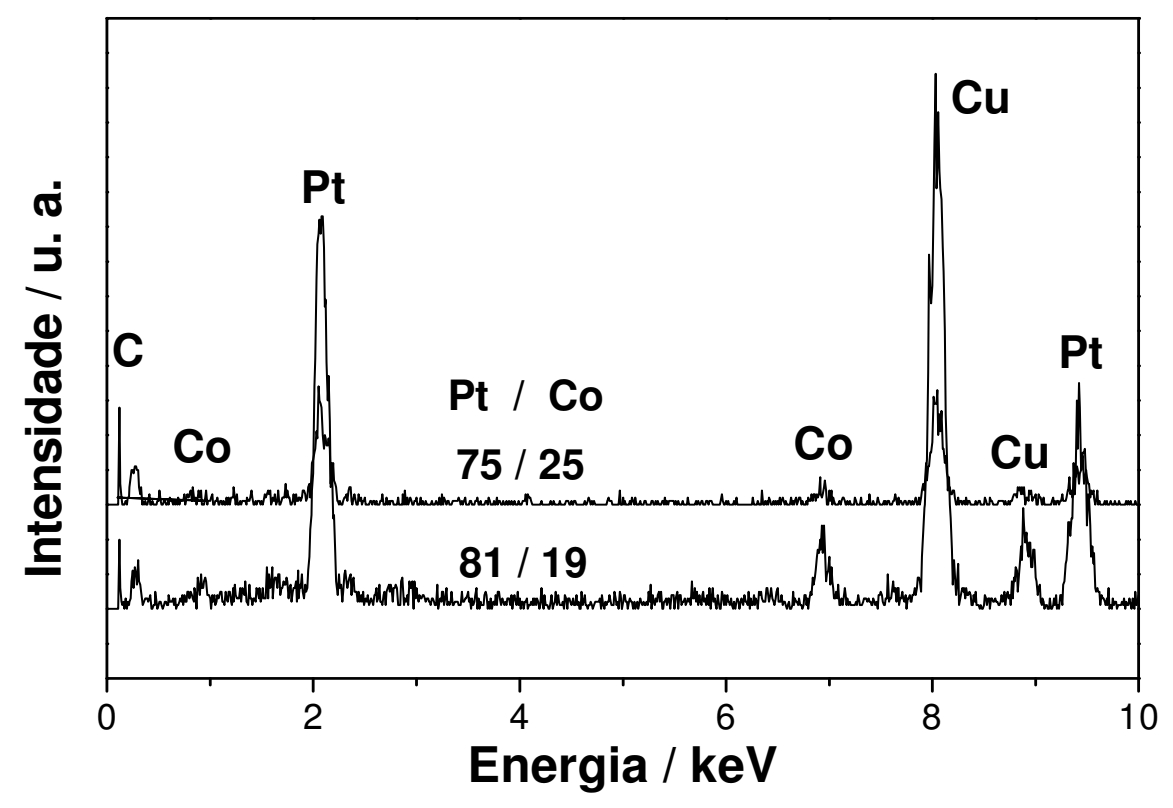

FIGURA 3.11. Espectro de EDX para o catalisador $\mathrm{Pt}_{75} \mathrm{Co}_{25} / \mathrm{C}$. Sonda $5 \mathrm{~nm}$. 
As micrografias em alta resolução e os espectros EDX para o material $\mathrm{Pt}_{85} \mathrm{Co}_{15} / \mathrm{C}$ são mostrados nas Figuras 3.12 e 3.13. As imagens das nanopartículas também apresentaram os planos característicos de uma estrutura fcc com forma cubo-octaédrica de faceta simétrica ou assimétrica [105]. Os resultados de EDX mostraram preponderância para composições atômicas próximas de 84:16, em acordo com o valor da composição nominal. Entretanto, a análise efetuada em uma nanopartícula de 5 nm, Figura 3.12 (c), apresentou composição atômica 90:10 (Pt:Co).

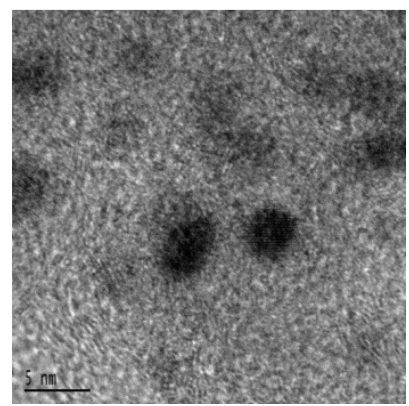

(a)

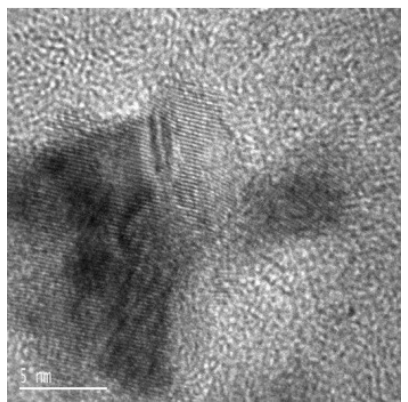

(b)

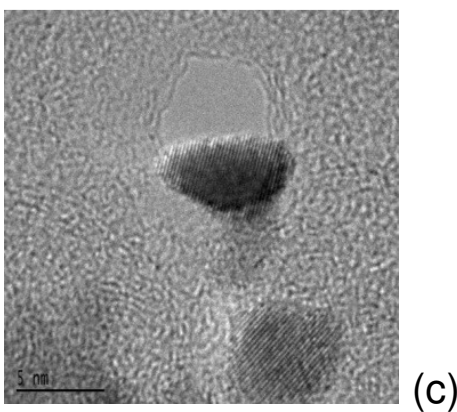

FIGURA 3.12. Micrografias de alta resolução obtidas por MET para o catalisador $\mathrm{Pt}_{85} \mathrm{Co}_{15} / \mathrm{C}$ : (a) região maior, (b) região média e (c) região pequena. Magnificação $800 k x$. 


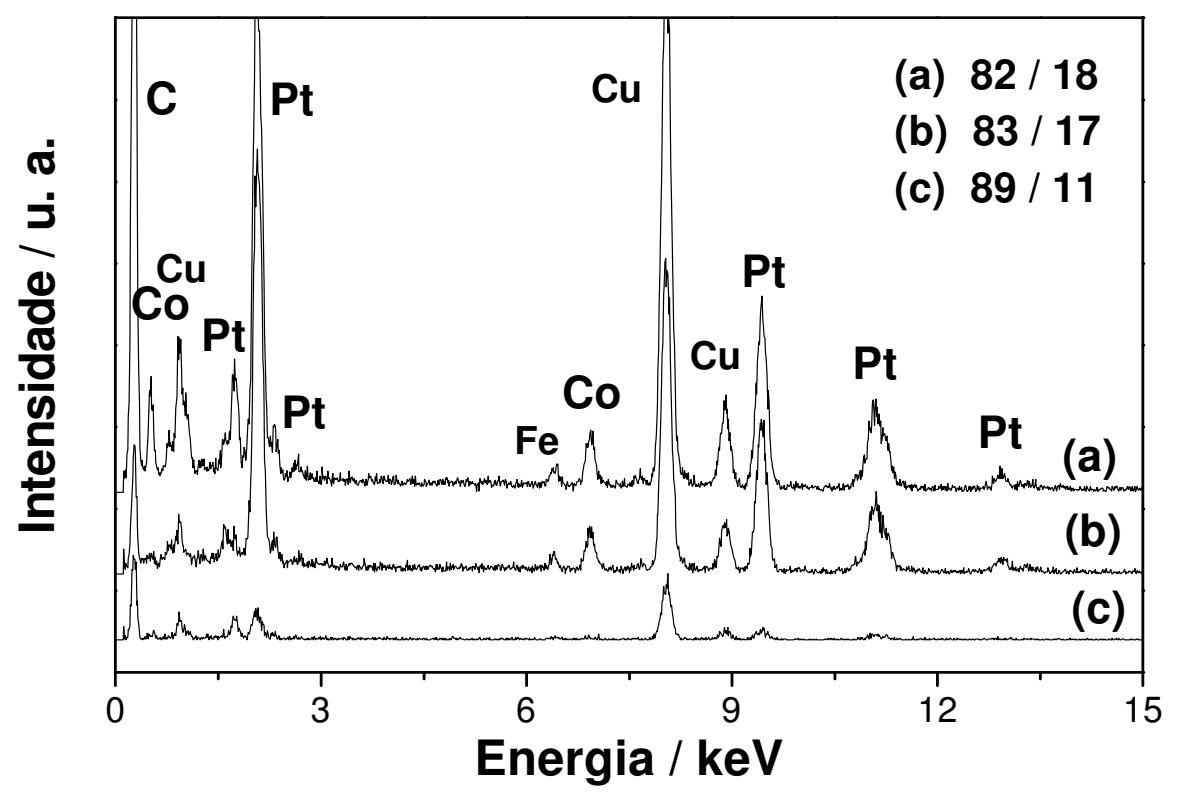

FIGURA 3.13. Espectros de EDX para os catalisadores $\mathrm{Pt}_{85} \mathrm{Co}_{15} / \mathrm{C}$, MB: (a) região maior, (b) região média e (c) região pequena. Sonda: $5 \mathrm{~nm}$.

\subsubsection{Espectroscopia de Absorção de Raios-X}

Os resultados das análises de espectroscopia de absorção de raios-X na região próxima da borda da platina - região XANES estão apresentados nas Figuras 3.14-3.16. A absorção na borda $L_{\text {III }}$ da $P t(11564 \mathrm{eV})$ corresponde às transições eletrônicas $2 p_{3 / 2}-5 d$ e a intensidade da magnitude da linha branca localizada a $5 \mathrm{eV}$ acima da borda pode ser diretamente relacionada à ocupação dos estados eletrônicos 5d da Pt [106,107].

A Figura 3.14 apresenta os espectros XANES para o material $\mathrm{Pt}_{85} \mathrm{Co}_{15} / \mathrm{C}, \mathrm{MB}$ obtido em vários potenciais e para a folha de Pt (padrão). Observa-se nos espectros, que as intensidades das magnitudes das linhas brancas são praticamente as mesmas para os potenciais de 100, 300, 500 e $800 \mathrm{mV}$ vs. ERH, sendo um pouco maior a $1100 \mathrm{mV}$. Neste potencial, que é a região onde ocorre a redução de oxigênio, o aumento da intensidade da magnitude da linha branca está relacionado com o aumento da vacância na banda d da Pt devido à adsorção de espécies 
oxigenadas provenientes do eletrólito sobre a superfície da Pt no catalisador [107].

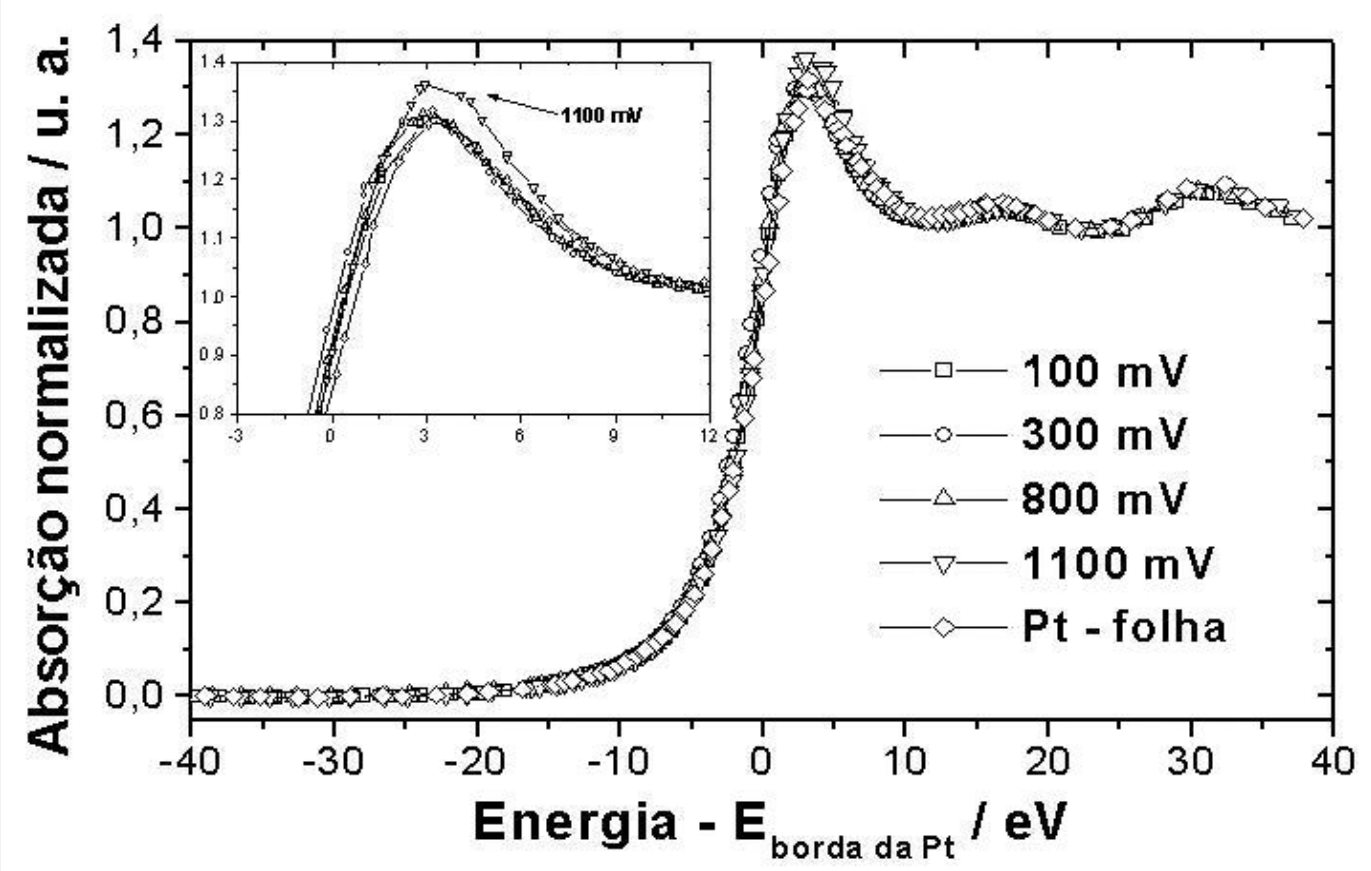

FIGURA 3.14. Espectros XANES na borda $L_{\text {III }}$ da Pt $(11564 \mathrm{eV})$ do catalisador $\mathrm{Pt}_{85} \mathrm{Co}_{15} / \mathrm{C} \mathrm{MB}$ a diferentes potenciais. $\mathrm{T}=25^{\circ} \mathrm{C}$.

As Figuras 3.15 e 3.16 apresentam os espectros XANES na borda $L_{\text {III }}$ da $P t$ para os catalisadores $\mathrm{Pt}_{75} \mathrm{Co}_{25} / \mathrm{C}(\mathrm{MI}), \mathrm{Pt}_{85} \mathrm{Co}_{15} / \mathrm{C}(\mathrm{MB}), \mathrm{Pt} / \mathrm{C}(\mathrm{E}-\mathrm{TEK})$ e para a folha de Pt nos potenciais de eletrodo de 300 e $1100 \mathrm{mV}$, respectivamente. Observa-se na Figura 3.15 a semelhança dos espectros com respeito à magnitude da linha branca em 300 mV (região da dupla camada) para todos os catalisadores. Porém, em 1100 $\mathrm{mV}$, Figura 3.16, (região de óxidos e hidróxidos) este aumento é menor para $\mathrm{Pt}_{85} \mathrm{Co}_{15} / \mathrm{C}$ e ainda menor para $\mathrm{Pt}_{75} \mathrm{Co}_{25} / \mathrm{C}$, quando estes são comparados à $\mathrm{Pt} / \mathrm{C}$. 


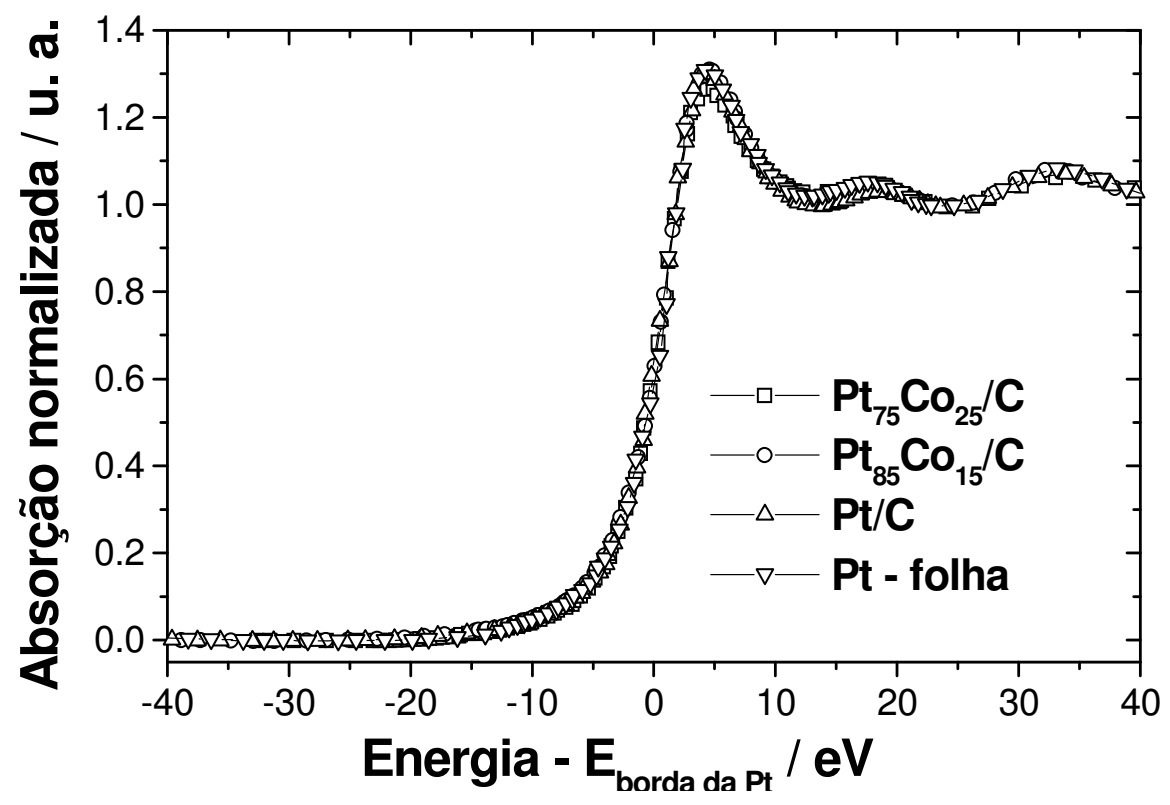

FIGURA 3.15. Espectros XANES na borda $L_{\text {III }}$ da Pt (11564 eV) dos catalisadores $\mathrm{Pt}_{75} \mathrm{Co}_{25} / \mathrm{C} \mathrm{Ml}$; $\mathrm{Pt}_{85} \mathrm{Co}_{15} / \mathrm{C} \mathrm{MB}$; Pt/C (E-TEK) e para a folha de Pt. Potencial de polarização $300 \mathrm{mV}$ vs. ERH. $T=25^{\circ} \mathrm{C}$.

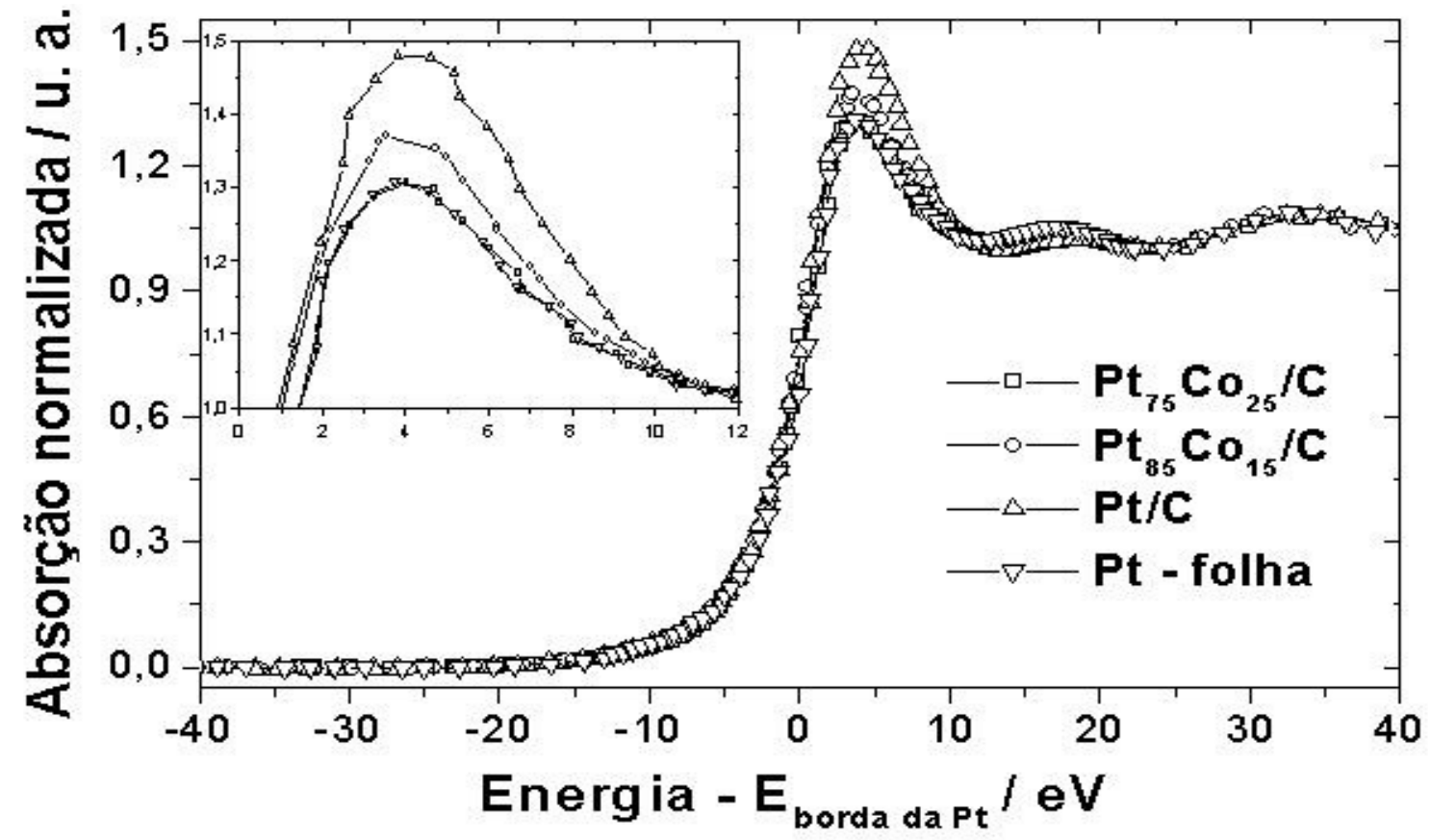

FIGURA 3.16. Espectros XANES na borda $L_{\text {III }}$ da Pt (11564 eV), dos catalisadores $\mathrm{Pt}_{75} \mathrm{Co}_{25} / \mathrm{C} \mathrm{Ml} ; \mathrm{Pt}_{85} \mathrm{Co}_{15} / \mathrm{C} \mathrm{MB}$; Pt/C (E-TEK) e para a folha de Pt. Potencial de polarização $1100 \mathrm{mV}$ vs. ERH. $T=25^{\circ} \mathrm{C}$. 
Como descrito por Shukla e col. [108], os espectros XANES podem ser ajustados por uma curva Lorenziana. A integração da linha branca dá informações sobre a ocupação da banda d da platina. Normalmente, a intensidade da borda $L_{\text {III }}$ aumenta com o aumento da vacância da banda d da Pt [108]. A diferença entre a intensidade integrada dos catalisadores (Pt-Co/C e Pt/C) a $1100 \mathrm{mV}$ e a folha de $\mathrm{Pt}$ foi dividida pela área da folha de Pt na região de energia entre -40 e $+40 \mathrm{eV}$. Entretanto, os valores da integração a $1100 \mathrm{mV}$ podem ser interpretados como um aumento de vacâncias da banda d ou um aumento da intensidade de adsorção de espécies oxigenadas sobre a superfície da $\mathrm{Pt}$, particularmente a adsorção de $\mathrm{OH}$. Os resultados encontrados foram 3,$75 ; 6,33$ e $7,06 \%$ para os catalisadores $\mathrm{Pt}_{75} \mathrm{Co}_{25} / \mathrm{C}(\mathrm{Ml}), \mathrm{Pt}_{85} \mathrm{Co}_{15} / \mathrm{C}(\mathrm{MB})$ e $\mathrm{Pt} / \mathrm{C}(\mathrm{E}-\mathrm{TEK})$, respectivamente. Os valores da integração a $300 \mathrm{mV}$ foram aproximadamente iguais a zero. Porém, para $\mathrm{Pt}_{85} \mathrm{Co}_{15} / \mathrm{C}$ $(6,33 \%)$ o aumento da vacância na banda d da Pt é menor quando comparado ao da $\mathrm{Pt} / \mathrm{C}(7,06 \%)$ e ainda menor para $\mathrm{Pt}_{75} \mathrm{Co}_{25} / \mathrm{C}(3,75 \%)$. Este resultado deve-se à falta de afinidade de adsorção química de espécies $\mathrm{OH}$ sobre a $\mathrm{Pt}$ em ligas bimetálicas, diferente do que ocorre sobre o catalisador Pt/C [44]. Conseqüentemente, este efeito aumenta com a quantidade de $\mathrm{Pt}$ nas ligas bimetálicas. A afinidade da adsorção de espécies oxigenadas também depende do tamanho das partículas e do grau de ligação. De acordo com Mukerjee e col. [38] o aumento na afinidade da adsorção química sobre Pt ocorre com o decréscimo do tamanho de partículas de Pt e não ocorre sobre as ligas de Pt [45]. 
Na Figura 3.17 são mostrados os resultados das análises de espectroscopia de absorção de raios-X na região estendida (EXAFS) para os catalisadores a 300 $m V$ e para a folha de Pt. A função EXAFS representa a superposição da contribuição de várias esferas de coordenação. Assim, a aplicação da Transformada de Fourier permite que se obtenham informações a respeito da contribuição individual de cada esfera em particular. Aqui, a esfera de maior interesse é a primeira, que corresponde aos vizinhos imediatos do átomo de Pt em estudo.

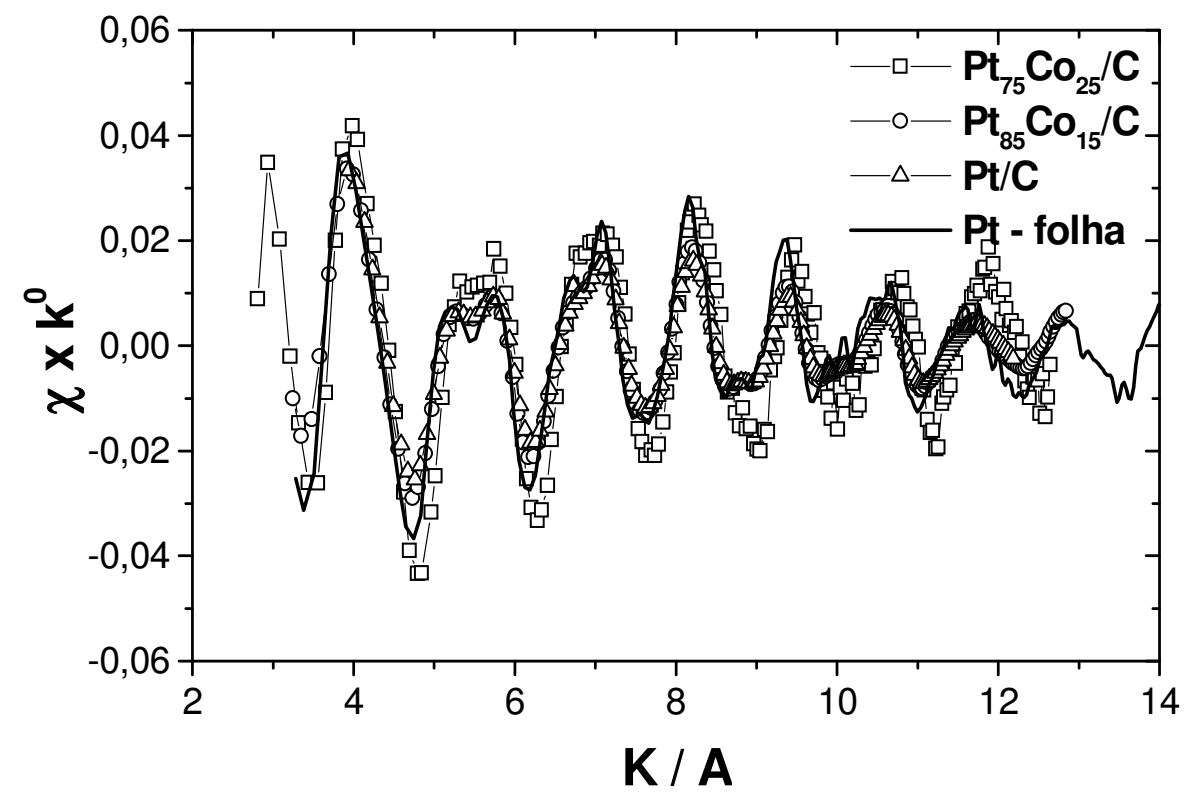

FIGURA 3.17. Espectro EXAFS na borda $L_{\text {III }}$ da $P t(11564 \mathrm{eV})$ para os catalisadores. $T=25{ }^{\circ} \mathrm{C}$. 
Para a obtenção das transformadas de Fourier usou-se a função Bessel $\left(\mathrm{k}^{3}\right)$ nos intervalos apresentados na Tabela 3.4. Platina e cobalto foram utilizados como padrão para a primeira esfera de coordenação, sendo usados 6 átomos de Pt e 6 átomos de Co (número de coordenação de 12 para uma estrutura fcc e distância PtPt de 2,77 ̊̊).

TABELA 3.4. Faixa de valores de $\Delta \mathrm{k}$ e $\Delta \mathrm{r}$ usados para as transformadas diretas e inversa de Fourier $\left(\mathrm{k}^{3}\right)$ na análise dos dados.

\begin{tabular}{|c|c|c|}
\hline Catalisador & $\Delta \mathbf{k} / \AA$ & $\Delta \mathbf{\mathbf { A }} / \AA$ \\
\hline $\mathbf{P t}_{75} \mathbf{C o}_{25} / \mathbf{C}, \mathbf{M I}$ & $3,675-12,265$ & $1,608-3,340$ \\
$\mathbf{P t}_{85} \mathbf{C o}_{15} / \mathbf{C}, \mathbf{M B}$ & $3,603-11,975$ & $1,589-3,409$ \\
$\mathbf{P t} / \mathbf{C}, \mathbf{E}-\mathrm{TEK}$ & $3,598-12,571$ & $1,570-3,294$ \\
Folha de Pt & $2,860-15,165$ & $1,850-3,523$ \\
\hline
\end{tabular}

A Figura 3.18 apresenta os pseudo função radial a $300 \mathrm{mV}$ para os catalisadores e para a folha de Pt. Observa-se uma semelhança dos espectros entre os materiais e apenas um pico relativamente intenso no eixo da coordenada radial de 2,6 A. Neste caso, pode-se perceber que os materiais apresentam estrutura fcc, característica da Pt metálica, em acordo com os resultados de DRX. 


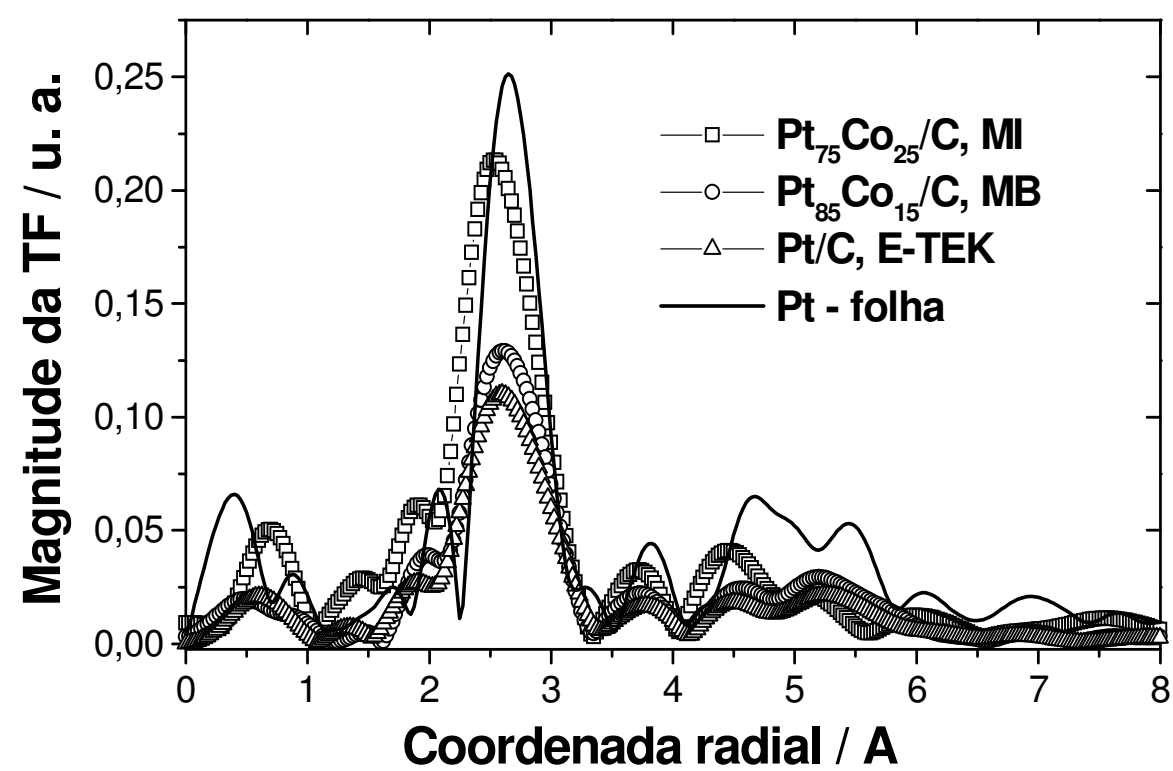

FIGURA 3.18. Transformadas de Fourier $\left(k^{3}\right)$ das oscilações EXAFS para os catalisadores. Potencial de polarização $300 \mathrm{mV} . T=25^{\circ} \mathrm{C}$.

A Tabela 3.5 mostra os resultados obtidos para os parâmetros estruturais: N é o número de coordenação, $R$ é a distância interatômica, $\sigma^{2}$ é o fator de Debye-Waller e $\Delta \mathrm{E}^{\circ}$ o deslocamento da energia de absorção. $\mathrm{O}$ valor de $\mathrm{S}_{0}{ }^{2}$ (que corresponde a um termo de redução da amplitude) está tipicamente entre 0,7 e 0,9 e deve ser levado em conta por ocasião do ajuste dos resultados EXAFS. Observa-se uma diminuição no número de coordenação e na distância interatômica Pt-Pt com o aumento da quantidade de Co. Estes resultados estão de acordo com os resultados obtidos por DRX. O fator de Debye-Waller e o número de coordenação são parâmetros que variam em uma forma inversa, isto é, se o fator de Debye-Waller sofre decréscimo o número de coordenação sofre um acréscimo. Entretanto, uma diminuição no fator de Debye-Waller é observada com o aumento da quantidade de Co, o qual reflete a diminuição do número de coordenação. 
TABELA 3.5. Características físicas das análises TF para os catalisadores na região de EXAFS. $N, R, \sigma^{2}$ e $\Delta E^{\circ}$. Ajuste em $R, S_{o}{ }^{2}$ igual a 0,7765 .

\begin{tabular}{|cccccc|}
\hline Catalisador & $\begin{array}{c}\text { Esfera de } \\
\text { coordenação }\end{array}$ & $\mathbf{N}$ & $\mathbf{R} / \AA$ & $\sigma^{2} / \AA^{2}$ & $\Delta \mathrm{E}^{\circ} / \mathbf{e V}$ \\
& & & & \\
$\mathbf{P t}_{75} \mathrm{Co}_{25} / \mathbf{C}$ & $\mathrm{Pt}-\mathrm{Co}$ & 2,779 & 2,686 & 0,0076 & 10,225 \\
& $\mathrm{Pt}-\mathrm{Pt}$ & 6,686 & 2,727 & 0,0005 & 10,225 \\
& $\mathrm{Pt}-\mathrm{Co}$ & 1,799 & 2,714 & 0,0181 & 10,066 \\
$\mathrm{Pt}_{85} \mathrm{Co}_{15} / \mathbf{C}$ & $\mathrm{Pt}-\mathrm{Pt}$ & 7,587 & 2,763 & 0,0033 & 10,066 \\
& $\mathrm{Pt}-\mathrm{Pt}$ & 10,131 & 2,751 & 0,0056 & 8,599 \\
$\mathrm{Pt} / \mathbf{C}$ & $\mathrm{Pt}-\mathrm{Pt}$ & 12 & 2,769 & 0,0042 & 8,582 \\
$\mathbf{P t}$ - folha & & & & & \\
\hline
\end{tabular}

\subsubsection{Espectroscopia Raman}

Os espectros Raman dos catalisadores $\mathrm{Pt}_{75} \mathrm{Co}_{25} / \mathrm{C} \mathrm{Ml} \mathrm{e} \mathrm{Pt}_{85} \mathrm{Co}_{15} / \mathrm{C} \mathrm{MB}$ são mostrados na Figura 3.19. Para comparação dos espectros, Pt/C (E-TEK) foi incluída e utilizada como referência. Observa-se que os espectros dos catalisadores $\mathrm{Pt}-\mathrm{Co} / \mathrm{C}$ mostram três bandas bem definidas em torno de 193, 474 e $676 \mathrm{~cm}^{-1}$ comumente associadas com óxidos de cobalto. Comparando os espectros dos materiais Pt-Co/C ao Pt/C observa-se que todas as bandas são tipicamente da ligação Co-O presente nos materiais bimetálicos suportados [94]. 


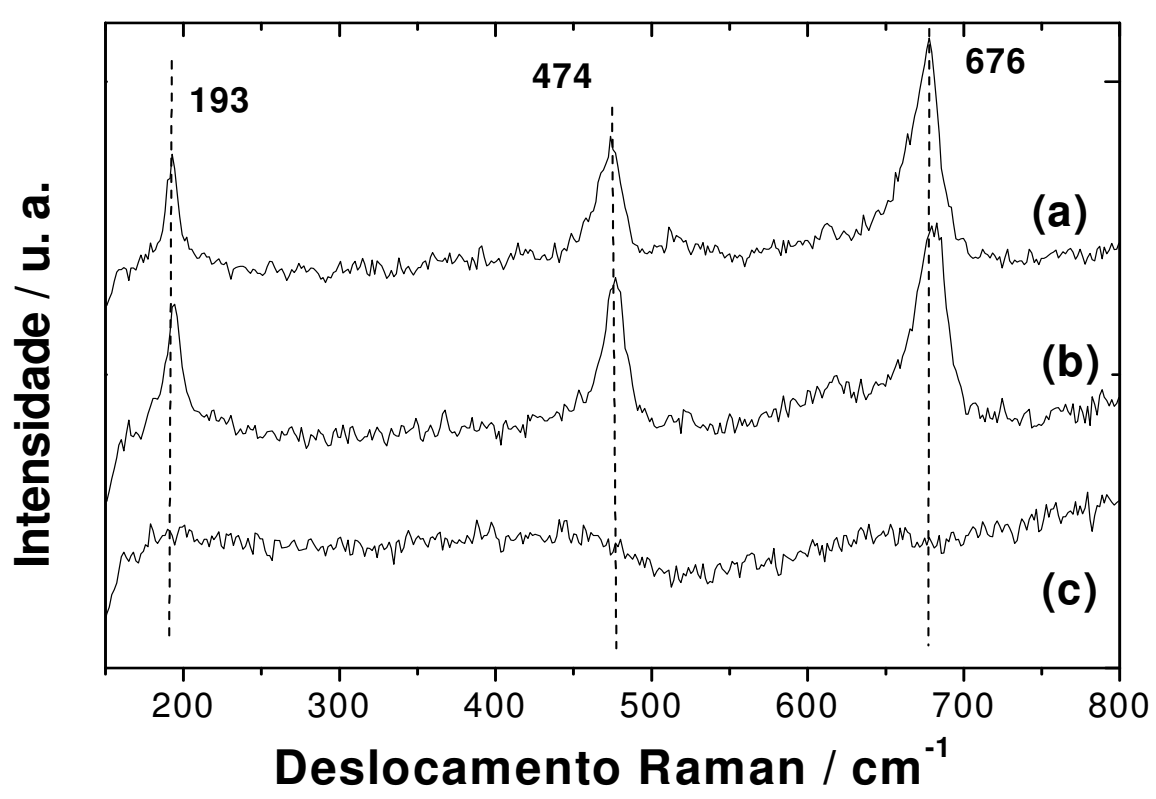

FIGURA 3.19. Espectros Raman para os catalisadores: (a) $\mathrm{Pt}_{75} \mathrm{Co}_{25} / \mathrm{C} \mathrm{MI}$, (b) $\mathrm{Pt}_{85} \mathrm{Co}_{85} / \mathrm{C} \mathrm{MB}$ e (c) Pt/C E-TEK.

\subsection{Caracterização Eletroquímica}

\subsubsection{Voltametria Cíclica}

A voltametria cíclica é uma técnica muito utilizada para caracterizar catalisadores de Pt lisa [75,97], Pt suportada em carbono [83] e ligas de Pt-M/C (M = $\mathrm{Co}, \mathrm{Cr}$ e $\mathrm{Ni}$ ) $[38,42]$, com o intuito de determinar a área eletroquimicamente ativa e também para elucidar as propriedades superficiais dos materiais.

Neste trabalho todos os resultados apresentados para a reação de redução de oxigênio foram normalizados por grama de platina ou pela área específica como indicado. 
Os voltamogramas cíclicos para os catalisadores $\mathrm{Pt}_{75} \mathrm{Co}_{25} / \mathrm{C} \mathrm{MI}, \mathrm{Pt}_{85} \mathrm{Co}_{15} / \mathrm{C}$ MB e Pt/C E-TEK exibiram perfis característicos da Pt policristalina suportada em carbono, como mostra a Figura 3.20. Observa-se que os VC's para Pt-Co/C apresentam menores densidades de corrente com relação à Pt/C [109]. No sentido da varredura positiva (75-800 mV vs. ERH), a região compreendida entre 75 e 350 $\mathrm{mV}$ corresponde a região de dessorção/oxidação de hidrogênio. O intervalo de potencial entre 350 e $450 \mathrm{mV}$ corresponde à região de dupla camada, onde somente correntes capacitivas são observadas. Em potenciais acima de $750 \mathrm{mV}$ ocorre o processo da formação de espécies oxigenadas sobre a superfície do eletrodo. $\mathrm{Na}$ varredura negativa ocorre a redução dos óxidos em potencial de $800 \mathrm{mV}$ e a adsorção/redução de hidrogênio na região entre $350-75 \mathrm{mV}$. Em toda a região de varredura, regiões de dessorção de hidrogênio e dupla camada, $\mathrm{Pt}-\mathrm{Co} / \mathrm{C}$ apresenta densidades de corrente menores do que às de $\mathrm{Pt} / \mathrm{C}$.

Para todos os materiais estudados, observam-se picos pouco definidos na região de adsorção e dessorção de hidrogênio. Por se tratar de um material policristalino, constituído de partículas de diversos diâmetros e suportado em carbono, não se pode esperar uma melhor resolução dos picos apresentados na Figura 3.20.

Os valores da área eletroativa foram obtidos pela integração da carga associada à oxidação de hidrogênio previamente adsorvido corrigida pela carga da região da dupla camada. Foi assumido uma carga de $210 \mu \mathrm{C} \mathrm{cm}$ para a formação de uma monocamada de hidrogênio adsorvido sobre a superfície da platina policristalina [96]. 
Neste cálculo foi considerada a área da superfície da platina sobre o suporte de carbono, assumindo ser desprezível a adsorção de hidrogênio sobre a superfície do Co, assim como sugerido por Mukerjee e col. [38,44,45].

Os valores das áreas eletroativas foram de 48,50 e $95 \mathrm{~m}^{2} \mathrm{~g}^{-1}$ para os catalisadores $\mathrm{Pt}_{75} \mathrm{Co}_{25} / \mathrm{C}(\mathrm{MI}), \mathrm{Pt}_{85} \mathrm{Co}_{15} / \mathrm{C}(\mathrm{MB})$ e $\mathrm{Pt} / \mathrm{C}(\mathrm{E}-\mathrm{TEK})$, respectivamente. Nota-se que os menores valores das áreas eletroquimicamente ativas para $\mathrm{Pt}-\mathrm{Co} / \mathrm{C}$ são conseqüência dos maiores tamanhos das partículas, como é observado pelo diâmetro médio determinado por DRX (Tabela 3.1) e MET (Tabela 3.3).

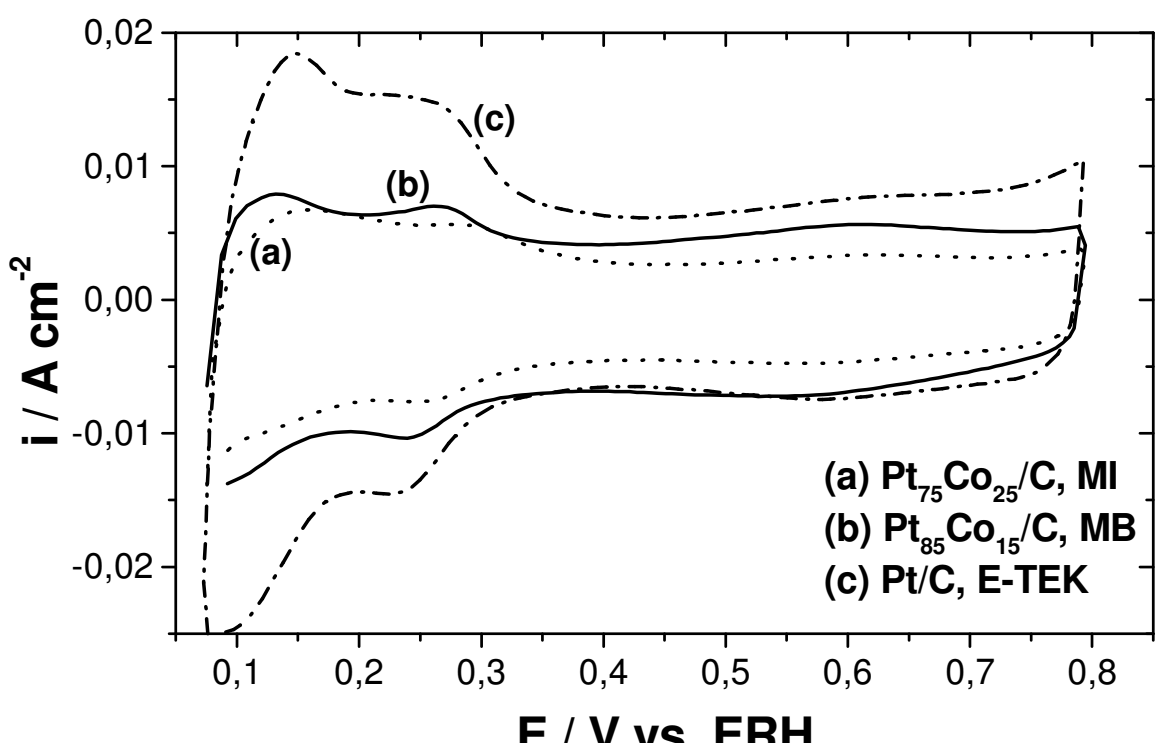

FIGURA 3.20. Voltamogramas cíclicos para os catalisadores Pt-Co/C em meia célula. $v=50 \mathrm{mV} \mathrm{s}^{-1}, T=25{ }^{\circ} \mathrm{C}$.

Para avaliar a estabilidade dos materiais $\mathrm{Pt}_{75} \mathrm{Co}_{25} / \mathrm{C}(\mathrm{MI})$ e $\mathrm{Pt} / \mathrm{C}$ (E-TEK) foram obtidos vários VC's sucessivamente [110]. Os resultados foram reprodutíveis e a liga bimetálica Pt-Co/C preparada pelo método de impregnação exibiu alta estabilidade em meio ácido [110]. Como será visto adiante, este resultado comparado com os resultados de Mukerjee e col. explica a estabilidade encontrada para o catalisador 
$\mathrm{Pt}_{3} \mathrm{Co}$ para a $\mathrm{RRO}$ em células a combustível, o qual mostra perda mínima de desempenho num período de 400 horas [38].

3.2.2. Voltametria de Varredura Linear Para a Redução de Oxigênio

As curvas voltamétricas para $\mathrm{Pt}_{75} \mathrm{Co}_{25} / \mathrm{C}(\mathrm{MI}), \mathrm{Pt}_{85} \mathrm{Co}_{15} / \mathrm{C}(\mathrm{MB})$ e $\mathrm{Pt} / \mathrm{C}(\mathrm{E}-\mathrm{TEK})$ para a reação de redução de oxigênio em solução de ácido sulfúrico são mostradas nas Figuras 3.21 e 3.22. Na Figura 3.21 as densidades de corrente são expressas em termos da área superficial geométrica, contendo a dispersão $1 \mathrm{mg} \mathrm{de} \mathrm{Pt} \mathrm{cm}^{-2} \mathrm{em}$ todos os eletrodos. Na Figura 3.22 as densidades de corrente são expressas em termos da área de platina calculada pela região de dessorção de hidrogênio, isto é, em termos da área específica. Observa-se nas Figuras 3.21 e 3.22 que para ambos os materiais (Pt-Co/C e Pt/C) o início da RRO se dá aproximadamente em 850 mV. Em relação à área geométrica as densidades de corrente da Pt/C são superiores às do Pt-Co/C (Figura 3.21). Por outro lado, em relação às áreas específicas, as densidades de corrente aumentam com o aumento da quantidade de Co no catalisador (Figura 3.22). 


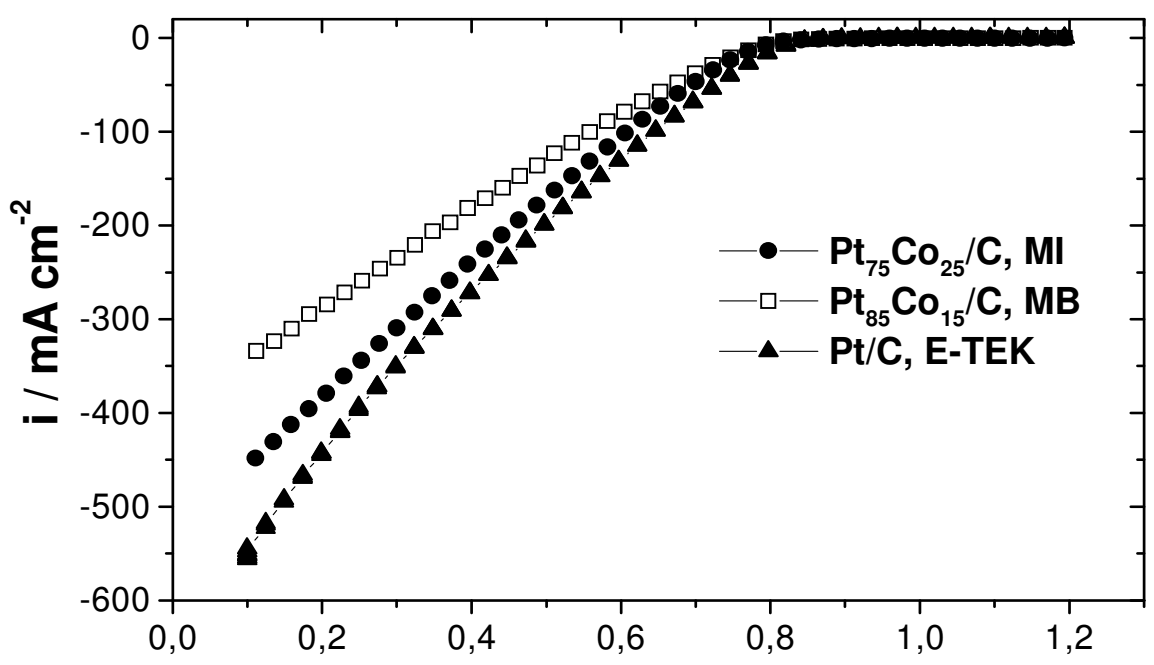

E / V vs. ERH

FIGURA 3.21. Curvas de varredura linear dos catalisadores $P t-C o / C$ e $P t / C$ para a $\mathrm{RRO}$ em $\mathrm{H}_{2} \mathrm{SO}_{4} 0,5 \mathrm{~mol} \mathrm{~L}^{-1}$. Densidade de corrente normalizada em relação à área superficial geométrica. $v=5 \mathrm{mV} \mathrm{s}^{-1}$ e $T=25^{\circ} \mathrm{C}$.

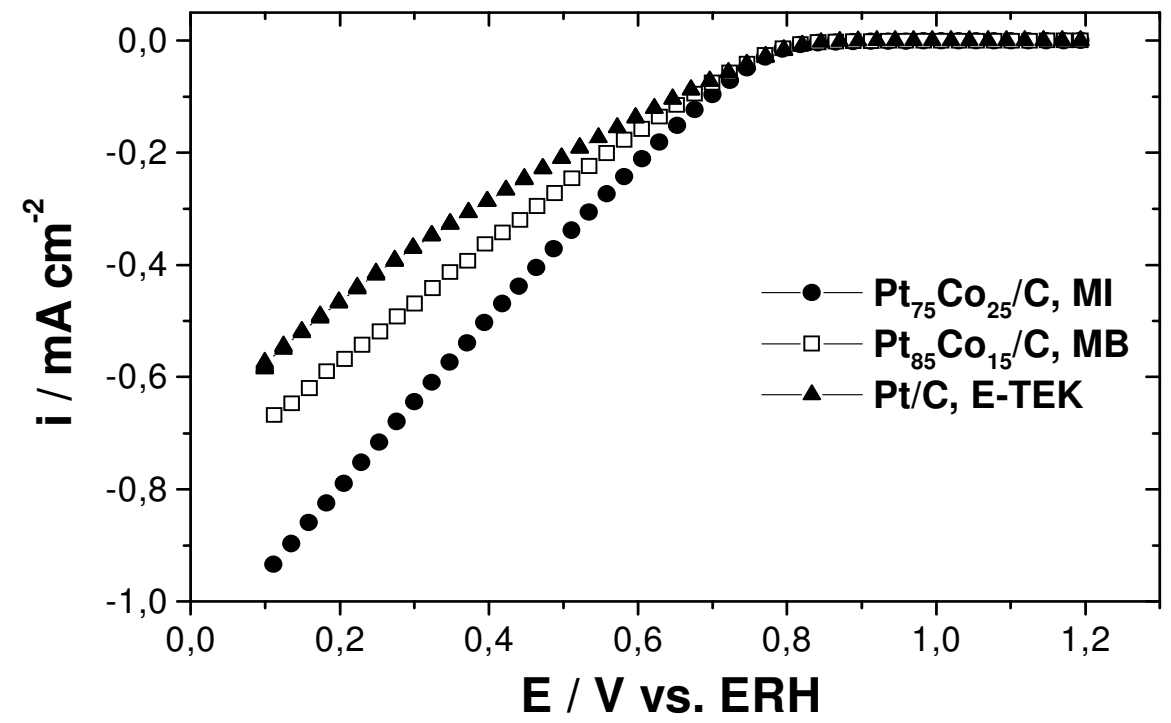

FIGURA 3.22. Curvas de varredura linear dos catalisadores Pt-Co/C e Pt/C para a $\mathrm{RRO}$ em $\mathrm{H}_{2} \mathrm{SO}_{4} \quad 0,5 \mathrm{~mol} \mathrm{~L}^{-1}$. Densidade de corrente normalizada em relação à área superficial específica da Pt. $v=5 \mathrm{mV} \mathrm{s}^{-1}$ e $T=25^{\circ} \mathrm{C}$. 


\subsubsection{Desempenho dos Catalisadores na Célula a Combustível de Membrana Trocadora de Prótons (PEMFC)}

Para avaliar o desempenho dos materiais preparados neste trabalho foram utilizados os parâmetros otimizados por Paganin [95] e Lizcano-Valbuena [98] para os experimentos na célula a combustível alimentada com $\mathrm{H}_{2} / \mathrm{O}_{2}$ (PEMFC) e metanol/ $\mathrm{O}_{2}$ (DMFC), respectivamente. Particularmente neste trabalho serão apresentados e discutidos os resultados do efeito dos catalisadores Pt-Co/C comparados à Pt/C para a reação de redução de oxigênio ( $R \mathrm{RO})$.

Para se obter informações detalhadas sobre os parâmetros cinéticos da RRO, os dados experimentais obtidos através das curvas de polarização ( $E$ vs. i) foram analisados usando-se uma equação semi-empírica [111-113]:

$$
E=E^{o}-b \log i-R i
$$

Para utilizar esta equação é necessário considerar que as limitações por transporte de massa e o sobrepotencial de ativação no eletrodo de hidrogênio são negligenciáveis. Na equação (3.2), Eº́ uma constante e pode ser expressa por:

$$
E^{o}=E^{r}-b \log i_{o}
$$


onde $E^{r}$ é o potencial reversível para a célula, $b$ a inclinação de Tafel e $i_{0}$ a densidade de corrente de troca para a RRO no catalisador. R é a tangente da região linear do gráfico E vs. i e representa a contribuição total das componentes de polarização linear que incluem a resistência de transferência de carga da reação de oxidação do hidrogênio, a resistência iônica do eletrólito (predominante), a resistência eletrônica dos eletrodos e seus contatos com os coletores de corrente e os termos de difusão linear na fase gasosa na camada difusora e/ou no filme fino de eletrólito/água [112,113].

Como a mudança na inclinação de Tafel de 60 para $120 \mathrm{mV} \mathrm{dec}^{-1}$ é esperada em potenciais por volta de $800 \mathrm{mV}[113,114]$, somente os dados acima deste potencial foram considerados para as análises.

Os parâmetros $\mathrm{E}^{\circ}$, b e $\mathrm{R}$ foram obtidos pelo método de mínimos quadrados ajustando-se os dados experimentais que foram obtidos das curvas $E$ vs. i e fazendo uso de um procedimento de Levenberg-Marquardt [113]. Os resultados dos parâmetros cinéticos são mostrados na Tabela 3.6 e as curvas de polarização foram corrigidas ( $E+i R$ vs log i) usando-se os valores de $R$ encontrados. Os resultados da atividade catalítica para os materiais $\mathrm{Pt}-\mathrm{Co} / \mathrm{C}$ comparados à $\mathrm{Pt} / \mathrm{C}$ serão discutidos a seguir. 
TABELA 3.6. Parâmetros cinéticos obtidos pelas curvas de polarização dos catalisadores em célula a combustível unitária.

\begin{tabular}{|c|c|c|c|c|c|c|}
\hline \multirow{2}{*}{ Catalisador } & \multirow[t]{2}{*}{$\mathrm{TT} /{ }^{\circ} \mathrm{C}$} & \multirow{2}{*}{$\begin{array}{l}\mathrm{E} \% / \\
\mathrm{mV}\end{array}$} & \multirow{2}{*}{$\begin{array}{l}\text { b / mV } \\
\mathrm{dec}^{-1}\end{array}$} & \multirow{2}{*}{$\begin{array}{l}\mathrm{R} / \Omega \\
\mathrm{cm}^{2}\end{array}$} & \multicolumn{2}{|c|}{$\mathbf{I}_{900 \mathrm{mV}} / \mathrm{mA} \mathrm{E}_{10 \mathrm{mAcm}-2} /$} \\
\hline & & & & & $\mathrm{cm}^{-2}$ & $\mathrm{mV}$ \\
\hline & preparado & 933 & 55 & 0,22 & 3,00 & 872 \\
\hline \multirow[t]{2}{*}{ MAF, 70:30 } & 500 & 941 & 74 & 0,24 & 3,80 & 862 \\
\hline & 900 & 951 & 62 & 0,32 & 6,30 & 887 \\
\hline \multirow[t]{2}{*}{$\mathrm{Pt} / \mathrm{C}, \mathrm{MAF}$} & preparado & 955 & 63 & 0,19 & 7,3 & 890 \\
\hline & 550 & 970 & 60 & 0,32 & 12,80 & 907 \\
\hline MIC, 85:15 & 900 & 961 & 61 & 0,23 & 10,70 & 901 \\
\hline MI, 75:25 & & 975 & 65 & 0,21 & 13,68 & 911 \\
\hline $80: 20$ & & 978 & 67 & 0,21 & 13,36 & 910 \\
\hline $85: 15$ & 900 & 975 & 68 & 0,27 & 12 & 905 \\
\hline \multirow[t]{2}{*}{$90: 10$} & & 952 & 62 & 0,36 & 6,5 & 888 \\
\hline & preparado & 961 & 65 & 0,18 & 8,00 & 894 \\
\hline MB, 85:15 & 500 & 945 & 66 & 0,23 & 4,70 & 878 \\
\hline \multirow[t]{2}{*}{$\mathrm{Pt} / \mathrm{C}, \mathrm{MB}$} & preparado & 955 & 65 & 0,22 & 6,3 & 887 \\
\hline & comercial & 960 & 64 & 0,24 & 9,00 & 897 \\
\hline E-TEK, 50:50 & 500 & 951 & 68 & 0,25 & 5,55 & 883 \\
\hline Pt/C, E-TEK & comercial & 957 & 65 & 0,17 & 7,00 & 890 \\
\hline
\end{tabular}




\subsubsection{Desempenho dos Catalisadores Preparados Pelo Método do Ácido Fórmico (MAF)}

A Figura 3.23 apresenta as curvas E vs. i e as curvas corrigidas de Tafel para os catalisadores $\mathrm{Pt}-\mathrm{Co} / \mathrm{C}$ e $\mathrm{Pt} / \mathrm{C}(\mathrm{MAF})$, como cátodos, em célula a combustível unitária. Os parâmetros cinéticos são apresentados na Tabela 3.6.

Observa-se na Figura 3.23 que o material $\mathrm{Pt}_{70} \mathrm{Co}_{30} / \mathrm{C}$ MAF como preparado apresentou densidades de corrente inferiores às do Pt/C (MAF). A menor atividade catalítica apresentada por este material é indicada pelos valores da Tabela $3.6\left(E^{\circ}\right.$, $\mathrm{I}_{900 \mathrm{mv}}$ e $\mathrm{E}_{10 \mathrm{~mA} \text { cm-2}}$ ), na região controlada pela ativação. Este resultado é devido ao efeito do tamanho de partícula (maiores para $\mathrm{Pt}-\mathrm{Co} / \mathrm{C}, \mathrm{MAF}$ ) e/ou a presença de $\mathrm{CoO}_{x}$ nos catalisadores bimetálicos, causando um decréscimo da área eletroquimicamente ativa. O aumento no valor de $\mathrm{R}\left(0,19 \Omega \mathrm{cm}^{2}\right.$ para Pt/C e $0,22 \Omega$ $\mathrm{cm}^{2}$ para $\mathrm{Pt}-\mathrm{Co} / \mathrm{C}$ ) é devido a um aumento das componentes de difusão linear, como conseqüência do decréscimo da área eletroquimicamente ativa.

Quando o material foi submetido a tratamento térmico a $500{ }^{\circ} \mathrm{C}$ a atividade catalítica para a RRO foi inferior se comparada ao material sem TT devido ao aumento do tamanho de partículas. No trabalho de Kinoshita [67], uma dependência da atividade catalítica para a RRO com o tamanho de partículas foi observada. $\mathrm{O}$ autor mostra que partículas com 3,5 nm apresentam um máximo na atividade catalítica, que decresce com o aumento do tamanho de partículas, uma vez que a área ativa diminui com este aumento.

Por outro lado, um aumento da atividade catalítica para $\mathrm{Pt}-\mathrm{Co} / \mathrm{C}$ foi observado quando a temperatura do tratamento térmico foi aumentada de 500 para $900{ }^{\circ} \mathrm{C}$, conforme os valores da Tabela $3.6\left(E^{\circ}\right.$, $\mathrm{I}_{900 \mathrm{mv}}$ e $\left.\mathrm{E}_{10 \mathrm{~mA} \mathrm{~cm}-2}\right)$ onde os valores são 
próximos aos da Pt/C, embora o tamanho de partículas seja aproximadamente cinco vezes maior. Em particular, os valores de $\mathrm{E}^{\circ}$ para os catalisadores $\mathrm{Pt}_{70} \mathrm{Co}_{30} / \mathrm{C} \mathrm{MAF}$ TT a $900{ }^{\circ} \mathrm{C}(21,3 \mathrm{~nm})$ e para o eletrodo contendo Pt/C (4,5 nm) foram comparáveis (951 e $955 \mathrm{mV}$ ). De fato, quando se aumenta o tamanho de partícula da Pt/C E-TEK de 4 para $8,5 \mathrm{~nm}$ (através do aumento da porcentagem de metal de 40 para $60 \%$ ) o valor de $\mathrm{E}^{\circ}$ sofre um possível decréscimo (960 para $915 \mathrm{mV}$ ) [115,116]. Esta perda de atividade mostra que, embora a comparação seja indireta, $\mathrm{Pt}_{70} \mathrm{Co}_{30} / \mathrm{C}$ tem atividade catalítica intrínseca superior a Pt/C (MAF), se compararmos materiais com tamanho de partícula similares.

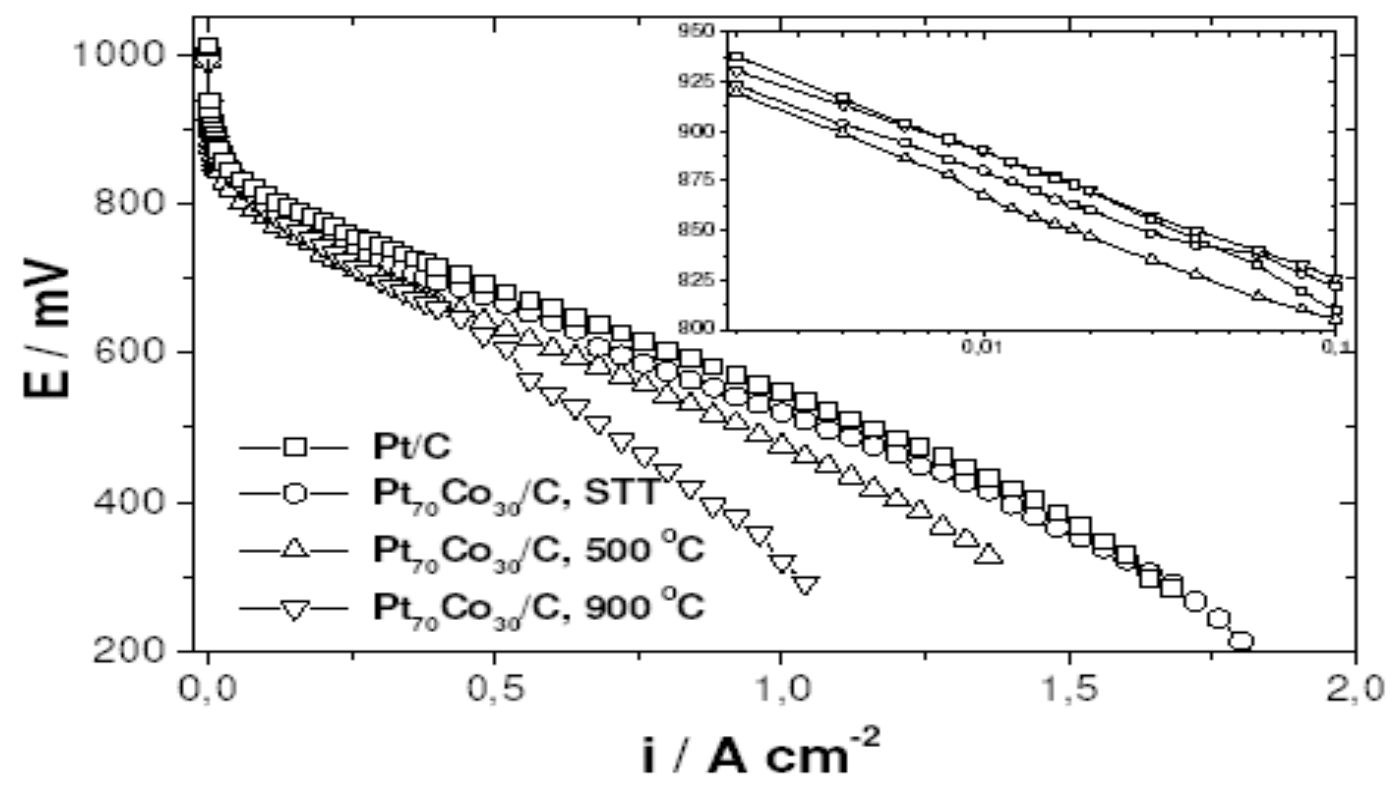

FIGURA 3.23. Curvas E vs. i (abaixo) e curvas corrigidas por queda ôhmica (acima) para os eletrodos contendo os materiais $\mathrm{Pt} / \mathrm{C}$ e Pt70 $\mathrm{Co}_{30} / \mathrm{C}$ MAF. 0,4 mg de Pt cm${ }^{-2}$; $15 \%$ de PTFE; Nafion ${ }^{\circledR} 115 . P=1 \mathrm{~atm} ; T_{\text {Célula }}=80^{\circ} \mathrm{C}$. $T_{\mathrm{H} 2 / \mathrm{O} 2}=95 / 85{ }^{\circ} \mathrm{C}$.

O efeito do cobalto sobre a atividade específica do catalisador foi avaliado anteriormente [117]. Nesta avaliação, considerou-se que a área eletroquimicamente ativa foi proporcional à área superficial da Pt. Os resultados atestam que a razão entre a área específica do catalisador Pt-Co e a área específica da Pt, aumenta com o aumento da temperatura do TT de $500{ }^{\circ} \mathrm{C}(1,53)$ para $900{ }^{\circ} \mathrm{C}(4,09)$. No entanto, 
como mostra a literatura [68-70], a atividade catalítica aumenta com o aumento do tamanho de partícula de $\mathrm{Pt}$, devido à diminuição da adsorção de espécies oxigenadas em partículas maiores. Quando o tamanho de partícula aumenta, as vacâncias dos orbitais d da Pt diminuem devido a diminuição da intensidade de adsorção de espécies oxigenadas adsorvidas. Assim, a redução de intermediários contendo oxigênio sobre a superfície da Pt é mais favorável. Como mostra Kinoshita [67], um aumento na atividade específica ocorre nas partículas com tamanho entre 4,5 e $12 \mathrm{~nm}$, e é menos pronunciado para partículas maiores do que $12 \mathrm{~nm}$. Com base nos resultados deste trabalho, a diferença na atividade específica entre os catalisadores $\mathrm{Pt}_{70} \mathrm{Co}_{30} / \mathrm{C}$ (MAF) quando submetido a TT a $500{ }^{\circ} \mathrm{C}$ (partículas de $\mathrm{Pt}$ de $12,4 \mathrm{~nm}$ ) e TT a $900{ }^{\circ} \mathrm{C}$ (partículas de Pt de $21,3 \mathrm{~nm}$ ) pode estar relacionada à formação de liga, conforme os resultados obtidos por DRX, Tabela 3.1.

O aumento do tamanho de partículas pela presença de Co (sem e com tratamento térmico) aumenta a componente de difusão linear, como pode ser visto no aumento dos valores de $\mathrm{R}$ para os cátodos com catalisadores $\mathrm{Pt}_{70} \mathrm{Co}_{30} / \mathrm{C}$ preparados pela redução com ácido fórmico, conforme os valores apresentados na Tabela 3.6 e Figura 3.23 .

\subsubsection{Desempenho dos Catalisadores Preparados Pelo Método de Impregnação Convencional (MIC)}

A Figura 3.24 apresenta as curvas corrigidas de Tafel para os catalisadores de $\mathrm{Pt}_{85} \mathrm{Co}_{15} / \mathrm{C}$ preparados pela redução em atmosfera de $\mathrm{H}_{2}$ a 550 e $900{ }^{\circ} \mathrm{C}$ (MIC) comparados com Pt/C ETEK. Observa-se na figura que os materiais $\mathrm{Pt}_{85} \mathrm{Co}_{15} / \mathrm{C}$ apresentaram densidades de corrente superiores as do Pt/C devido à formação de 
liga Pt-Co/C, conforme resultados da caracterização física obtidos por DRX. Observa-se também na Figura 3.24 que $0 \quad \mathrm{Pt}_{85} \mathrm{Co}_{15} / \mathrm{C}$ TT $550{ }^{\circ} \mathrm{C}$ apresenta densidades de corrente pouco superiores ao material TT a $900{ }^{\circ} \mathrm{C}$. Este resultado é devido ao efeito do tamanho de partículas sendo que com o aumento da temperatura de 550 para $900{ }^{\circ} \mathrm{C}$ houve um aumento no tamanho de partículas $(3,9$ para $6,8 \mathrm{~nm}$ ). Neste caso, o aumento da atividade catalítica destes não só depende da área superficial específica, como também depende da formação de liga conforme resultados obtidos por DRX que favorece a RRO.

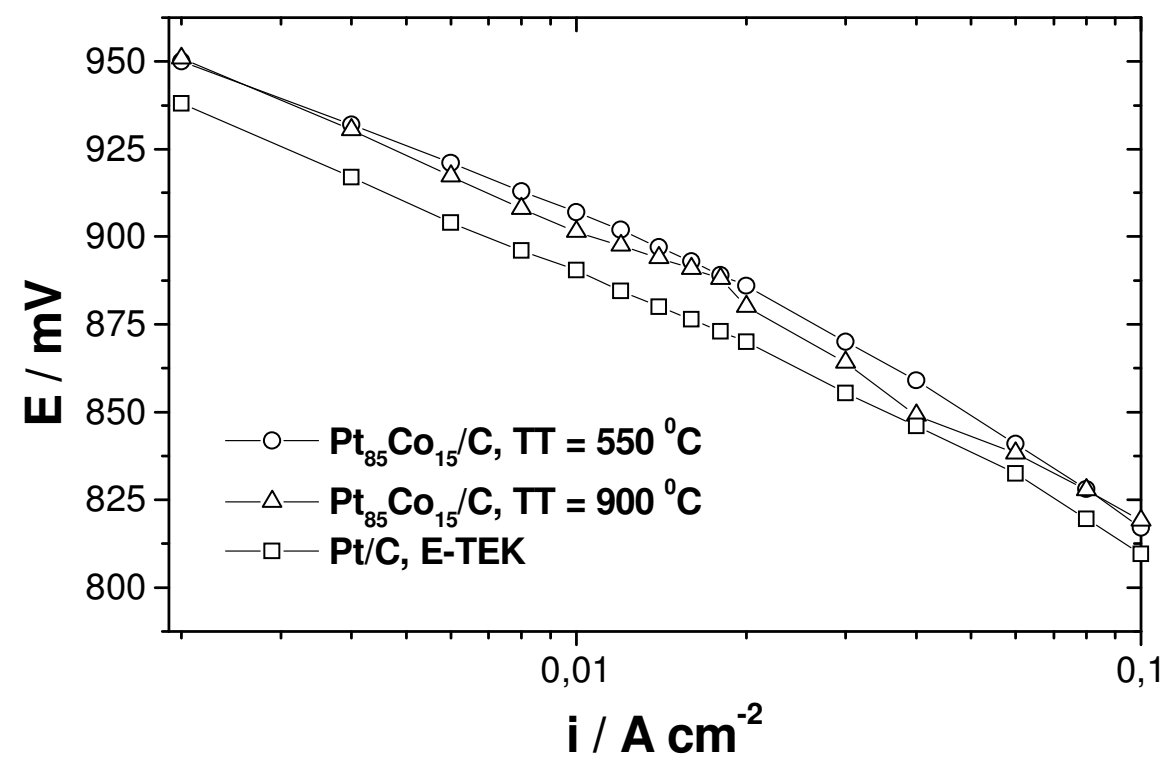

FIGURA 3.24. Curvas corrigidas por queda ôhmica para os eletrodos contendo os catalisadores Pt-Co/C MIC e Pt/C E-TEK. 0,4 mg de Pt cm ${ }^{-2} ; 15 \%$ de PTFE; Nafion ${ }^{\circledR}$ 115. $P=1 \mathrm{~atm} ; T_{\text {Célula }}=80^{\circ} \mathrm{C} . T_{\mathrm{H} 2 / \mathrm{O} 2}=95 / 85^{\circ} \mathrm{C}$.

\subsubsection{Desempenho dos Catalisadores Preparados pelo Método de Impregnação em Diferentes Composições de Cobalto (MI)}

A Figura 3.25 apresenta o desempenho dos catalisadores $\mathrm{Pt}$-Co/C preparados pelo $\mathrm{Ml}$ com diferentes composições atômicas comparados à Pt/C (E-TEK) para a 
RRO em célula a combustível alimentada com $\mathrm{H}_{2} / \mathrm{O}_{2}$. A figura também apresenta as curvas de Tafel corrigidas para os catalisadores. Os parâmetros cinéticos já foram apresentados na Tabela 3.6. Observa-se que o catalisador $\mathrm{Pt}_{75} \mathrm{Co}_{25} / \mathrm{C}$ (Ml) apresenta o melhor desempenho para a RRO em toda a faixa de densidades de corrente.

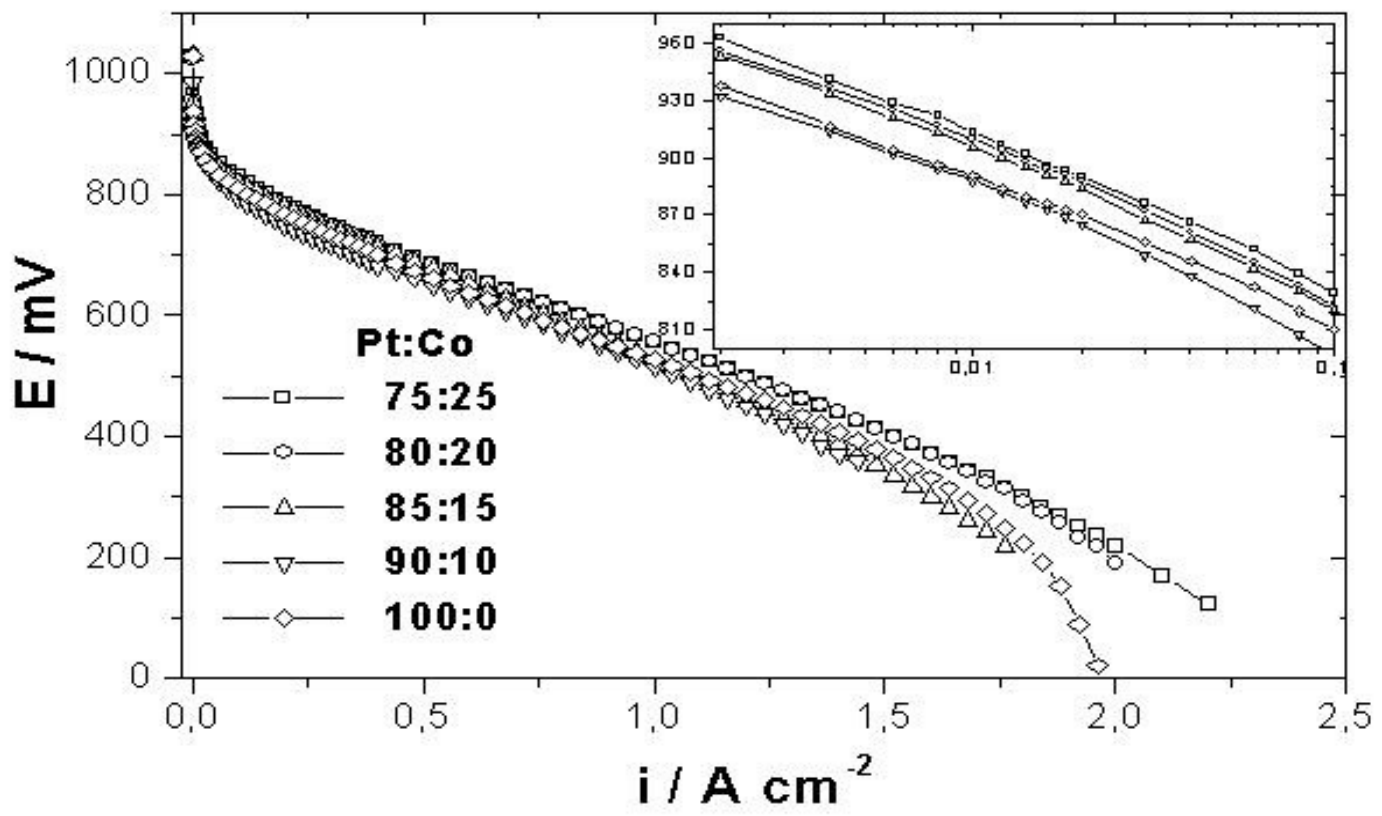

FIGURA 3.25. Curvas E vs. i (abaixo) e curvas corrigidas por queda ôhmica (acima) para os eletrodos contendo Pt-Co/C MI de diferentes composições e para Pt/C. 0,4 mg de Pt cm${ }^{-2} ; 15 \%$ de PTFE; Nafion ${ }^{\otimes} 115 . P=1 \mathrm{~atm} ; T_{\text {Célula }}=80^{\circ} \mathrm{C} . T_{\mathrm{H} 2 / \mathrm{O} 2}=$ $95 / 85^{\circ} \mathrm{C}$.

De acordo com os resultados dos estudos de Mukerjee e col. [45] um gráfico da atividade catalítica (igoomv) em função da distância interatômica média exibe uma curva com comportamento tipo volcano. Os autores obtiveram diferentes distâncias interatômicas médias para diferentes ligas bimetálicas à base de Pt. O material $\mathrm{Pt}-\mathrm{Cr}$ aparece na parte superior da curva, sendo sua distância interatômica de 0,273 nm. Como mostrado nas Tabelas 3.1 e 3.6, o valor máximo da atividade catalítica a 900 $\mathrm{mV}\left(13,68 \mathrm{~mA} \mathrm{~cm}^{-2}\right)$ e o valor da distância interatômica média $(0,2716 \mathrm{~nm})$, obtidos 
para $\mathrm{Pt}_{75} \mathrm{Co}_{25} / \mathrm{C} \mathrm{Ml}$ estão de acordo com os de Mukerjee e col. [45]. A altas densidades de corrente $\mathrm{Pt}_{75} \mathrm{Co}_{25} / \mathrm{C}$ apresentou melhor desempenho devido à baixa quantidade de Co não ligado à Pt e menor tamanho de partículas, resultando em um aumento da corrente limite.

\subsubsection{Desempenho dos Catalisadores Preparados Pelo Método do Borohidreto de Sódio e Efeito do Tratamento Térmico}

Na Figura 3.26 são apresentadas as curvas E vs. i e as curvas de Tafel corrigidas para os catalisadores $\mathrm{Pt}-\mathrm{Co} / \mathrm{C}$ preparados pelo método do borohidreto de sódio e E-TEK, antes e após o TT a $500{ }^{\circ} \mathrm{C}$ e para Pt/C MB e E-TEK. Os parâmetros cinéticos são mostrados na Tabela 3.6. As atividades catalíticas dos catalisadores $\mathrm{Pt}-\mathrm{Co} / \mathrm{C}$ para a RRO, normalizadas pela área geométrica do eletrodo, são maiores do que a do Pt/C, como mostram a Tabela 3.6 e Figura 3.26. Uma tendência similar é observada para os valores de $\mathrm{E}^{\circ}$ e o potencial a $10 \mathrm{~mA} \mathrm{~cm}{ }^{-2}$. Ainda com relação à área geométrica, o desempenho frente a $\mathrm{RRO}$ para o catalisador $\mathrm{Pt}_{85} \mathrm{Co}_{15} / \mathrm{C}(\mathrm{MB})$ é inferior ao observado para $\mathrm{Pt}_{50} \mathrm{Co}_{50} / \mathrm{C}$ (E-TEK). Por outro lado, o valor da densidade de corrente a $900 \mathrm{mV}$ calculado em relação a área eletroquimicamente ativa [118], como obtida das medidas VC's, indica que a atividade para o catalisador $\mathrm{Pt}_{85} \mathrm{Co}_{15} / \mathrm{C}$ para a RRO é maior do que $\mathrm{Pt}_{50} \mathrm{Co}_{50} / \mathrm{C}$. O material $\mathrm{Pt}-\mathrm{Co} / \mathrm{C}$ E-TEK apresenta uma maior corrente limite difusional comparado ao material $\mathrm{Pt}-\mathrm{Co} / \mathrm{C} \mathrm{MB}$, conforme mostra na Tabela 3.6 devido ao maior valor de R. Este resultado é conseqüência da presença de uma maior quantidade de Co não ligado (em forma de óxido), como mostraram os resultados de DRX, causando limitações de transporte difusional do gás reagente nas partículas do catalisador. 
Depois do TT as densidades de corrente dos materiais $\mathrm{Pt}-\mathrm{Co} / \mathrm{C}$ foram inferiores às de $\mathrm{Pt}$-Co/C sem tratamento térmico e Pt/C. Observa-se na Tabela 3.6 que os resultados da inclinação de Tafel (b) apresentam um aumento pouco significativo para os materiais após TT em comparação aos materiais não tratados. Estes valores, próximos de $70 \mathrm{mV}$ dec $^{-1}$, estão de acordo com os valores encontrados para os catalisadores baseados em Pt [44]. Conforme discutido anteriormente, o efeito do TT se deve provavelmente à eliminação de impurezas presentes na superfície do material, as quais bloqueiam os sítios ativos para a reação, combinado com a redução de óxidos de Pt. Por outro lado, com o tratamento térmico aumenta o tamanho das partículas e conseqüentemente diminui a área superficial, que por sua vez compromete o desempenho do catalisador.

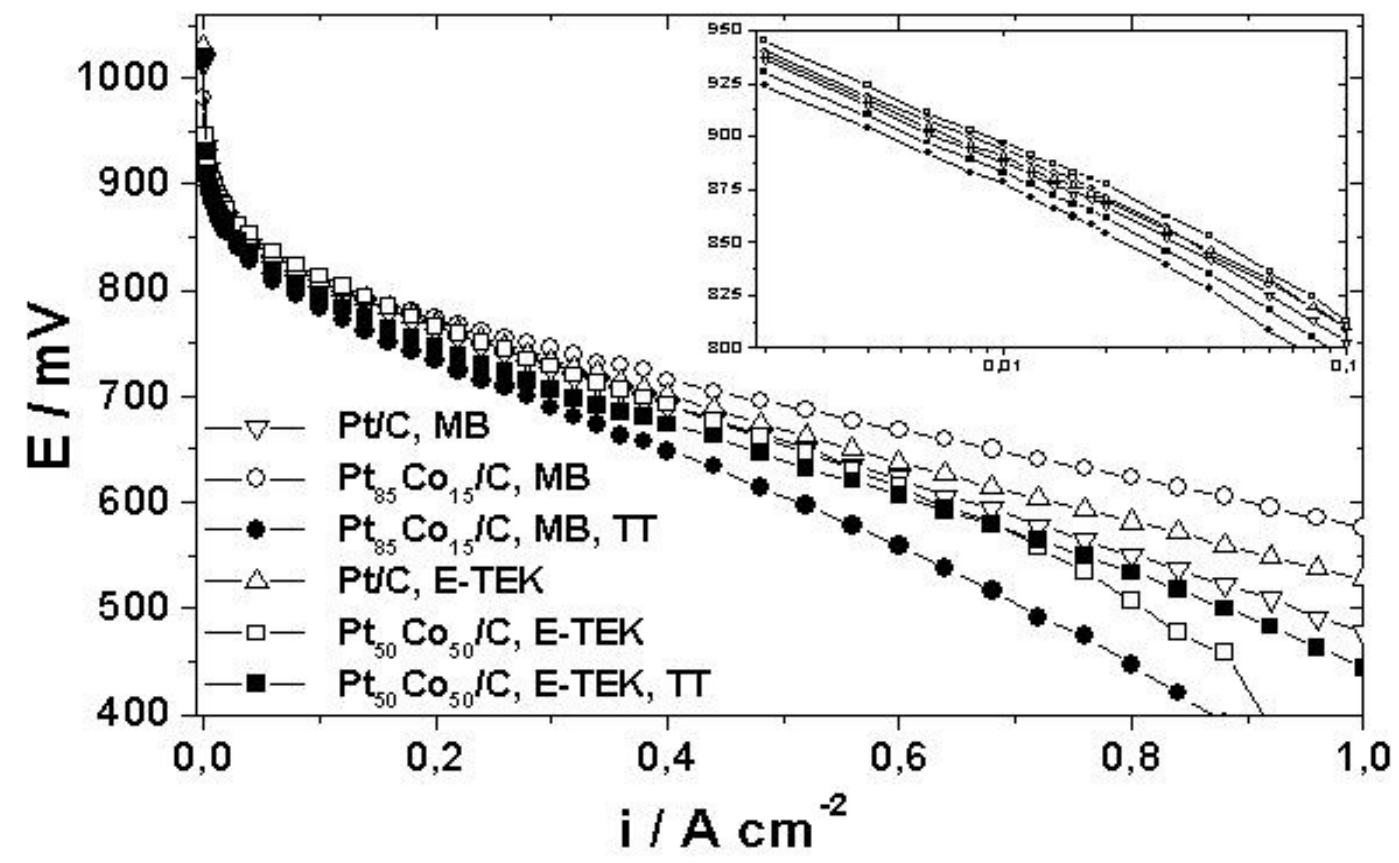

FIGURA 3.26. Curvas E vs. i (abaixo) e curvas corrigidas por queda ôhmica (acima) para os eletrodos contendo $\mathrm{Pt}_{85} \mathrm{Co}_{15} / \mathrm{C} \mathrm{MB}$ (sem e com TT), $\mathrm{Pt}_{50} \mathrm{CO}_{50} / \mathrm{C}$ (E-TEK, sem e com TT), Pt/C MB e Pt/C E-TEK. 0,4 mg de Pt cm ${ }^{-2} ; 15$ \% de PTFE; Nafion ${ }^{\circledR} 115$. P $=1 \mathrm{~atm} ; T_{\text {Célula }}=80^{\circ} \mathrm{C} . T_{\mathrm{H} 2 / \mathrm{O} 2}=95 / 85^{\circ} \mathrm{C}$. 
Em potenciais abaixo de $800 \mathrm{mV}$ a inclinação de Tafel foi de aproximadamente $120 \mathrm{mV} \mathrm{dec}^{-1}$ para ambos os catalisadores $\mathrm{Pt} / \mathrm{C}$ e Pt-Co/C. A mudança de $b$ nesta região de potencial é uma conseqüência da mudança do grau de cobertura da superfície da Pt por espécies oxigenadas, acompanhando a mudança da isoterma de Temkin (alta cobertura) a baixo sobrepotencial ( $\mathrm{E}>850$ $\mathrm{mV}$ ), para a isoterma de Langmuir (baixa cobertura) a alto sobrepotencial $(\mathrm{E}<850$ mV) [119-121]. Como a inclinação de Tafel é a mesma para Pt-Co/C e Pt/C supõemse que o mecanismo e a etapa determinante da velocidade da reação sejam os mesmos. Portanto, o menor sobrepotencial observado com a liga $\mathrm{Pt}-\mathrm{Co} / \mathrm{C}$ indica uma maior atividade catalítica deste material com relação ao Pt/C.

O efeito do TT foi observado em catalisadores com a mesma composição atômica (Pt-Co 90:10) e com diferentes tamanhos de partículas; e com catalisadores de tamanhos de partículas aproximados tendo diferentes composições atômicas. Desta forma, é possível avaliar separadamente o efeito de cada um desses parâmetros sobre a atividade específica. Como pode ser visto nas Tabelas 3.1 e 3.6, os catalisadores MB e E-TEK de mesma composição mostram melhor atividade catalítica para partículas maiores. Na Figura 3.27, a relação da atividade específica para a RRO aumenta com o tamanho de partícula. O aumento da atividade catalítica com o aumento do tamanho de partícula pode ser devido à menor intensidades de adsorção de espécies $\mathrm{OH}$ em partículas maiores. A ocupação dos orbitais na banda d está correlacionada ao tamanho de partículas. Estudos prévios [70-70] indicaram que a formação de óxidos e as vacâncias na banda d dependem do tamanho das partículas de Pt. A hibridização do estado $5 \mathrm{~d}$ da Pt com o estado desocupado do nível de Fermi reduz o número de elétrons, e esta hibridização torna-se menos favorável com o aumento do tamanho de partícula. Com isto, a ocupação dos 
orbitais d da Pt decresce, sugerindo que a adsorção de espécies oxigenadas é dificultada. Assim, a redução de intermediários contendo oxigênio sobre a superfície da Pt é mais fácil. De forma semelhante, os catalisadores com aproximadamente o mesmo tamanho de partículas mostraram maior atividade comparados ao $\mathrm{Pt} / \mathrm{C}$, ao menos na presença de cobalto.

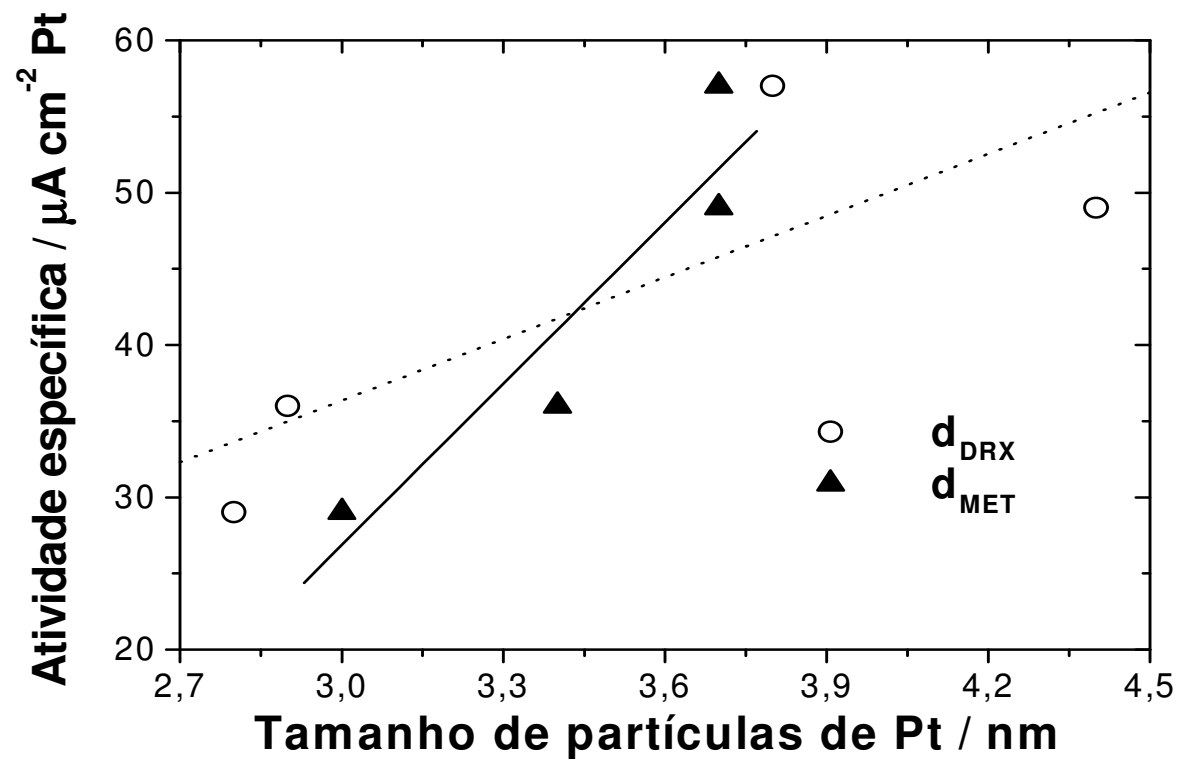

FIGURA 3.27. Atividade especifica vs. tamanho de partículas de Pt obtidas por DRX e MET para $\mathrm{Pt}_{85} \mathrm{Co}_{15} / \mathrm{C} \mathrm{MB}$ (sem TT) e Pt $t_{50} \mathrm{Co}_{50} / C$ (E-TEK, sem TT) e Pt/C (MB e ETEK). 
Com o tratamento térmico a $500{ }^{\circ} \mathrm{C}$ ocorre um decréscimo da atividade catalítica em baixas densidades de corrente para ambos os catalisadores de PtCo/C, como pode ser visto na Figura 3.26 e Tabela 3.6. O decréscimo da atividade catalítica depois do TT também foi previamente observado em catalisadores bimetálicos [122]. Este comportamento pode ser explicado considerando-se que diferente de outros sistemas formados pela fase simples $\mathrm{Pt}_{3}$ Co não suportado [123], o catalisador MB é formado por uma liga verdadeira e não por um óxido de Co. Enquanto no caso de se formar somente uma estrutura externa de Co, estes átomos de Co não ligados, se misturam à solução sólida durante o aquecimento, aumentando a formação de uma superfície rica em Co na solução sólida de Pt-Co sobre outras camadas de metal. Tem sido mencionado na literatura que $500{ }^{\circ} \mathrm{C}$ não é temperatura alta suficiente para formar uma liga homogênea. Com base nisto, devido à formação de uma estrutura externa rica em $\mathrm{Pt}$, a quantidade de Co na segunda camada é muito maior. É conhecido também que algumas propriedades catalíticas da estrutura externa rica em Pt nas ligas bimetálicas são diferentes da superfície da Pt pura [124,125]. Este comportamento foi atribuído ao efeito eletrônico da ligação intermetálica da liga com o componente presente na segunda camada do metal em átomos de Pt que são maioria na superfície. O decréscimo da atividade catalítica do catalisador provocado pelo tratamento térmico pode ser devido ao aumento da vacância da banda d na camada externa da superfície de Pt causado pela liga subjacente [55]. Com base em outro modelo, o aumento da vacância provoca um aumento da densidade eletrônica na superfície da Pt, resultando em um aumento de adsorção de $\mathrm{O}_{2}$ e enfraquecimento da ligação O-O. Quando a vacância da banda 5 d ou o nível de Fermi aumenta (pela adição do segundo elemento), a ligação Pt-O torna-se forte e a retroação é dificultada, resultando em menor 
velocidade da RRO. Quando a porcentagem do segundo elemento torna-se muito grande, a razão vacância/átomo para a banda d aumenta, o que acarreta o aumento da energia de ligação O-O, decrescendo a atividade da RRO. A formação de tais ligas ricas em Co sobre a superfície das partículas de Pt não pode ser detectada por DRX, sendo necessário o uso de outras técnicas de caracterização para que se possa entender melhor estes comportamentos.

\subsubsection{Estabilidade do Catalisador}

Uma das mais importantes propriedades das ligas de Pt para a reação de redução de oxigênio é a estabilidade em termos de atividade catalítica após longos períodos de operação das células. Para este propósito, o potencial das células unitárias contendo cátodos de $\mathrm{Pt}_{75} \mathrm{Co}_{25} / \mathrm{C} \mathrm{Ml} \mathrm{e} \mathrm{Pt/C} \mathrm{MAF} \mathrm{[83]} \mathrm{foi} \mathrm{avaliado} \mathrm{em} \mathrm{função}$ do tempo a uma densidade de corrente constante de $500 \mathrm{~mA} \mathrm{~cm}^{-2}$.

A Figura 3.28 mostra o potencial monitorado sobre um curto período de 24 horas de operação das células, podendo ser observadas variações nos potenciais. Para $\mathrm{Pt}_{75} \mathrm{Co}_{25} / \mathrm{C}(\mathrm{MI})$ observa-se uma perda de potencial de $12 \mathrm{mV}$ comparado com o potencial de início da operação. A célula operando com o material $\mathrm{Pt}_{75} \mathrm{Co}_{25} / \mathrm{C}$ apresentou estabilidade superior à $\mathrm{Pt} / \mathrm{C}$ (MAF), sendo que este último apresenta queda de potencial de $25 \mathrm{mV}$ no final de 24 horas. Estes resultados são muito similares aos resultados encontrados por Srinivasan e col $[38,44,45]$. 


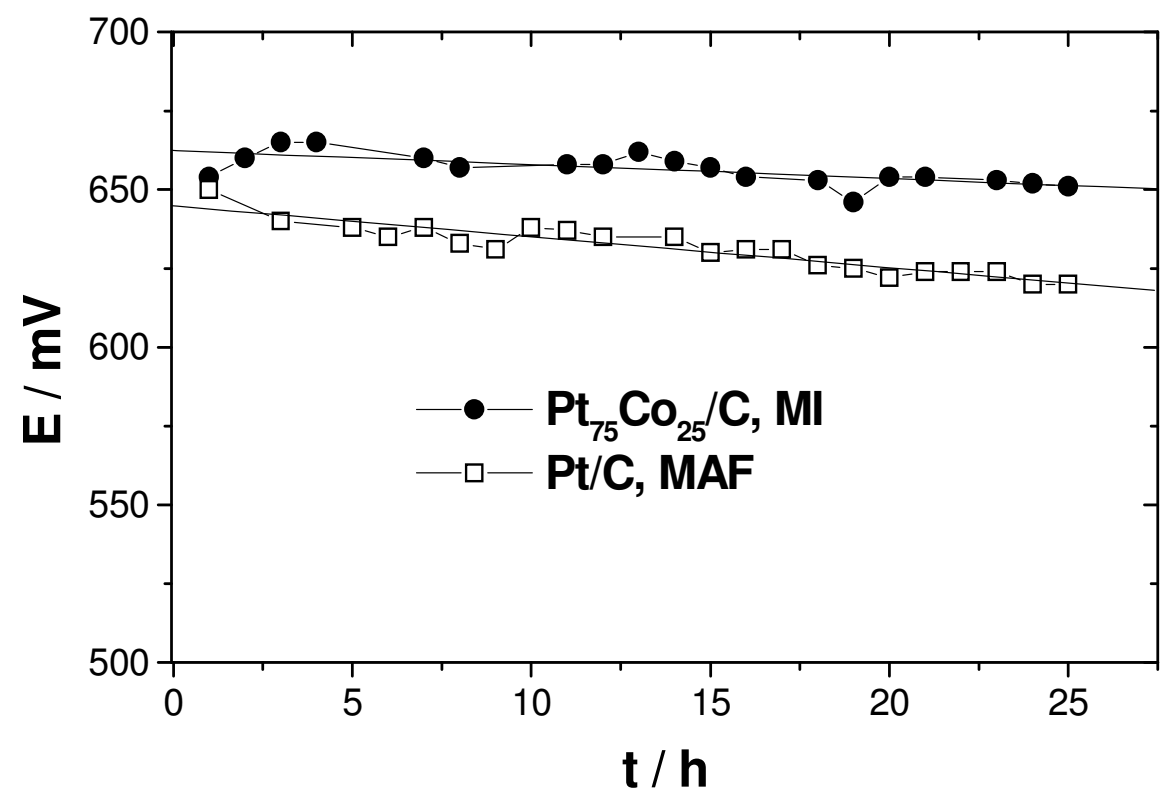

FIGURA 3.28. Gráfico do potencial da célula vs. tempo de operação. Corrente aplicada $500 \mathrm{~mA} \mathrm{~cm}{ }^{-2} . P=1 \mathrm{~atm} ; T_{\text {Célula }}=80^{\circ} \mathrm{C} . T_{\mathrm{H} 2 / \mathrm{O} 2}=95 / 85{ }^{\circ} \mathrm{C}$.

Para avaliar o efeito da operação em célula a combustível sobre a composição e a estrutura física do catalisador Pt-Co/C foram feitas medidas de EDX e DRX. A composição atômica dos catalisadores foi obtida pelas análises de EDX/MEV com os eletrodos retirados dos MEA's depois da operação por 24 horas. Foi verificado que a razão Pt:Co mudou de 75:25 para 82:18. Entretanto, os DRX do catalisador $\mathrm{Pt}_{75} \mathrm{Co}_{25} / \mathrm{C}(\mathrm{MI})$ mostrados na Figura 3.29, não apresentaram mudanças na estrutura cristalográfica. A perda de cobalto mostrada pelos resultados de EDX após 24 horas de operação, possivelmente refere-se ao cobalto que não formava liga com platina. 


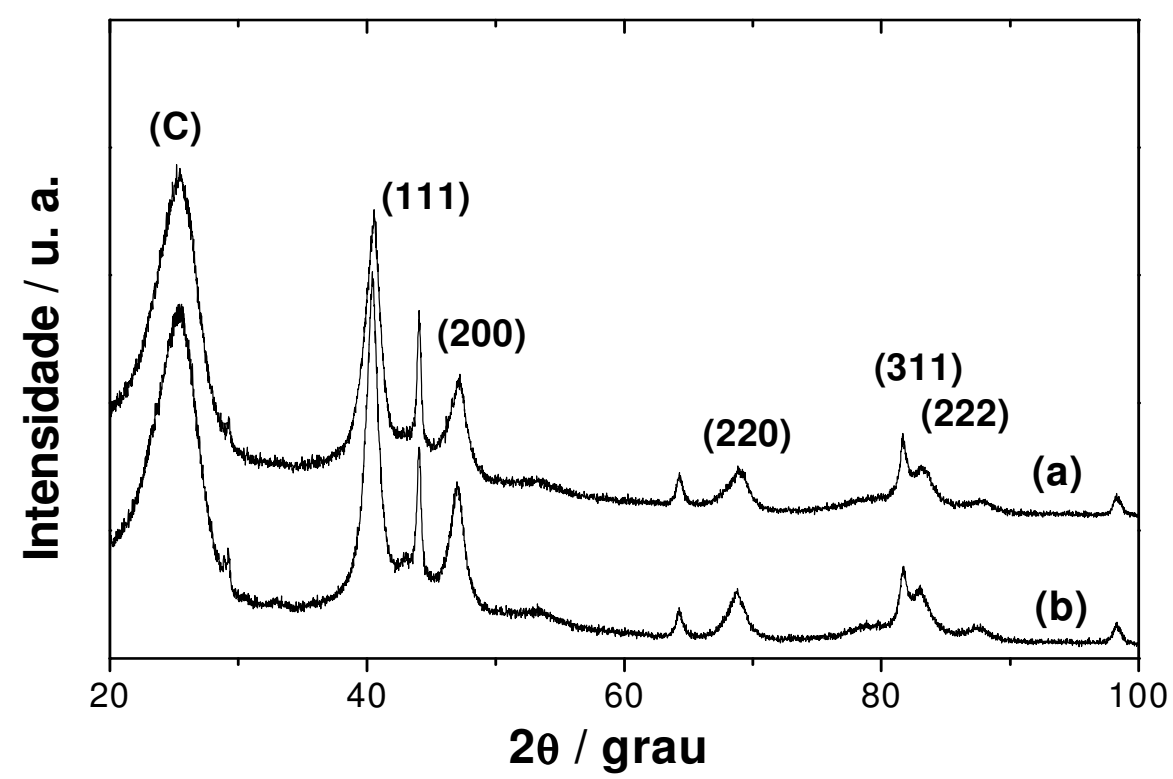

FIGURA 3.29. Difratogramas de raios- $X$ para os catalisadores $P t_{75} \mathrm{Co}_{25} / \mathrm{C}$ : (a) antes e (b) após a operação em célula unitária.

Os resultados de análise do mapeamento elementar para estes materiais, antes e após a operação na célula unitária são mostrados nas Figuras 3.30 e 3.31 . Observa-se de maneira geral que os metais estão distribuídos de maneira uniforme em toda a superfície do carbono. Entretanto, comparando as imagens das Figuras 3.30 (d) (antes da operação) e 3.31 (d) (depois da operação) observa-se que a quantidade de cobalto é menor depois da operação na célula unitária. 


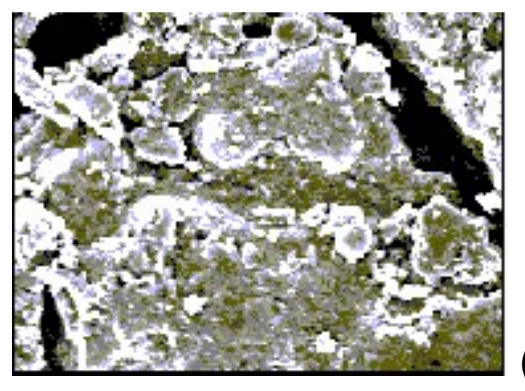

(a)
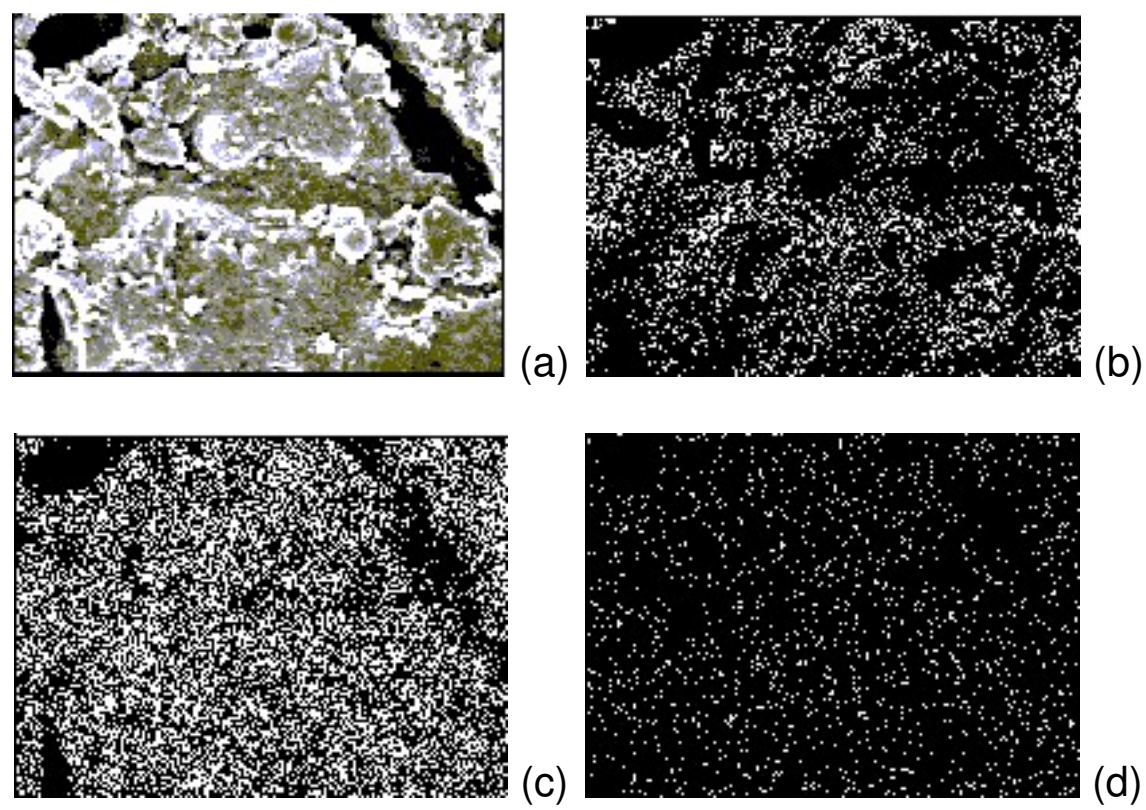

(c)

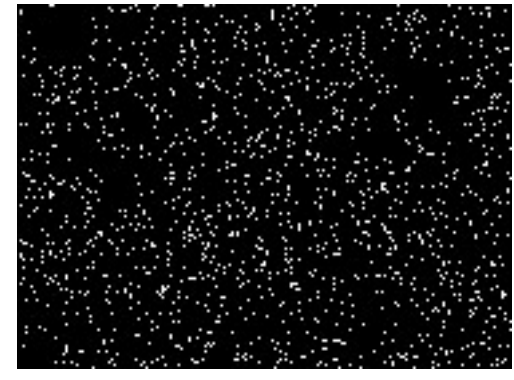

(d)

FIGURA 3.30. Mapeamento elementar do catalisador $\mathrm{Pt}_{75} \mathrm{Co}_{25} / \mathrm{C} \mathrm{MI}$ antes da operação na célula unitária: (a) morfologia geral; (b) carbono; (c) platina e (d) cobalto. Resolução 9 kx.

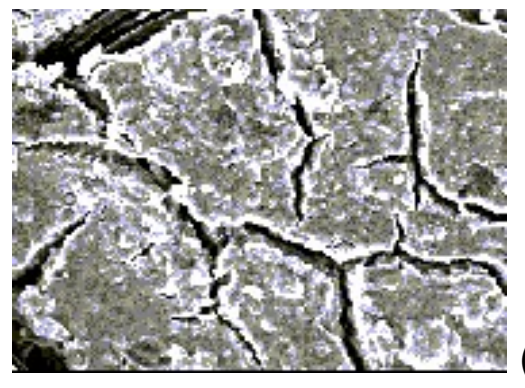

(a)
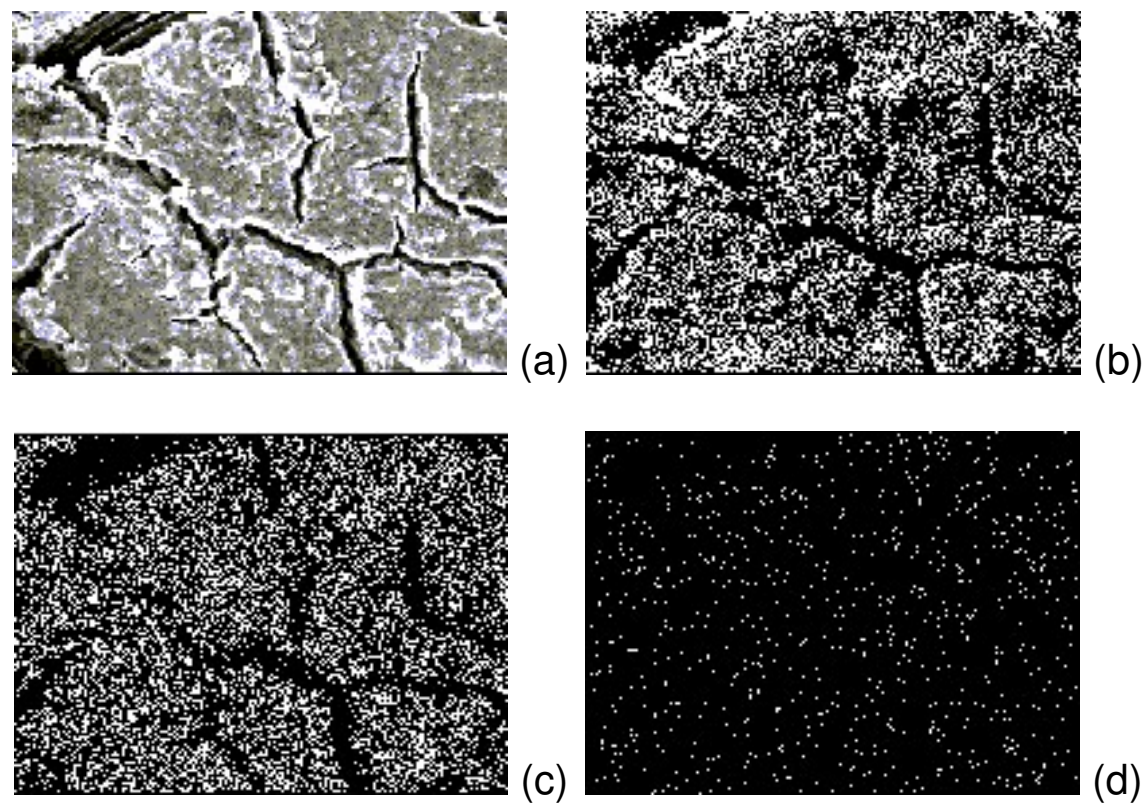

(d)

FIGURA 3.31. Mapeamento elementar do catalisador $\mathrm{Pt}_{75} \mathrm{Co}_{25} / \mathrm{C} \mathrm{MI}$ após a operação na célula unitária: (a) morfologia geral; (b) carbono; (c) platina e (d) cobalto. Resolução 9 kx. 


\subsubsection{Desempenho dos Catalisadores em Meia Célula e Célula a Combustível de Metanol Direto (DMFC)}

3.2.4.1. Voltametria de Varredura Linear para a Redução de Oxigênio na Ausência e Presença de Metanol

As Figuras $3.32(\mathrm{a}-\mathrm{c})$ mostram as curvas de varredura linear da RRO para os catalisadores $\mathrm{Pt}-\mathrm{Co} / \mathrm{C}$ e para o $\mathrm{Pt} / \mathrm{C}$ na presença de várias concentrações de metanol (de 0 a $3 \mathrm{~mol} \mathrm{~L}^{-1} \mathrm{CH}_{3} \mathrm{OH}$ ). Observa-se que todos os materiais mostram um aumento no sobrepotencial para a RRO com o aumento da concentração de metanol no eletrólito. Pode ser observado também na Figura 3.32, que a tolerância ao metanol é maior para o catalisador $\mathrm{Pt}-\mathrm{Co} / \mathrm{C}$ (em ambas as composições atômicas), particularmente em altas concentrações de metanol. Esta maior tolerância com relação à Pt pura pode ser claramente visualizada na Figura 3.33, onde o potencial a $0 \mathrm{~A} \mathrm{~cm}^{-2}\left(\mathrm{E}_{\mathrm{OAcm}-2}\right)$ relacionado à Figura 3.32 é graficado em relação à concentração de metanol. A escolha deste valor de densidade de corrente é arbitrária, sendo similar à tendência para todo valor de densidade de corrente. O decréscimo do potencial com o aumento da concentração de metanol para $\mathrm{Pt} / \mathrm{C}$ é muito maior do que para as ligas bimetálicas, mostrando que os catalisadores $\mathrm{Pt}_{75} \mathrm{Co}_{25} / \mathrm{C}$ (MI) e $\mathrm{Pt}_{85} \mathrm{Co}_{15} / \mathrm{C}(\mathrm{MB})$ são mais tolerantes à presença de metanol do que o $\mathrm{Pt} / \mathrm{C}(\mathrm{E}-\mathrm{TEK})$ em soluções ácidas. 


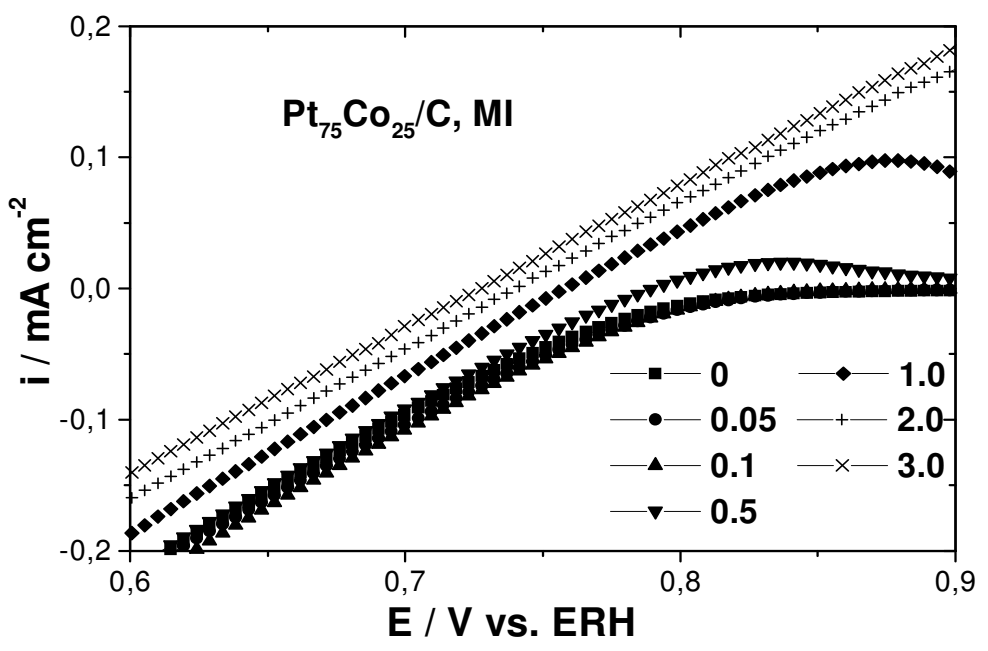

(a)

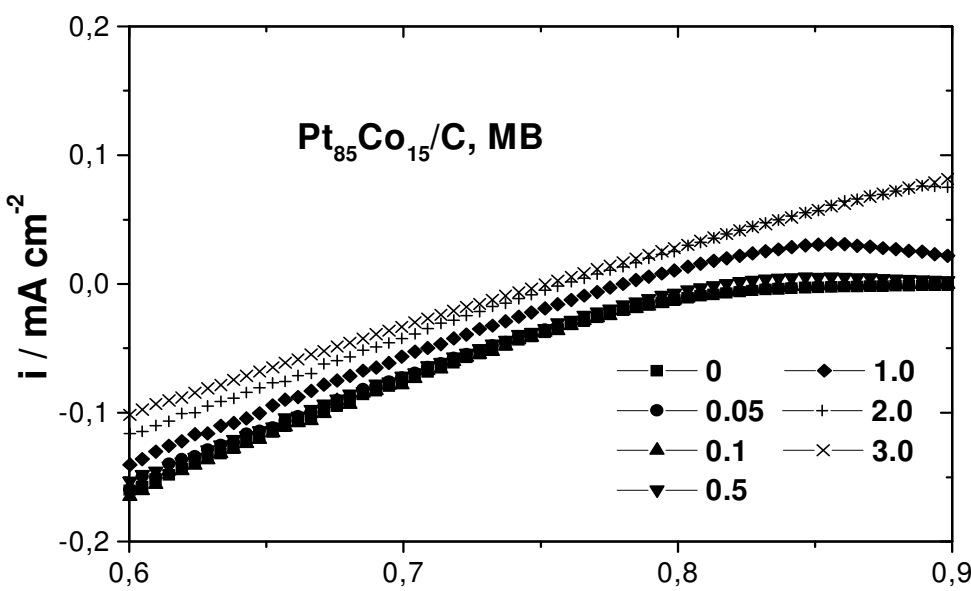

E / V vs. ERH

(b)

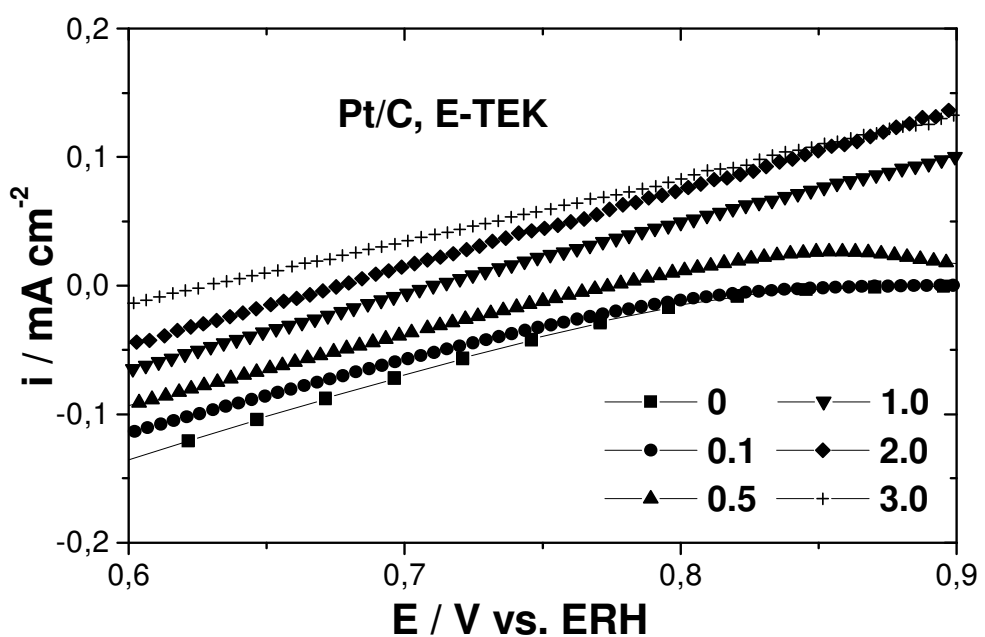

(c)

FIGURA 3.32. Redução de oxigênio em $\mathrm{H}_{2} \mathrm{SO}_{4} \quad 0,5 \mathrm{~mol} \mathrm{~L}^{-1}$ contendo diferentes quantidades de metanol. Catalisadores $\mathrm{Pt}_{75} \mathrm{Co}_{25} / \mathrm{C} \mathrm{MI}$ (a), $\mathrm{Pt}_{85} \mathrm{Co}_{15} / \mathrm{C} \mathrm{MB}$ (b) e Pt/C E-TEK (c). $v=5 \mathrm{mV} \mathrm{s}^{-1}$ e $T=25^{\circ} \mathrm{C}$. 


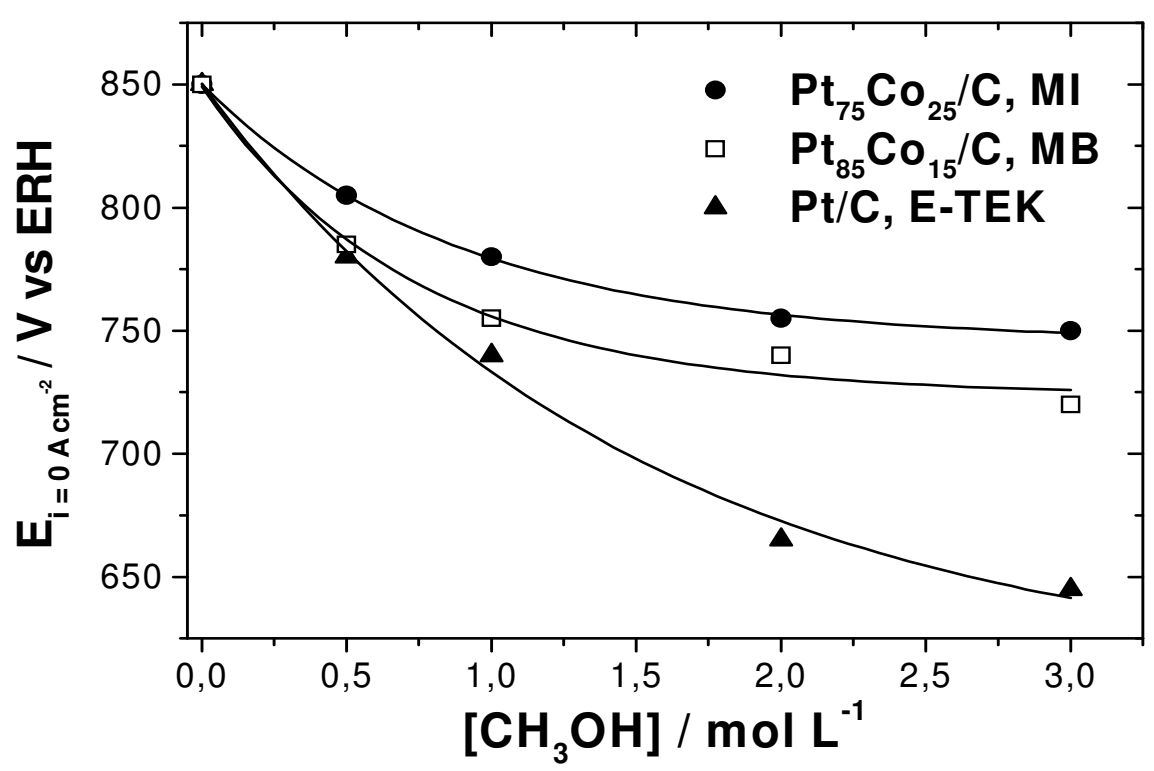

FIGURA 3.33. Dependência do potencial a $0 \mathrm{~A} \mathrm{~cm}^{-2}$ (E $\left.E_{O A c m-2}\right)$ durante a redução de oxigênio em $\mathrm{H}_{2} \mathrm{SO}_{4} 0,5 \mathrm{~mol} \mathrm{~L}^{-1}$ com diferentes concentrações de metanol.

\subsubsection{Voltametria de Varredura Linear para a Oxidação de Metanol em Meia}

\section{Célula}

As curvas de voltametria de varredura linear para a oxidação de metanol sobre os catalisadores $\mathrm{Pt} / \mathrm{C}$ e ligas bimetálicas $\mathrm{Pt}-\mathrm{Co} / \mathrm{C}$ em $\mathrm{H}_{2} \mathrm{SO}_{4} 1 \mathrm{~mol} \mathrm{~L}^{-1} \mathrm{e}$ $\mathrm{CH}_{3} \mathrm{OH} 3 \mathrm{~mol} \mathrm{~L}^{-1}$ saturado com nitrogênio são mostradas na Figura 3.34. O eletrólito contendo metanol foi previamente saturado com nitrogênio para eliminar qualquer contaminação com oxigênio. Observa-se que as densidades de corrente para a reação de oxidação de metanol sobre as ligas $\mathrm{Pt}-\mathrm{Co} / \mathrm{C}$ são muito menores do que àquelas para o catalisador $\mathrm{Pt} / \mathrm{C}$. Os potenciais de início da oxidação de metanol sobre as ligas foram 550 e $620 \mathrm{mV}$ para $\mathrm{Pt}_{85} \mathrm{Co}_{15} / \mathrm{C}$ (MB) e $\mathrm{Pt}_{75} \mathrm{Co}_{25} / \mathrm{C}$ (MI), respectivamente. Isto indica novamente que os catalisadores bimetálicos $\mathrm{Pt}-\mathrm{Co} / \mathrm{C}$ são menos ativos do que o catalisador Pt/C (E-TEK) para a oxidação de metanol. 
Este fato poderia explicar a tolerância ao metanol dos catalisadores $\mathrm{Pt}-\mathrm{Co} / \mathrm{C}$ na reação de redução de oxigênio.

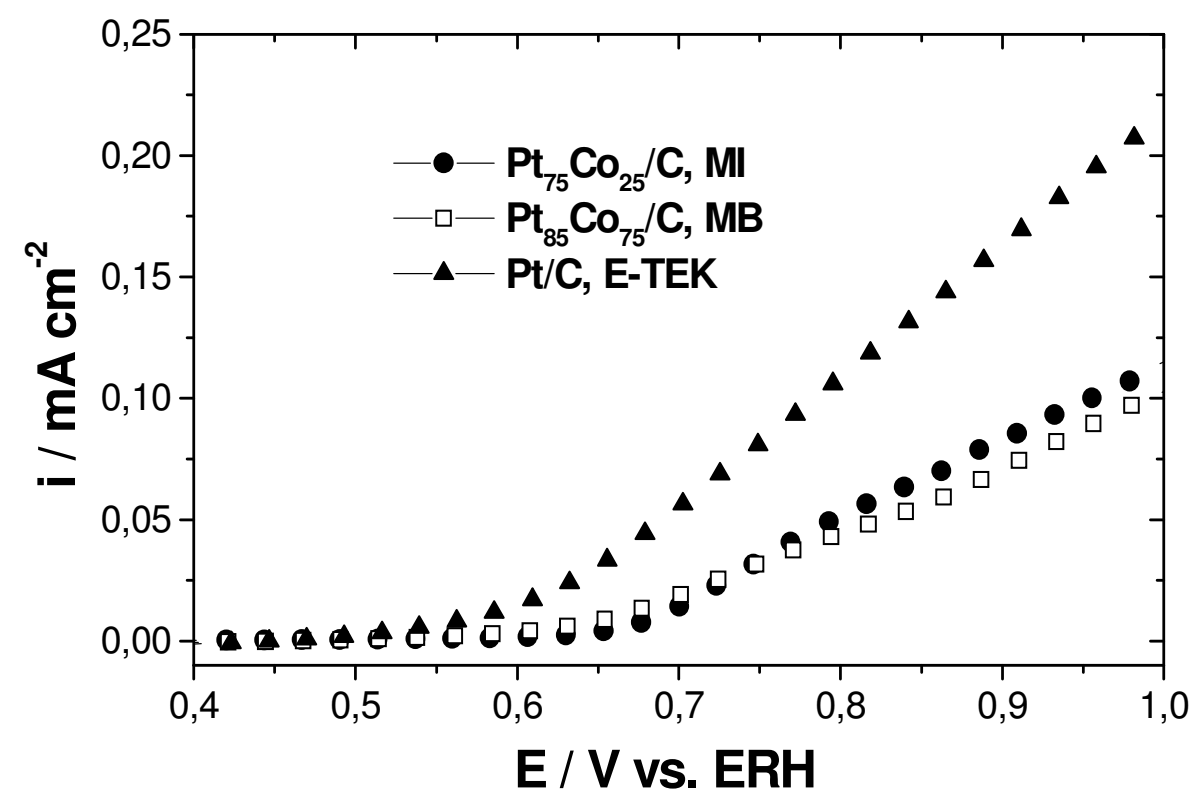

FIGURA 3.34. Curvas de varredura linear para a oxidação de metanol sobre catalisadores em $\mathrm{H}_{2} \mathrm{SO}_{4}$ 0,5 mol L-1 e metanol 3,0 mol L-1. $v=5 \mathrm{mV} \mathrm{s}^{-1}$ e $T=25{ }^{\circ} \mathrm{C}$.

Maillard e col. [126] observaram que catalisadores para a RRO com tamanho de partícula pequenos aumentam a tolerância ao metanol. Neste caso, a maior tolerância observada para Pt-Co/C não pode ser atribuída ao tamanho de partículas, conforme já discutido.

É discutido na literatura que a adsorção de metanol e/ou de oxigênio competem pelos os sítios ativos da superfície dos materiais. Além disso, é estabelecido que para a oxidação de metanol, ao menos três sítios adjacentes no arranjo cristalográfico são necessários para que a adsorção deste álcool ocorra $[39,55,122]$.

Para um catalisador Pt-Co/C, a probabilidade de encontrar três sítios vizinhos de Pt é menor do que para Pt/C, considerando-se que não haja um enriquecimento 
de Pt sobre a superfície. Desta forma, a presença de sítios de Co ao redor da Pt, impediriam a adsorção de metanol. Por outro lado, a adsorção de oxigênio, que pode ser considerada como adsorção química dissociativa e requer somente dois sítios adjacentes, não é influenciada pela presença de átomos de cobalto. De fato, a adsorção de oxigênio, a que pode ser considerada como a adsorção química dissociativa e requer somente dois sítios adjacentes, não é influenciada pela presença de átomos de cobalto.

É interessante notar que ambas as densidades de corrente na Figura 3.34 e a mudança em di/dE na presença de metanol na Figura 3.32 b são menores para catalisadores $\mathrm{Pt}_{85} \mathrm{Co}_{15} / \mathrm{C}(\mathrm{MB})$ que para $\mathrm{Pt}_{75} \mathrm{Co}_{25} / \mathrm{C}(\mathrm{Ml})$. Este resultado sugere que apesar do Co diminuir a probabilidade de encontrar átomos vizinhos à Pt para a adsorção do metanol, o resultado pode ser explicado com base no efeito eletrônico do Co sobre a ocupação da banda $5 d$ da platina. De fato, a forte adsorção de $\mathrm{OH}$ e CO sobre partículas pequenas $(<5 \mathrm{~nm})$ impede a oxidação de metanol, como resultado do aumento significativo das vacâncias na banda 5d da Pt [38]. O decréscimo das vacâncias na banda $5 \mathrm{~d}$ da Pt também ocorre pelo aumento da quantidade de metal não precioso no catalisador [44,45]. Assim, a liga com uma maior quantidade de Co torna-se mais tolerante ao metanol. 


\subsubsection{Curvas de Polarização dos Catalisadores como Cátodos nas Células Unitárias de Metanol Direto}

As curvas de polarização (potencial da célula vs. densidade de corrente) na célula a combustível unitária de metanol direto para Pt/C e Pt-Co/C são mostradas na Figura 3.35.

O melhor desempenho da célula foi obtido com o conjunto contendo o catalisador $\mathrm{Pt}_{75} \mathrm{Co}_{25} / \mathrm{C} \mathrm{Ml}$ (MEA com Nafion ${ }^{\circledR} 117$ ). O desempenho da $\mathrm{Pt}_{85} \mathrm{Co}_{15} / \mathrm{C} \mathrm{MB}$ (inferior à Pt/C, E-TEK) pode ser devido ao uso de membrana mais fina (MEA com Nafion ${ }^{\circledR}$ 115). De fato, de acordo com Heinzel e Barragan [127], o cruzamento de metanol aumenta com o decréscimo da espessura da membrana e como conseqüência o desempenho da célula a baixa densidade de corrente decresce. Com relação à atividade específica (Figura 3.36), observou-se um aumento do desempenho da célula com catalisadores contendo Co se comparados ao Pt/C. Estes resultados indicam que os catalisadores bimetálicos $\mathrm{Pt}-\mathrm{Co} / \mathrm{C}$ apresentam melhores atividades catalíticas para a RRO na presença de metanol com relação ao $\mathrm{Pt} / \mathrm{C}$, corroborando os resultados em meia célula na ausência e presença de metanol.

Levando-se em consideração os resultados para a RRO em célula a combustível alimentada com $\mathrm{H}_{2} / \mathrm{O}_{2}$ (PEMFC) e o desempenho na célula a combustível de metanol direto alimentada com $\mathrm{CH}_{3} \mathrm{OH} / \mathrm{O}_{2}$, os catalisadores Pt-Co/C mostraram desempenho superior ao $\mathrm{Pt} / \mathrm{C}$ devido ao aumento da atividade catalítica da liga bimetálica. Estes resultados também foram confirmados por XANES em análises feitas a $1100 \mathrm{mV}$ (Figura 3.16), que mostram que a forte adsorção de espécies oxigenadas sobre a Pt a altos potenciais, inibe a reação de redução de 
oxigênio. Conforme já discutido, a adsorção de espécies oxigenadas nos sítios de Pt em $\mathrm{Pt}_{85} \mathrm{Co}_{15} / \mathrm{C}(\mathrm{MB})$ é maior que sobre a Pt presente em $\mathrm{Pt}_{75} \mathrm{Co}_{25} / \mathrm{C}(\mathrm{MI})$, o que explicaria a tolerância do Pt-Co ao metanol e a melhor atividade para a reação de redução de oxigênio para este último. 


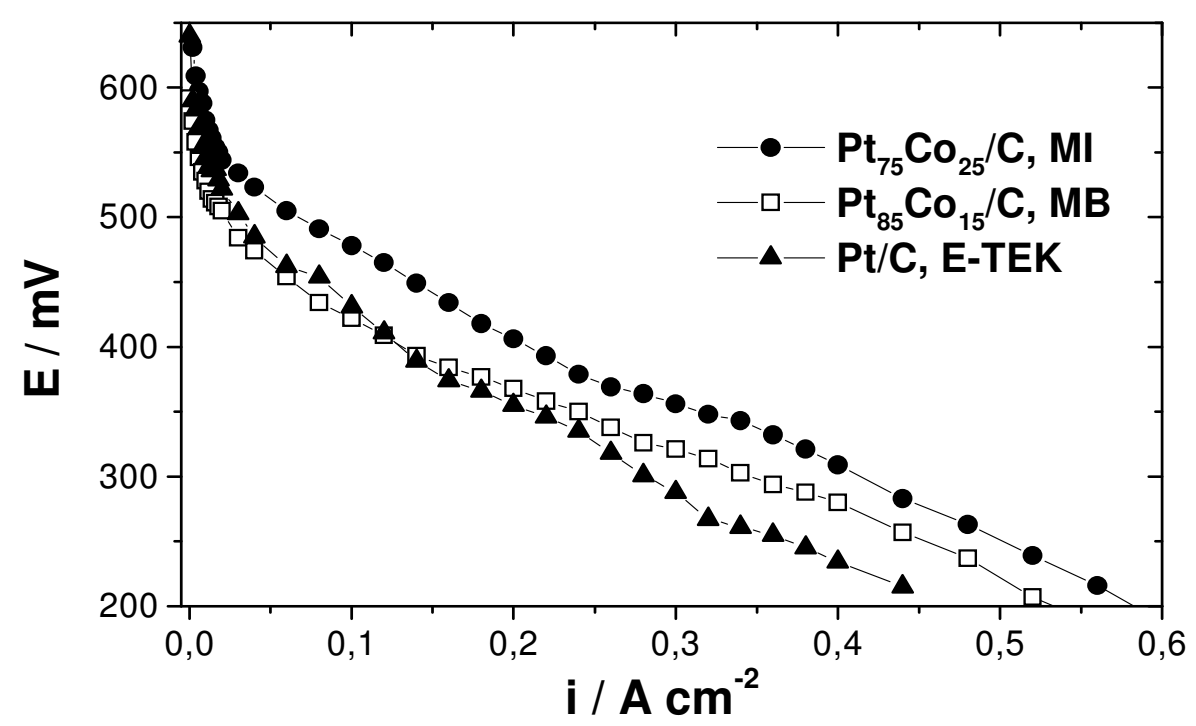

FIGURA 3.35. Curvas de polarização para os catalisadores para a RRO em DMFC. Densidades de corrente normalizadas com relação à área geométrica. Ânodo $P t_{80} R u_{20} / C$. Solução de metanol $2 \mathrm{~mol} \mathrm{~L}^{-1}, T_{\text {célula }}=T_{O 2}=90{ }^{\circ} \mathrm{C}, P_{O 2}=3 \mathrm{~atm}$.

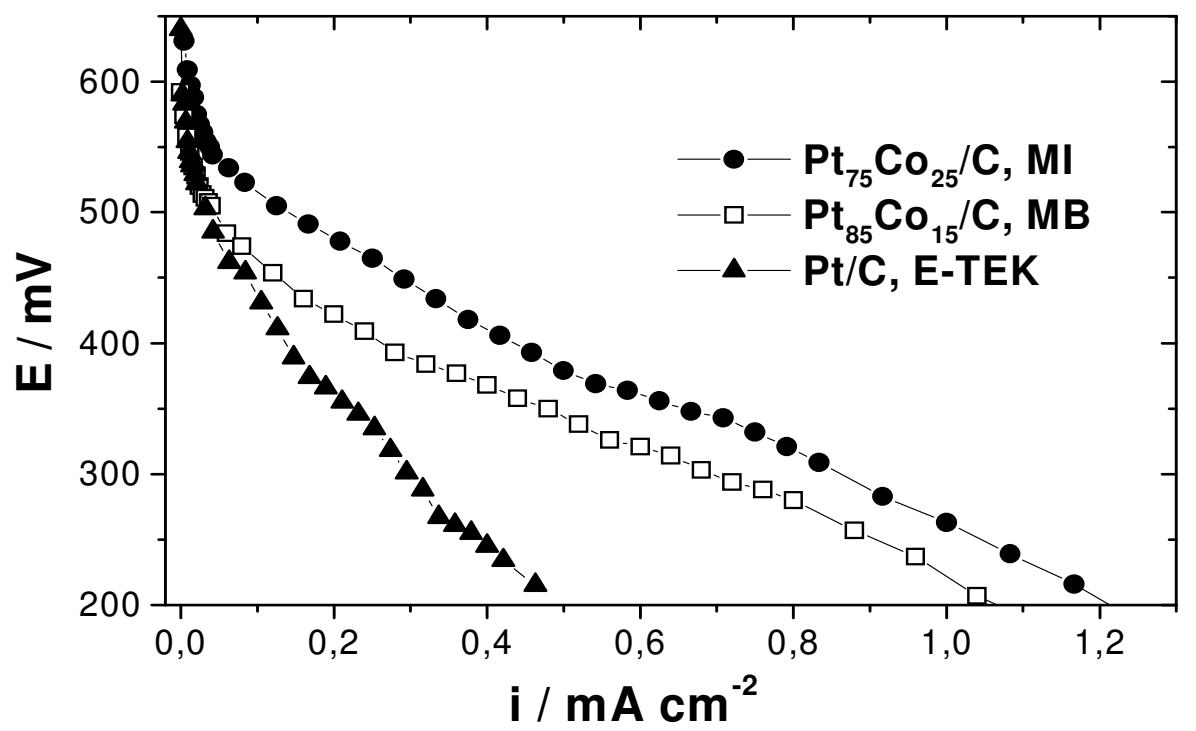

FIGURA 3.36. Curvas de polarização para os catalisadores para a RRO em DMFC. Densidades de corrente normalizadas com relação à área superficial específica da Pt. Ânodo Pt $t_{80} R u_{20} / C$. Solução de metanol $2 \mathrm{~mol} \mathrm{~L}^{-1}, T_{\text {célula }}=T_{O 2}=90{ }^{\circ} \mathrm{C}, P_{\mathrm{O} 2}=3 \mathrm{~atm}$. 


\section{CAPÍTULO IV}

\section{CONCLUSÕES}

Após os estudos com os catalisadores de $\mathrm{Pt}-\mathrm{Co} / \mathrm{C}$, preparados por diferentes métodos, para a reação de redução de oxigênio (RRO) podem ser destacadas as seguintes conclusões:

(i) os catalisadores de $\mathrm{Pt}-\mathrm{Co} / \mathrm{C}$ apresentaram maior atividade catalítica para a RRO comparada à do $\mathrm{Pt} / \mathrm{C}$;

(ii) Dentre os métodos de preparação de catalisadores de Pt-Co/C estudados, o método de impregnação, deposição do Co sobre o Pt/C seguida pela exposição à alta temperatura, foi o método que apresentou melhor resultado. A baixa adsorção de espécies oxigenadas sobre a superfície da Pt presente no catalisador $\mathrm{Pt}_{75} \mathrm{Co}_{25} / \mathrm{C}$ (melhor composição) comparada ao $\mathrm{Pt} / \mathrm{C}$ mostrou que o material possui boa atividade catalítica para a RRO em células a combustível. Outros fatores positivos apresentados por este material são a provável formação de liga, o menor tamanho de partícula e menor distância interatômica Pt-Pt (características requeridas para o ganho da atividade), além de apresentar boa estabilidade; 
(iii) $\mathrm{O}$ desempenho eletroquímico do catalisador $\mathrm{Pt}_{70} \mathrm{Co}_{30} / \mathrm{C}$ (obtido através do MAF) foi inferior ao do Pt/C devido ao aumento excessivo do tamanho de partícula; os resultados de EDX mostraram que este material não foi reduzido pela simples adição de ácido fórmico, pois o agente redutor não é forte o suficiente para promover a formação de $\mathrm{Pt}-\mathrm{Co} / \mathrm{C}$. Entretanto, depois do tratamento térmico a $900{ }^{\circ} \mathrm{C}$ (em atmosfera de $\mathrm{H}_{2} / \mathrm{Ar}$ ) houve a formação da liga $\mathrm{Pt}_{70} \mathrm{Co}_{30} / \mathrm{C}$, sendo o desempenho eletroquímico para a RRO próximo ao do $\mathrm{Pt} / \mathrm{C}$, apesar do tamanho da partícula aumentar cerca de cinco vezes;

(iv) o catalisador $\mathrm{Pt}_{85} \mathrm{Co}_{15} / \mathrm{C}$ preparado através do método do borohidreto (MB) apresentou boa atividade catalítica e bom desempenho para a RRO. Com relação à área geométrica, a atividade catalítica do Pt-Co/C MB foi melhor do que a do Pt/C, mas foi pior do que a do material $\mathrm{Pt}_{50} \mathrm{Co}_{50} / \mathrm{C}$ E-TEK, devido ao menor tamanho de partícula. Por outro lado, considerando a área específica, a atividade catalítica do Pt$\mathrm{Co} / \mathrm{C} \mathrm{MB}$ foi superior a do material comercial Pt-Co/C.

(v) o catalisador Pt-Co/C mostrou boa tolerância ao metanol quando usado no cátodo, aumentando a atividade frente à $\mathrm{RRO}$ em comparação ao $\mathrm{Pt} / \mathrm{C}$, tanto em ácido sulfúrico como na presença de metanol ou na célula a combustível direta de metanol; uma fração atômica em torno de 15 \% de cobalto mostra-se suficiente para aumentar a tolerância ao metanol deste material devido à baixa atividade para a oxidação do álcool. 


\section{CAPÍTULO V}

\section{REFERÊNCIAS BIBLIOGRÁFICAS}

[1]. Vielstich, W.; Lamm, A.; Gasteiger, H.A. Handbook of Fuel Cells: Fundamentals, Technology and Applications. v.1,2,3,4, New York, 2003.

[2]. Kordesch, K.; Simader, G. Fuel Cells and Their Applications. Weinheim, VCH, 1996.

[3]. Ticianelli, E.A.; Gonzalez, E.R. Células a combustível: uma alternativa promissora para a geração de eletricidade. Quim. Nova, v.12, p.268-272, 1989.

[4]. Wendt, H.; Gotz, M.; Linardi, M. Tecnologia de células a combustível. Quim. Nova, v.23, p.538-546, 2000.

[5]. Thomas, C.E.; James, B.D.; Lomax Jr., F.D.; Kuhn Jr., I.F. Fuel options for the fuel cell vehicle: hydrogen, methanol or gasoline? Int. J. Hydrogen Energy, v.25, p.551-567, 2000.

[6]. Rifkin, J. A Economia do Hidrogênio. Editora M. Books, 2003.

[7]. Lamy, C.; Lima, A.; Lerhun, V.; Delime, F.; Coutanceau, C.; Léger, J.-M., Recent advances in the development of direct alcohol fuel cells (DAFC). J. Power Sources, v.105, p.283-296, 2002

[8]. Waszczuk, P.; Wieckowski, A.; Zelenay, P.; Gottesfeld, S.; Coutanceau, C.; Léger, J.-M.; Lamy, C. J. Electroanal. Chem., v.511, p.55-64, 2001.

[9]. Delime, F.; Léger, J-M.; Lamy, C.; Enhancement of the electrooxidation of ethanol on a Pt-PEM electrode modified by tin. Part I: Half cell study. J. Appl. Electrochem., v.29, p.1249-1254, 1999. 
[10]. Aricó, A.S.; Poltarzewski, Z.; Kim, H.; Morana, A.; Giordano, N.; Antonucci, V. Investigation of a carbon-supported quaternary Pt-Ru-Sn-W catalysts for methanol oxidation. J. Power Sources, v.55, p.159-166, 1995.

[11]. Zhou, W.; Zhou, Z.; Song, S.; LI, W.; SUN, G.; TSIAKARAS, P.; XIN, Q. Pt based anode catalysts for direct ethanol fuel cells. Appl. Catal. B, v.46, p.273-285, 2003.

[12]. HAMANN, C.H.; HAMNETT, A.; VIELSTICH, W. Electrochemistry. Wiley-VCH, 1998.

[13]. Ticianelli, E.A.; Gonzalez, E.R. Eletroquímica: Princípios e Aplicações. Edusp, 1998.

[14]. kinohita, k. Electrochemical Oxygen Technology. John Wiley \& Sons, INC, 1992.

[15]. Wasmus, S.; Küver, A. Methanol oxidation and direct methanol fuel cells: a selective review. J. Electroanal. Chem., v.461, p.14-31, 1999.

[16]. Heinzel, A.; Barragan, V.M. A review of the state-of-the-art of the methanol crossover in direct methanol fuel cells J. Power Sources, v.84, p.70-74, 1999.

[17]. LAMY, C.; LÉGER, J.-M.; SRINIVASAN, S. Direct Metanol Fuel Cells: From a Twentieth Century Electrochemist's Dream to a Twenty-first Century Emerging Technology. v.3, p.53-118, 2001.

[18] Gurau, B.; Smotkin, E.S. Methanol crossover in direct methanol fuel cells: a link between power and energy density. J. Power Sources, v.112, p.339-352, 2002.

[19] Urban, P.M.; Funke, A.; Muller, J.T.; Himmen, M.; Docter, A. Catalytic processes in solid polymer electrolyte fuel cell systems. Appl. Catal. A: General, v.221, p.459470, 2001.

[20] Ramya, K.; Dhathathreyan, K.S. Direct methanol fuel cells: determination of fuel crossover in a polymer electrolyte membrane. J. Electroanal. Chem., v.542, p.109115, 2003. 
[21] Cruickshank, J.; Scott, K.; The degree and effect of methanol crossover in the direct methanol fuel cell. J. Power Sources, v.70, p.40-47, 1998.

[22]. Waszczuk, P.; Wieckowski, A.; Zelenay, P.; Gottesfeld, S.; Coutanceau, C.; LÉGER, J.-M.; LAMY, C. Adsorption of CO poison on fuel cell nanoparticle electrodes from methanol solutions: a radioactive labeling study. J. Electroanal. Chem., v.511, p.55-64, 2001.

[23]. HAN, J.; KIM, I.S.; CHOI, K.S. Purifier-integrated methanol reformer for fuel cell vehicles. J. Power Sources, v.86, p.223-227, 2000.

[24]. ZHOU, W.J.; LI, W.Z.; SONG, S.Q.; ZHOU, Z.H.; JIANG, L.H.; SUN, G.Q.; XIN, Q.; Poulianitis, K.; Kontou, S.; Tsiakaras, P. Bi- and tri-metallic Pt-based anode catalysts for direct ethanol fuel cells. J. Power Sources, v.131, p.217-223, 2004.

[25]. Gojkovi, S.L.; Vidakovi, T. R. Methanol oxidation on an ink type electrode using Pt supported on high area carbons. Electrochim. Acta, v.47, p.633-642, 2001.

[26]. Lizcano-Valbuena, W.H.; Paganin, V.A.; Gonzalez, E.R.; Methanol electrooxidation on gas diffusion electrodes prepared with $\mathrm{Pt}-\mathrm{Ru} / \mathrm{C}$ catalysts. Electrochim. Acta, v.47, p.3715-3722, 2002.

[27]. Watanabe, M.; Uchida, M.; Motoo, S. Preparation of highly dispersed Pt+Ru alloy clusters and the activity for the electrooxidation of methanol. J. Electroanal. Chem., v.229, p.395-406, 1987.

[28]. Waszczuk, P.; LU, G.Q.; Wieckowski, A.; LU, C.; RISE, C.; Masel, R. I. UHV and electrochemical studies of $\mathrm{CO}$ and methanol adsorbed at platinum/ruthenium surfaces and reference to fuel cell catalysis. Electrochim. Acta, v.47, p.3637-3652, 2002.

[29]. Goikovic, S.L.; Vidakovic, T.R.; Durovic, D.R. Kinetic study of methanol oxidation on carbon-supported Pt-Ru electrocatalyst. Electrochim. Acta, v.48, p.36073614, 2003.

[30]. Iwasita, T. Electrocatalysis of methanol oxidation. Electrochim. Acta, v.47, p.3663-3674, 2002. 
[31]. RALPH, T.R.; HOGARTH, M.P. Catalysis for Low Temperature Fuel Cells. Platinum Metals Rev., v.46, p.3-14, 2002.

[32]. Schubert, B.; Tributsch, H.; Alonso-Vante, N.; Perrin, A.; Influence of d-state density and chemistry of transition metal cluster selenides on electrocatalysis. J. Catal., v.112, p.384-391, 1988.

[33]. Gouérec, P.; Savy, M. Oxigen reduction electrocatalysis: ageing of pyrolyzed cobalt macrocycles dispersed on an active carbon. Electrochim. Acta, v.44, p.26532661, 1999.

[34] ALONSO-VANTE, N.; TRIBUSCH, H. Nature, v.323, p.431, 1996.

[35]. SCHMIDT, T.J.; PAULUS, U.A.; GASTEIGER, H.A.; VANTE-ALONSO, N.; BEHM, R.J. Oxigen reduction on $\mathrm{Ru}_{1.92} \mathrm{Mo}_{0.08} \mathrm{SeO}_{4}, \mathrm{Ru} /$ carbon, and $\mathrm{Pt} /$ carbon in pure and methanol-containing electrolytes. J. Electochem. Soc., v.147, p.2620-2624, 2000.

[36]. JIANG, R.J.; CHU, D. Remarkably Active Catalysts for the Electroreduction of $\mathrm{O}_{2}$ to $\mathrm{H}_{2} \mathrm{O}$ for Use in an Acidic Electrolyte Containing Concentrated Methanol. J. Electrochem. Soc., v.147, p.4605-4609, 2000.

[37]. CONVERT, P.; COUTANCEAU, C.; CROUIGNEAU, P.; GLOAGUEN, F.; LAMY, C. Electrodes modified by electrodeposition of CoTAA complexes as selective oxygen cathodes in a direct methanol fuel cell. J. Appl. Electrochem., v.31, p.945952, 2001.

[38]. Faubert, G.; Côté, R.; DODELET, J.P.; LEFEVRE, M.; BERTRAND, P. Oxigen reduction catalysts for polymer electrolyte fuel cell from the pyrolysis of $\mathrm{Fe}(\mathrm{II})$ acetate adsorbed on 3, 4, 9, 10-perylenetetracarboxylic dianhydride. Electrochim. Acta, v.44, p.2589-2603, 1999.

[39]. JALAN, V.; TAYLOR, E.J. Importance of interatomic spacing in catalytic reduction of oxygen in phosphoric acid. J. Electrochem. Soc., v.130, p.2299-2301, 1983. 
[40]. Mukerjee S; Srinivasan S. Enhanced electrocatalysis of oxygen reduction on platinum alloys in proton exchange membrane fuel cells. J. Electroanal. Chem., v.357, p.201-224, 1993.

[41]. Paffett, M. T; Berry, G. J; Gottesfeld, S. Oxygen reduction at $\mathrm{Pt}_{0.65} \mathrm{Cr}_{0.35}$, $\mathrm{Pt}_{0.2} \mathrm{Cr}_{0.8}$ and roughened platinum. J. Electrochem. Soc., v.135, p.1431-36, 1988.

[42]. Watanabe, M; Tsurumi, K; Mizukami, T; Nakamura, T; Stonehart, P. Activity and stability of ordered and disordered Co-Pt alloys for phosphoric acid fuel cells. J. Electrochem. Soc., v.141, p.2659-68, 1994.

[43]. Beard, B.C.; ROSS, P.N. Characterization of a titanium-promoted supported platinum electrocatalyst. J. Electrochem. Soc., v.133, p.1839-45, 1986.

[44]. Min, M; CHO, J; CHO, K, KIM, H. Particle size and alloying effects of Pt-based alloy catalysts for fuel cell applications. Electrochim. Acta, v.45, p.4211-17, 2000.

[45]. Cambanis, G.; Chadwick, D. Platinum-vanadium carbon supported catalysts for fuel cell applications. Appl. Catal., v.25, p.191-198, 1986.

[46]. Mukerjee, S.; Srinivasan, S.; Soriaga, M.P.; MCBREEN, J. Effect of preparation conditions of $\mathrm{Pt}$ alloys on their electronic, structural, and electrocatalytic activities for oxygen reduction - XRD, XAS, and electrochemical studies. J. Phys. Chem., v.99, p.4577-89, 1995.

[47] MUKERJEE, S.; SRINIVASAN, S.; SORIAGA, M.P.; MCBREEN, J. Role of structural and electronic properties of $\mathrm{Pt}$ and $\mathrm{Pt}$ alloys on electrocatalysis of oxygen reduction - An in-situ XANES and EXAFS investigation. J. Electrochem. Soc., v.142, p.1409-22, 1995.

[48]. PAULUS, U.A.; SCHERER, G.G.; WOKAUN, A.; SCHMIDT, T.J.; STAMENKOVIC, V.; RADMILOVIC, V.; MARKOVIC, N.M.; ROSS, P.N. Oxygen reduction on carbon-supported Pt-Ni and Pt-Co alloy catalysts. J Phys. Chem. B, v.106, p.4181-91, 2002. 
[49]. Antolini, E; Passos, R.R.; Ticianelli, E.A. Electrocatalysis of oxygen reduction on a carbon supported platinum-vanadium alloy in polymer electrolyte fuel cells. Electrochim. Acta, v.48, p.263-70, 2002.

[50]. Tamizhmani, G.; Capuano, G.A. Improved Electrocatalytic Oxygen Reduction Performance of Platinum Ternary Alloy-Oxide in Solid-Polymer-Electrolyte Fuel Cells. J. Electrochem. Soc., v.141, p.968-974, 1994.

[51]. Gottesfeld, S.; Paffett, M.T.; REDONDO, A. The ellipsometric characterization of $\mathrm{Pt}+\mathrm{Cr}$ alloy surfaces in acid solutions. J. Electroanal. Chem.,v.205, p.163-184, 1986.

[52]. Paffett, M.T.; DAUBE, K.A.; Gottesfeld, S.; CAMPELL, C.T. Electrochemical and surface science investigations of Pt-Cr alloy electrodes. J. Electroanal. Chem., v.220, p.269-285, 1987.

[53]. BEARD, B.C.; ROSS, P.N. The structure and activity of Pt-Co alloys as oxygen reduction electrocatalysts. J. Electrochem. Soc., v.137, p.3368-74, 1990.

[54]. KIM, K.T.; HWANG, J.T.; KIM, Y.G.; CHUNG, J.S. Surface and Catalytic Properties of Iron-Platinum/Carbon Electrocatalysts for Cathodic Oxygen Reduction in PAFC. J. Electrochem. Soc., v.140, p.31-36, 1993.

[55]. TamizhMani, G.; Dodelet, J.P.; Guay, D.; Dignard-Bailey, L. A rapid half-cell technique for the pre-screening of polymer fuel cell catalysts. J. Electroanal. Chem., v. 444, p.121-125, 1998.

[56]. TODA, T.; IGARASHI, H.; WATANABE, M. Enhancement of the electrocatalytic $\mathrm{O}_{2}$ reduction on Pt-Fe alloys. J. Electroanal. Chem., v.460, p.258-262, 1999.

[57]. TODA, T.; IGARASHI, H.; UCHIDA, H.; WATANABE, M. Enhacement of the electroredution of oxigen on Pt alloys with $\mathrm{Fe}, \mathrm{Ni}$ and Co. J. Electochem. Soc., v.146, p.3750-3756, 1999.

[58]. Glass, J.T.; CAHEN, G.L.; STONER, G.E. The Effect of Metallurgical Variables on the Electrocatalytic Properties of Pt-Cr Alloys. J. Electrochem. Soc., v.134, p.5865, 1987. 
[59]. Appleby, A.J. Phosphoric acid fuel cells. Energy, v.11, p.13-94, 1986.

[60]. Kim, T.; Takahashi, M.; Nagai, M.; Kobayashi, K. Preparation and characterization of carbon supported Pt and Pt-Ru alloy catalysts reduced by alcohol for polymer electrolyte fuel cell. Electrochim. Acta, v.50, p.813-817, 2004.

[61]. Ould Ely, T.; PAN, C.; AMIENS, C.; CHAUDRET, B.; DASSENOY, F.; LECANTE, P.; CASANOVE, M.J.; MOSSET, A.; RESPAUND, M.; BROTO, J.M. Nanoscale Bimetallic $\mathrm{Co}_{x} \mathrm{Pt}_{1-x}$ Particles Dispersed in Poly(vinylpyrrolidone): Synthesis from Organometallic Precursors and Characterization. J. Phys. Chem. B, v.104, p.695-702, 2000.

[62]. ANTOLINI, E. Formation of carbon-supported PtM alloys for low temperature fuel cells: a review. Mater. Chem. Phys., v.78, p.563-573, 2003.

[63]. SHUKLA, A.K.; NEEGART, M.; PARTHASARA, B.; JAYARAM, V.; HEGDE, M.S. An XPS study on binary and ternary alloys of transition metals with platinized carbon and bearing upon oxygen electroreduction in direct methanol fuel cell. J. Electroanal. Chem., v.504, p.111-119, 2001.

[64]. PARK, K.W.; CHOI, J.H.; KWON, B.K.; LEE, S.A.; SUNG, Y.E.; HONG, S.A.; KIM, H.S.; WIECKOWSKI, A. Chemical and Electronic Effects of $\mathrm{Ni}$ in $\mathrm{Pt} / \mathrm{Ni}$ and $\mathrm{Pt} / \mathrm{Ru} / \mathrm{Ni}$ Alloy Nanoparticles in Methanol Electrooxidation. J. Phys. Chem. B, v.106, p.1869-77, 2002.

[65]. XIONG, L.; KANNAN, A.M.; MANTHIRAM, A. Pt-M (M= Fe, Co, Ni and Cu) electrocatalysts synthesized by an aqueous route for proton exchange membrane fuel cells. Electrochem. Commun., v.4, p.898-903, 2002.

[66]. bregoli, L. The influence of platinum crystallite size on the electrochemical reduction of oxygen in phosphoric acid. Electrochim. Acta, v.23, p.489-492, 1978.

[67]. bett, J.; LUNDQUIST, J.; WASHINGTON, E.; STONEHART, P.; Platinum crystallite size considerations for electrocatalytic oxygen reduction-I Electrochim. Acta, v.18, p.343-348, 1973. 
[68]. WATANABE, M.; SEI, H.; STONEHART, A. The influence of platinum crystallite size on the electroreduction of oxigen. J. Electroanal. Chem., v.261, p.375-387, 1989.

[69]. KINOSHITA, K. Particle size effects for oxygen reduction on highly dispersed platinum in acid electrolyte. J. Electrochem. Soc., v.137, p.845-48, 1990.

[70]. YOSHITAKE, H; IWASAWA, Y. Electronic metal support interaction in $\mathrm{Pt}$ catalysts under deuterium ethene reaction conditions and the microscopic nature of the active sites. J. Phys. Chem., v.96, p.1329-34, 1992.

[71]. Erron, M.E.; DOYLE, S.E.; PIZZINI, S.; ROBERTS, K.J.; ROBINSON, J.; HARDS, G.; WALSH, F.C. In-situ studies of a dispersed platinum on carbon electrode using X-ray adsorption spectroscopy. J. Electroanal. Chem., v.324, p.24358, 1992.

[72]. Stonehart P. Surface interactions affecting quasi-equilibrium adsorption. Electrochim. Acta, v.15, p.1853-58, 1970.

[73]. Drillet, J.F.; Ee, A.; Friedemann, J.; Kötz, R.; Schnyder, B.; SCHMIDT, V.M. Oxigen reduction at $\mathrm{Pt}$ and $\mathrm{Pt}_{70} \mathrm{Ni}_{30}$ in $\mathrm{H}_{2} \mathrm{SO}_{4} / \mathrm{CH}_{3}$ solution. Electrochim. Acta, v.47, p.1983-1988, 2002.

[74]. YANG, H.; ALONSO-VANTE, N.; Leger, J.-M.; Lamy, C. Tailoring, Structure, and Activity of Carbon-Supported Nanosized Pt-Cr Alloy Electrocatalysts for Oxygen Reduction in Pure and Methanol-Containing Electrolytes. J. Phys. Chem. B, v.108, p.1938-1947, 2004.

[75]. SHUKLA, A.K.; RAMAN, R.K.; CHOUDHURY, N.A.; Priolkar, K.R.; SARODE, P.R.; EMURA, S.; KUMASHIRO, R. Carbon-supported Pt-Fe alloy as a methanolresistant oxygen-reduction catalyst for direct methanol fuel cells. J. Electroanal. Chem., v.563, p.181-90, 2004. 
[76]. NEERGAT, M.; SHUKLA, A.K.; GANDHI, K.S. Platinum-based alloys as oxigenreduction catalysts for solid-polymer-electrolyte direct methanol fuel cell. J. Appl. Electrochem., v.31, p.373-378, 2001.

[77]. Perez, J.; Gonzalez, E.R.; Ticianelli, E.A. Oxigen electrocatalysis on thin porous coating rotating platinum electrodes. Electrochim. Acta, v.44, p.1329-1339, 1998.

[78]. PAGANIN, V.A.; TICIANELLI, E.A.; GONZALEZ, E.R.; Development and electrochemical studies of gas diffusion electrodes for polymer electrolyte fuel cells. J. Appl. Electrochem., v.26, p.297-304, 1996.

[79]. TICIANELLI, E.A. Eletrodos de difusão de gás. Livre-Docência, Instituto de Química de São Carlos/Universidade de São Paulo, 1992.

[80]. Yeager, E.B. Electrocatalysts for $\mathrm{O}_{2}$ reduction. Electrochim. Acta, v.29, p.152734, 1984.

[81]. Yeager, E.B. Recents advances in the science of electrocatalysts, J. Electrochem. Soc., v.128, p.160-171, 1981.

[82]. Gonzalez E.R.; Ticianelli, E.A.; Pinheiro, A.L.N.; Perez, J.; Processo de obtenção de catalisadores de platina dispersa através da redução com ácido fórmico. /Patente Brasileira, INPI-SP n00321, 1997.

[83]. CARMO, M.; PAGANIN, V.A.; ROSSOLEN, J.M.; GONZALEZ, E.R. Alternative supports for the preparation of catalysts for low-temperature fuel cells: the use of carbon nanotubes. J. Power Sources, in press, 2004.

[84]. LU, J.; DREISINGER, D.B.; COOPER, W.C.; Cobalt precipitation by reduction with sodium borohydride. Hydrometallurgy, v.45, p.305-322, 1997.

[85]. SALGADO, J.R.C.; GONZALEZ, E.R. Correlação entre a atividade catalítica e o tamanho de partículas de Pt/C preparados por diferentes métodos, Ecl. Quim., v.28, p.77-86, 2003.

[86]. COLMATI JUNIOR F.; LIZCANO-VALBUENA, W.H.; CAMARA, G.A.; TICIANELLI, E.A.; GONZALEZ, E.R. Carbon monoxide oxidation on Pt-Ru 
electrocatalysts supported on high surface area carbon. J. Braz. Chem. Soc. v.13, p.474-482, 2002.

[87]. NETO, A.O.; LINARDI, M.; GONZALEZ, E.R. Oxidação eletroquímica do metanol sobre partículas de Pt-Ru e Pt-Mo suportadas em carbono de alta área superficial. Ecl. Qui., v.28, p.55-62, 2003.

[88]. NETO, A.O.; GIZ, M.J.; PEREZ, J.; TICIANELLI, E.A.; GONZALEZ, E.R. The Electro-oxidation of Ethanol on Pt-Ru and Pt-Mo Particles Supported on HighSurface-Area Carbon. J. Electrochem. Soc., v.149, p.A272-A279, 2002.

[89]. Rietveld, H.M. A profile refinement method for nuclear and magnetic structures. J. Appl. Crystallogr., v.2, p.65-\& Part 2, 1969.

[90] WARREN, B.E. X-ray diffraction, Reading, MA: Addison-Wesley, 1969.

[91]. Mascarenhas, Y.P.; Pinheiro, J.M.V. Programa para Cálculo de Parâmetro de Rede pelo Método de Mínimos Quadrados, SBPC, 1985.

[92]. Larson, A.C.; Robert, V.D. GSAS-General Structure Analysis System, Los Alamos National Laboratory, 2001.

[93]. Ressler, T. WinXAS: A new software package not only for the analysis of energy-dispersive XAS data. J. Physique IV, v.7, p.269-270, 1997.

[94]. TEO, B.K. EXAFS: Basic Principles and Data Analysis. Ed. Bell Telephone Laboratories, incorporated, 1986.

[95] Tolentino, H; CEZAR, J.C.; CRUZ, D.Z.; Compagnon-Caillol, V.; Tamura, E.; Alves, M.C. Commissioning and first results of the LNLS XAFS beamline. J. Synch. Rad.; v.5, p.521-23, 1998.

[96]. Simionato, M.; Assaf, E. M. Preparation and Characterization of AluminaSupported Co and Ag/Co Catalysts. Mater. Res., v.6, p.535-539, 2003.

[97]. Paganin, V.A. Desenvolvimento e caracterização de eletrodos de difusão de gás para células a combustível contendo Nafion como eletrólito. São Carlos, 1997. 
120p. Tese (Doutorado) - Instituto de Química de São Carlos/ Universidade de São Paulo.

[98]. TICIANELLI, E.A.; BEERY, J.G.; SRINIVASAN, S. Dependence of performance of solid polymer electrolyte fuel cells with low platinum loading on morphologic characteristics of the electrodes. J. Appl. Electrochem., v.21, p.597-605, 1991.

[99]. Essalik, A.; Amouzegar, K.; Savadogo, O. Quantitative determination of dispersed platinum in carbon by cyclic voltammetry. J. Appl. Electrochem., v.25, p.404-407, 1995.

[100]. Lizcano-Valbuena, W.H.; AZEVEDO, D.C.; GONZALEZ, E.R. Supported metal nanoparticles as electrocatalysts for low-temperature fuel cells. Electrochim. Acta, v.49, p.1289-1295, 2004.

[101]. Ficha catalográfica, 04-0802, Joint Committee on Powder Diffraction Standards - International Centre for Diffraction Data, 1601, JCPDS -ICDD, 4-802, Park Lane, Swarthmore, Pa. 19081.

[102]. Endo, K.; Nakamura, K.; Katayama, Y.; Miura, T.; Pt-Me $(\mathrm{Me}=\mathrm{Ir}, \mathrm{Ru}, \mathrm{Ni})$ binary alloys as an ammonia oxidation anode. Electrochim. Acta, v.49, p.2503-2509, 2004.

[103]. Luna, A.M.C.; CAMARA, G.A.; PAGANIN, V.A.; TICIANELLI, E.A. Effect of thermal treatment on the performance of $\mathrm{CO}$-tolerant anodes anodes for polymer electrolyte fuel cells. Electrochem. Commun., v.2, p.222-225, 2000.

[104]. HILL, J.R.; MADSEN, C.I. Data Collection Strategies for Constant Wavelength Rietveld Analysis. Powder Diffraction, .v.2, p.146-163,1987.

[105]. HALL, M.M. The Approximation of Symmetric X ray Peaks by Pearson type VII distributions. J. Appl. Crystalogr., v.10, p.66-68,1977.

[106]. Radmilovic, V.; GASTEIGER, H.A.; ROSS, P.N. Structure and chemical composition of a supported Pt-Ru electrocatalyst for methanol oxidation. J. Catal., v.154, p.98-106, 1995. 
[107]. Sattler, M.L.; ROSS, P.N. Ultramicroscopy, v.20, p.21, 1986.

[108]. McBREEN, J.; MUKERJEE, S. In situ X-ray absorption studies of a Pt-Ru electrocatalyts, J. Electrochem. Soc., v.142, p.3399-3404, 1995.

[109]. Mukerjee, S; McBreen, J. Effect of particle size on the electrocatalysis by carbon-supported electrocatalysts: an in-situ XAS investigation. J. Electroanal. Chem., v.448, p.163-171, 1998.

[110]. SHUKLA, A.K.; RAMAN, R.K.; CHOUDHURY, N.A.; PRIOLKAR, K.R.; SARODE, P.R.; EMURA, S.; KUMASHIRO, R. Carbon-supported Pt-Fe alloy as a methanol-resistant oxygen-reduction catalyst for direct methanol fuel cells. J. Electroanal. Chem., v.563, p.181-90, 2004.

[111]. STARZ, K.A.; AUER, E.; LEHMANN, T.; ZUBER, R. Characteristics of platinum-based electrocatalysts for mobile PEMFC applications. J. Power Sources, v.84, p.167-172, 1999.

[112]. Salgado, J.R.C.; ANTOLINI, E.; GONZALEZ, E.R. Structure and activity of carbon-supported Pt-Co electrocatalysts for oxygen reduction. J. Phys. Chem. B, v.108, p.17767-17774, 2004.

[113]. TICIANELLI, E.A.; DEROUIN, C.R.; SRINIVASAN, S. Localization of platinum in low catalyst loading electrodes to attain high power densities in SPE fuel cells. J. Electroanal. Chem., v.251, p.275-295, 1998.

[114]. RHO, W.; VELEV, O.A.; SRINIVASAN, S. Mass Transport Phenomena in Proton Exchange Membrane Fuel Cells Using O2/He, O2/Ar, and O2/N2 Mixtures. I. Experimental Analysis. J. Electrochem. Soc., v.141, p.2084-2088, 1994.

[115]. RHO, W.; VELEV, O.A.; SRINIVASAN, S. Mass Transport Phenomena in Proton Exchange Membrane Fuel Cells Using O2/He, O2/Ar, and O2/N2 Mixtures. II. Theoretical Analysis. J. Electrochem. Soc., v.141, p. 2089-2096, 1994.

[116]. PAGANIN, V.A.; FREIRE, T.J.P.; TICIANELLI, E.A.; GONZALEZ, E.R. A test station facility for research and development on fuel cell components and materials. Rev. Sci. Instrum., v.68, p.3540-3543, 1997. 
[117]. ANTOLINI, E.; GIORGI, L.; CARDELLINI, F.; PASSALACQUA, E. Physical and morphological characteristics and electrochemical behaviour in PEM fuel cells of PtRu/ catalysts. J. Solid State Electrochem., v.5, p.131-140, 2001.

[118]. PAGANIN, V.A.; TICIANELLI, E.A.; GONZALEZ, E.R. Development and electrochemical studies of gas diffusion electrodes for polymer electrolyte fuel cells. J. Appl. Electrochem., v.26, p.297-304, 1996.

[119]. SALGADO, J.R.C.; ANTOLINI, E.; GONZALEZ, E.R. Carbon supported $\mathrm{Pt}_{70} \mathrm{CO}_{30}$ electrocatalyst prepared by the formic acid method for the oxygen reduction reaction in polymer electrolyte fuel cells. J. Power Sources, in press, 2004.

[120]. SALGADO, J.R.C.; ANTOLINI, E.; GONZALEZ, E.R. Pt-Co/C electrocatalysts for the oxygen reduction in $\mathrm{H}_{2} / \mathrm{O}_{2}$ PEM fuel cells synthesized by the borohydride method. J. Electrochem. Soc., v.151, p.A2143-49, 2004.

[121]. SEPA, D.B.; VOJNOVIC, M.V.; DAMJANOVIC, A. Different views regarding the kinetics and mechanisms of oxygen reduction at $\mathrm{Pt}$ and $\mathrm{Pd}$ electrodes. Electrochim. Acta, v.32, p.129134, 1987.

[122]. SENA, D.R. de; TICIANELLI, E.A.; GONZALEZ, E.R. Characterization of the limiting structural effects on the electrochemical behavior of porous gas diffusion electrodes. J. Electroanal. Chem., v.357, p.225-236, 1993.

[123]. SENA, D.R. de; TICIANELLI, E.A.; PAGANIN, V.A.; GONZALEZ, E.R. Effect of water transport in a PEFC at low temperatures operating with dry hydrogen. J. Electroanal. Chem., v.477, p.164-170, 1999.

[124]. ANTOLINI, E.; PASSOS, R.R.; TICIANELLI, E.A. Electrocatalysts of oxygen reduction on a carbon supported platinum-vanadium alloy in polymer electrolyte fuel cells. Electrochim. Acta, v.48, p.263-270, 2002. 
[125]. ARICO, A.S.; SHUKLA, A.K.; KIM, H.; PARK, S.; MIN, M.; ANTONUCCI, V. An XPS study on oxidation states of $\mathrm{Pt}$ and its alloys with $\mathrm{Co}$ and $\mathrm{Cr}$ its relevance to electroreduction of oxygen. Appl. Surf. Sci., v.172, p.33-40, 2001.

[126]. BARDI, U.; ATREI, A.; ZANAZZI, E.; ROVIDA, G.; ROSS, P.N. Study of the reconstructed (001) surface of the $\mathrm{Pt}_{80} \mathrm{Co}_{20}$ alloy. Vacuum, v.41, p.437-440, 1990.

[127]. BARDI, U.; BEARD, B.; ROSS, P.N. CO chemisorption on the [111] and [100] oriented single crystal surfaces of the alloy $\mathrm{CoPt}_{3}$. J. Catal., v.124, p.22-29, 1990.

[128]. Maillard, F.; Martin, M.; Gloaguen, F.; Leger, J.-M. Oxygen electroreduction on carbon-supported platinum catalysts. Particle-size effect on the tolerance to methanol competition. Electrochimica Acta., v.47, p.3431-3440, 2002.

[129]. HEINZEL, A.; BARRAGAN, V.M. A rewiew of the state of the art of the methanol crossover in direct methanol fuel cells. J. Power Sources, v.84, p.70-74, 1999. 